\title{
The fracture liaison service : from risk evaluation towards risk reduction?
}

Citation for published version (APA):

Huntjens, K. M. B. (2014). The fracture liaison service : from risk evaluation towards risk reduction?

[Doctoral Thesis, Maastricht University]. Maastricht University. https://doi.org/10.26481/dis.20140221kh

Document status and date:

Published: 01/01/2014

DOI:

10.26481/dis.20140221kh

Document Version:

Publisher's PDF, also known as Version of record

\section{Please check the document version of this publication:}

- A submitted manuscript is the version of the article upon submission and before peer-review. There can be important differences between the submitted version and the official published version of record.

People interested in the research are advised to contact the author for the final version of the publication, or visit the DOI to the publisher's website.

- The final author version and the galley proof are versions of the publication after peer review.

- The final published version features the final layout of the paper including the volume, issue and page numbers.

Link to publication

\footnotetext{
General rights rights.

- You may freely distribute the URL identifying the publication in the public portal. please follow below link for the End User Agreement:

www.umlib.nl/taverne-license

Take down policy

If you believe that this document breaches copyright please contact us at:

repository@maastrichtuniversity.nl

providing details and we will investigate your claim.
}

Copyright and moral rights for the publications made accessible in the public portal are retained by the authors and/or other copyright owners and it is a condition of accessing publications that users recognise and abide by the legal requirements associated with these

- Users may download and print one copy of any publication from the public portal for the purpose of private study or research.

- You may not further distribute the material or use it for any profit-making activity or commercial gain

If the publication is distributed under the terms of Article $25 \mathrm{fa}$ of the Dutch Copyright Act, indicated by the "Taverne" license above, 


\title{
The Fracture Liaison Service: From risk evaluation towards risk reduction?
}

\author{
Kirsten MB Huntjens
}





\title{
Fracture Liaison Service: From risk evaluation towards risk reduction?
}

\author{
Proefschrift \\ ter verkrijging van de graad van doctor \\ aan de Universiteit Maastricht, \\ op gezag van de Rector Magnificus, Prof dr. L.L.G. Soete \\ volgens het besluit van het College van Decanen, \\ in het openbaar te verdedigen \\ op vrijdag 21 februari 2014 om 16.00 uur
}

door

Kirsten Marie-Thérèse Bert Huntjens 


\section{Promotores}

Prof. dr. P.R.G. Brink

Prof. dr. P.P. Geusens (MUMC en University Hasselt, Belgium)

\section{Copromotor}

Dr. S.H. van Helden (Isala Klinieken, Zwolle)

Dr. T.A.C.M. van Geel

\section{Beoordelingscommissie}

Prof. dr. L.W. van Rhijn (voorzitter)

Dr. A.A.M. Franken (Isala Klinieken, Zwolle)

Prof. dr. W.F. Lems (Vumc, Amsterdam)

Prof. dr. M. Verhofstad (Erasmus MC, Rotterdam)

ISBN 978-94-6169-474-4

Cover illustration by: $=1$

Layout and print: Optima Grafische Communicatie, Rotterdam, the Netherlands

Printing of this thesis was financially supported by

Nederlandse Vereniging voor Traumatologie, Stichting IWO, Maatschap Chirurgie Isala Klinieken, Takeda, Biomet, Servier, Eijkman \& Kuipers Healthcare BV, Pro-Motion Group bv., Novartis, Depuy-Synthes, ABN Amro, Bodyfit Bunde, Paul Roumans Makelaardij, MCR Hydrauliek BV, A\&A Wiel, Stubbe dienstengroep.

(c) 2014 Kirsten Huntjens, Maastricht, the Netherlands

The copyright of the articles that have been published or have been accepted for publication has been transferred to the respective journals. No parts of this thesis may be reproduced or transmitted in any form, by any means, without prior written permission of the author. 


\section{CONTENTS}

$\begin{array}{lll}\text { Chapter } 1 & \text { General introduction } & 7\end{array}$

Part I Subsequent fracture risk in patients with a recent non-vertebral fracture

Chapter 2 Risk of subsequent fracture and mortality within 5 years after a non-vertebral fracture

Chapter 3 Timing of subsequent fractures after an initial fracture

Part II

Fracture Liaison Service: risk evaluation

Chapter 4 The role of the combination of bone and fall related risk factors on short-term subsequent fracture risk and mortality

Chapter 5 Implementation of osteoporosis guidelines: a survey of five large fracture liaison services in the Netherlands

Part III Fracture Liaison Service: risk reduction?

Chapter 6 Impact of guideline implementation by a fracture nurse on subsequent fractures and mortality in patients presenting with non-vertebral fractures

Chapter 7 Fracture Liaison Service: impact on subsequent nonvertebral fracture incidence and mortality

Part IV

Summary and conclusions

Chapter 8 Summary and conclusions

Chapter 9 Samenvatting en conclusies

Dankwoord 



\section{Chapter 1}

General introduction 



\section{FRACTURES}

A fracture is defined as a local separation of an object or material into two or more pieces or fragments under the action of an external stress. Although fractures are occurring throughout life, most fractures occur after the age of 50 . The yearly fracture incidence in women and men in this age group in the Netherlands approximates $80,000^{1}$. The remaining life-time risk of sustaining a fracture in Caucasian women older than 50 years is $>50 \%$ and of Caucasian men $>20 \%{ }^{2}$. This burden of fractures leads to an increase in morbidity, mortality, re-fracture risk and healthcare costs. Especially the occurrence of a hip fracture is associated with loss of independence, higher morbidity, mortality and subsequent fracture risk $^{3,4}$. Moreover, the number of fractures is expected to increase mainly due to the world's ageing population ${ }^{5}$. Besides the health impact on the individual patient, the socioeconomic burden of fractures is substantial. Therefore, it is essential to optimize the evaluation and treatment of each fracture patient and concordantly to reduce subsequent fracture incidence.

\section{Vertebral versus non-vertebral fractures}

At the Emergency Departments (ED) throughout the Netherlands $95 \%$ of all fractures are non-vertebral fractures ${ }^{1}$. This is quite remarkable, as radiographic vertebral fractures are the most frequent fractures after the age of 50 years in women and in men $^{2}$. However, only one in three radiographic vertebral fractures come to clinical attention with the clinical signs and symptoms of an acute fracture and they can occur without trauma or fall ${ }^{6}$. Even when the clinical expression of a vertebral fracture is acute or chronic back pain, or imaging of the spine is available, they are often overlooked ${ }^{7}$. Lastly, due to the subclinical course of most vertebral fractures, it is most often not possible to specify the exact timing when the vertebral fracture occurred.

In contrast, non-vertebral fractures are easily diagnosed (with the exception of some stress fractures). The consequence is that patients with a non-vertebral fracture are clinically easily identifiable; that radiographic confirmation is simple in most cases and that the exact timing of the fracture is known. In addition, nonvertebral fractures are major contributors to the cost of acute fracture care ${ }^{8-11}$.

Because non-vertebral fractures are the most frequent in ED, are clinically and radiographically easily identifiable in terms of location and timing and are costly, 
we concentrate in this thesis on patients with a first or repeat non-vertebral fracture.

\section{Timing of fractures}

The risk of sustaining a subsequent fracture is double of sustaining a first fracture after the age of 50 years, but this risk increase is not constant over time ${ }^{12,13}$. The highest risk is within the first years following the fracture, while the hazard decreases gradually over time ${ }^{14}$. This has been shown for repeat radiographic and clinical vertebral fractures, for repeat hip fractures and for any repeat non-vertebral fractures ${ }^{14-21}$. This implicates that there might be a window of opportunity shortly after the first fracture to intervene in order to diminish the re-fracture risk.

\section{THE FRACTURE LIAISON SERVICE}

There is a growing interest among orthopedic and trauma surgeons in patients with a recent clinical fracture to not only focus on fracture treatment by a cast or surgery, but also on bone- and fall- related fracture risk evaluation and treatment. A Fracture Liaison Service (FLS) is one of the initiatives in the field of post-fracture care to integrate risk evaluation and secondary prevention in fracture patients ${ }^{22-25}$, and is considered the most effective strategy to maximize the implementation of diagnostic and therapeutic decisions for secondary fracture prevention. ${ }^{26-28}$ In the Netherlands, many FLSs are managed by a fracture nurse who coordinates and examines all patients who are able and willing to participate, according to the guidelines on osteoporosis and fracture prevention and on fall prevention and are supervised by an endocrinologist, rheumatologist or surgeon $23,24,29$.

\section{Risk evaluation at the FLS}

The risk of fractures is multifactorial. In general, the risk factors for fractures can be divided into risk factors that contribute to bone fragility (such as osteoporosis), to extraskeletal factors that increase the risk of trauma, mostly falls (such as sarcopenia) or to a combination of both (e.g. age). 


\begin{tabular}{lll} 
Bone & & \\
\\
\hline Bone mass & - Age & Falls \\
Architecture & - Hormones & - Neuromuscular \\
- Micro & function \\
- Macro & - Fenetics & Cognitive \\
Secondary & - Previus fractures & - Medications \\
mineralization & - Length & - Falls \\
Bone remodelling & - Weight & - Energy absorption \\
composition & - Sarcopenia & \\
& - Mobility &
\end{tabular}

Figure 1. Multifactorial etiology of (hip) fractures

\section{Factors related to bone fragility}

Bone is a complex organ, consisting of cortical bone, that contributes to its stiffness, and of trabecular bone, that contributes to its flexibility. It is a composite material, consisting of layers of collagen fibers, calcium-phosphate crystals (hydroxy-apatite) and proteins (such as growth factors). This composite material is continuously remodeled during life by the bone cells, which consist of osteoclasts, osteoblasts, osteocytes and lining cells. Bone cells communicate with each other and with systemic factors. As a result, in young healthy subjects, bone is strong, yet light, stiff, yet flexible, and as such quoted as optimal bone quality ${ }^{30}$.

Of the factors that contribute to bone quality are its mass and density, which can be measured by bone densitometry using DXA. For each decrease in 1 Standard Deviation (SD) in BMD, the risk of fractures is doubled. For epidemiological purposes, the World Health Organization (WHO) defined osteoporosis as a systemic disease, characterized by low bone mass microarchitecturial disruption, resulting in an increased risk of fractures ${ }^{31}$. Osteoporosis was defined as a BMD below a T-score of -2.5 , and severe osteoporosis in the presence of a T-score of $<-2.5$ and a fracture ${ }^{32}$. However, most patients with a recent fracture do not have osteoporosis at time of the fracture according to this definition ${ }^{33,34}$, even in elderly older than 80 years with a hip fracture ${ }^{33}$. 
Therefore BMD alone is not sufficient to provide an accurate prediction of fracture risk. Other clinical, non-BMD risk factors are known to be important for estimating an adequate probability of fracture risk as well ${ }^{35,36}$, and several of these risk factors contribute to both bone fragility and fall risk.

A history of any fracture predisposes for sustaining a subsequent fracture. Specifically, a non-vertebral fracture is associated with a doubling of the risk of a subsequent fracture, while this risk is quadrupled after a vertebral fracture ${ }^{1,12,13,19,37}$. Other known clinical risk factors which increase fracture risk are age, female gender, family history of a hip fracture in the parents, immobility, low body weight (<60 kg), underlying diseases, medications (e.g. glucocorticosteroids), smoking and excessive alcohol intake 1,37. In 2011 the WHO developed and launched a Fracture Risk Assessment tool (FRAX Ó) to evaluate the 10-year fracture risk of patients. In the FRAX clinical risk factors, with or without a BMD, predict the 10year probability of a major or hip fracture for an individual patient ${ }^{38}$. The FRAX does not include evaluation of fall risk, or the number of prior falls and fractures, which are actually included in the Garvan Fracture Risk Calculator ${ }^{39}$. This Garvan calculator gives higher estimates for fracture risk then FRAX in patients with a history of falls and multiple fractures ${ }^{40}$. Both internet-based tools are freely available, easy to use for professionals and helpful in calculating the absolute fracture risk in an individual.

\section{Fall-related risk factors}

Each year, more than one-third of all people aged 65 years and older fall, of whom $50 \%$ are repeat fallers ${ }^{41}$. Furthermore, approximately one out of ten falls results in serious injury such as a fracture, hematoma or head injury. Moreover, of all ED visits of elderly $80-90 \%$ is due to a fall ${ }^{42}$. Risk of falling is also multifactorial of origin and associated with age, female gender, other health conditions such as arthritis, depressive symptoms, impairment in cognition and/or vision, balance gait, orthostatic hypotension, impairment of muscle strength (sarcopenia), polypharmacia (>4 prescript medications) and urinary incontinence $41,43,44$.

\section{Fracture prevention strategies}

In order to prevent fractures, guidelines have been developed that focused on protecting or increasing bone quality (as proved by a reduction in fracture risk) and focused on non-skeletal factors in order to decrease the risk of falls. 
In RCTs, many drugs have been shown to reduce the risk of vertebral fractures by $40-80 \%$ and for hip fractures by $33 \%$. In contrast, the risk reduction in nonvertebral fractures is less pronounced, for anti-resorptives, in the order of $25 \%$ in a recent meta-analysis ${ }^{45}$. In general, guidelines advocate drugs that have been proven to have a broad spectrum of fracture reduction (preventing vertebral, non-vertebral and hip fractures) as a first choice in high-risk patients, together with sufficient calcium intake and vitamin D supplements. In the context of secondary fracture prevention, all guidelines advocate bone risk evaluation and drug treatment in high-risk patients. Recent data suggest that not only fractures but also mortality is decreased with the use of (oral and intravenous) bisphosphonates (BPs) for osteoporosis ${ }^{33,46-51}$. The mechanisms seem to be multifactorial and are probably related to extra skeletal effects of $\mathrm{BPs}^{49}$. A small proportion of the reduction in mortality is due to prevention of subsequent fractures ${ }^{33}$.

In RCTs on fall prevention, a multifactorial falls risk assessment and management programme as well as exercise programme has been shown to reduce the risk of falls by $14-18 \%{ }^{52}$. However, until today, no fall prevention study has shown a fracture reduction by reducing falls $s^{52,53}$. Guidelines on fall prevention advocate that all $50+$ patients with a recent fracture should have a fall risk evaluation in order to reduce the risk of a subsequent fall.

\section{STUDY DESIGN}

We followed for 5 -years a cohort of fracture patients of $\geq 50$ years with a recent non-vertebral fracture treated at the Maastricht University Medical Centre, the Netherlands, between 1999 and 2001. A different cohort of patients $\geq 50$ years with a recent non-vertebral fracture were evaluated, treated and followed for 2-years at the Fracture Liaison Service in the same hospital between 2004 and 2006. All patients were followed for 2-years for occurrence of subsequent non-vertebral fractures or mortality. To be able to do a cross over study a fracture patient cohort of the VieCuri Medical Centre Venlo, The Netherlands, was followed in the similar study period of 2004-2006. With these fracture cohorts we were able to do a preversus post- FLS analyses. 


\section{AIM AND OUTLINE OF CURRENT THESIS}

The aim of the current thesis was first to evaluate the level of risk for subsequent non-vertebral fractures and mortality in 50+ patients with a recent non-vertebral fracture in relation to the presence of risk factors. Second, we compared the refracture and mortality risk in hospitals with and without FLS and before and after the introduction of the FLS in the same hospital. Third, the implementation of the Dutch guideline on osteoporosis and fracture prevention was evaluated in $5 \mathrm{FLSs}$ in the Netherlands.

In the first chapter a general introduction into the field is given with the thesis outline and its aims. The second chapter focuses on defining the 5 -year subsequent non-vertebral fracture risk and mortality in $50+$ with a recent non-vertebral fracture. The third chapter examines the timing of subsequent fractures over time. The scope of the fourth chapter is on bone- and fall related risk factors in patients with a recent non-vertebral fracture regarding subsequent fracture incidence and mortality. The fifth chapter describes five FLSs throughout the Netherlands and their implementation of osteoporosis guidelines. In the sixth chapter, a comparison is made between patients treated at a FLS and patients who received usual care on subsequent non-vertebral fracture incidence and mortality. In the seventh chapter the benefit of a FLS in fracture patients was evaluated between a hospital with and a hospital without a FLS, focused on subsequent non-vertebral fracture incidence and mortality. The eight and last chapter of this thesis encompasses a summary and conclusions and some future perspectives. 


\section{REFERENCES}

1. $\mathrm{CBO}$ KvdG. Osteoporose, tweede herziene richtlijn. Van Zuiden Communications 2002.

2. Sambrook P, Cooper C. Osteoporosis. Lancet 2006; 367(9527):2010-8.

3. Boonen S, Singer AJ. Osteoporosis management: impact of fracture type on cost and quality of life in patients at risk for fracture I. Current medical research and opinion 2008; 24(6):1781-8.

4. Chrischilles EA, Butler CD, Davis CS, et al. A model of lifetime osteoporosis impact. Archives of internal medicine 1991; 151(10):2026-32.

5. Bliuc D, Ong CR, Eisman JA, et al. Barriers to effective management of osteoporosis in moderate and minimal trauma fractures: a prospective study. Osteoporosis international : a journal established as result of cooperation between the European Foundation for Osteoporosis and the National Osteoporosis Foundation of the USA 2005; 16(8):977-82.

6. Nevitt MC, Ettinger B, Black DM, et al. The association of radiographically detected vertebral fractures with back pain and function: a prospective study. Annals of internal medicine 1998; 128(10):793-800.

7. Gehlbach SH, Bigelow $C$, Heimisdottir $\mathrm{M}$, et al. Recognition of vertebral fracture in a clinical setting. Osteoporos Int 2000; 11(7):577-82.

8. Pike C, Birnbaum HG, Schiller M, et al. Direct and indirect costs of non-vertebral fracture patients with osteoporosis in the US. PharmacoEconomics 2010; 28(5):395409.

9. Song X, Shi N, Badamgarav E, et al. Cost burden of second fracture in the US health system. Bone 2011; 48(4):828-36.

10. Pike CT, Birnbaum HG, Schiller M, et al. Prevalence and costs of osteoporotic patients with subsequent non-vertebral fractures in the US. Osteoporosis international : a journal established as result of cooperation between the European Foundation for Osteoporosis and the National Osteoporosis Foundation of the USA 2011; 22(10):261121.

11. Pike C, Birnbaum HG, Schiller M, et al. Economic burden of privately insured nonvertebral fracture patients with osteoporosis over a 2-year period in the US. Osteoporosis international : a journal established as result of cooperation between the European Foundation for Osteoporosis and the National Osteoporosis Foundation of the USA 2011; 22(1):47-56.

12. Klotzbuecher CM, Ross PD, Landsman PB, et al. Patients with prior fractures have an increased risk of future fractures: a summary of the literature and statistical synthesis. J Bone Miner Res 2000; 15(4):721-39.

13. Kanis JA, Johnell $O$, De Laet $C$, et al. A meta-analysis of previous fracture and subsequent fracture risk. Bone 2004; 35(2):375-82. 
14. van Geel TA, van Helden S, Geusens PP, et al. Clinical subsequent fractures cluster in time after first fractures. Ann Rheum Dis 2008.

15. von Friesendorff M, Besjakov J, Akesson K. Long-term survival and fracture risk after hip fracture: a 22-year follow-up in women. Journal of bone and mineral research : the official journal of the American Society for Bone and Mineral Research 2008; 23(11):1832-41.

16. Chen JS, Cameron ID, Simpson JM, et al. Low-trauma fractures indicate increased risk of hip fracture in frail older people. Journal of bone and mineral research : the official journal of the American Society for Bone and Mineral Research 2011; 26(2):428-33.

17. Lindsay R, Silverman SL, Cooper C, et al. Risk of new vertebral fracture in the year following a fracture. Jama 2001; 285(3):320-3.

18. Johnell O, Oden A, Caulin F, et al. Acute and long-term increase in fracture risk after hospitalization for vertebral fracture. Osteoporos Int 2001; 12(3):207-14.

19. Center JR, Bliuc D, Nguyen TV, et al. Risk of subsequent fracture after low-trauma fracture in men and women. JAMA : the journal of the American Medical Association 2007; 297(4):387-94.

20. Ryg J, Rejnmark L, Overgaard S, et al. Hip fracture patients at risk of second hip fracture: a nationwide population-based cohort study of 169,145 cases during 19772001. Journal of bone and mineral research : the official journal of the American Society for Bone and Mineral Research 2009; 24(7):1299-307.

21. van Helden S, Cals J, Kessels F, et al. Risk of new clinical fractures within 2 years following a fracture. Osteoporos Int 2006; 17(3):348-54.

22. McLellan AR, Gallacher SJ, Fraser M, et al. The fracture liaison service: success of a program for the evaluation and management of patients with osteoporotic fracture. Osteoporos Int 2003; 14(12):1028-34.

23. Blonk MC, Erdtsieck RJ, Wernekinck MG, et al. The fracture and osteoporosis clinic: 1-year results and 3-month compliance. Bone 2007; 40(6):1643-9.

24. Hegeman JH, Willemsen G, van Nieuwpoort J, et al. [Effective tracing of osteoporosis at a fracture and osteoporosis clinic in Groningen; an analysis of the first 100 patients]. Nederlands tijdschrift voor geneeskunde 2004; 148(44):2180-5.

25. Chevalley $\mathrm{T}$, Hoffmeyer $\mathrm{P}$, Bonjour JP, et al. An osteoporosis clinical pathway for the medical management of patients with low-trauma fracture. Osteoporosis international : a journal established as result of cooperation between the European Foundation for Osteoporosis and the National Osteoporosis Foundation of the USA 2002; 13(6):450-5.

26. Ganda K, Puech M, Chen JS, et al. Models of care for the secondary prevention of osteoporotic fractures: a systematic review and meta-analysis. Osteoporosis international : a journal established as result of cooperation between the European 
Foundation for Osteoporosis and the National Osteoporosis Foundation of the USA 2013; 24(2):393-406.

27. Sale JE, Beaton D, Posen J, et al. Systematic review on interventions to improve osteoporosis investigation and treatment in fragility fracture patients. Osteoporosis international : a journal established as result of cooperation between the European Foundation for Osteoporosis and the National Osteoporosis Foundation of the USA 2011; 22(7):2067-82.

28. Marsh D, Akesson $\mathrm{K}$, Beaton DE, et al. Coordinator-based systems for secondary prevention in fragility fracture patients. Osteoporosis international : a journal established as result of cooperation between the European Foundation for Osteoporosis and the National Osteoporosis Foundation of the USA 2011; 22(7):2051-65.

29. van Helden S, Cauberg E, Geusens $P$, et al. The fracture and osteoporosis outpatient clinic: an effective strategy for improving implementation of an osteoporosis guideline. J Eval Clin Pract 2007; 13(5):801-5.

30. Seeman E, Delmas PD. Bone quality--the material and structural basis of bone strength and fragility. The New England journal of medicine 2006; 354(21):2250-61.

31. Prevention and management of osteoporosis. World Health Organization technical report series 2003; 921:1-164, back cover.

32. Consensus development conference: diagnosis, prophylaxis, and treatment of osteoporosis. Am J Med 1993; 94(6):646-50.

33. Lyles KW, Colon-Emeric CS, Magaziner JS, et al. Zoledronic acid and clinical fractures and mortality after hip fracture. N Engl J Med 2007; 357(18):1799-809.

34. Langsetmo L, Goltzman D, Kovacs CS, et al. Repeat low-trauma fractures occur frequently among men and women who have osteopenic BMD. Journal of bone and mineral research : the official journal of the American Society for Bone and Mineral Research 2009; 24(9):1515-22.

35. Kanis JA. Assessment of fracture risk and its application to screening for postmenopausal osteoporosis: synopsis of a WHO report. WHO Study Group. Osteoporos Int 1994; 4(6):368-81.

36. Kanis JA. Diagnosis of osteoporosis and assessment of fracture risk. Lancet 2002; 359(9321):1929-36.

37. СBO. Osteoporosis and fracture prevention 2011. Available at: http://www.cbo.nl/ thema/Richtlijnen/Overzicht-richtlijnen/Geriatrie/. Accessed 2011-11-07.

38. WHO, Kanis JA. http://www.shef.ac.uk/FRAX/?lang=en. Available at: http://www. shef.ac.uk/FRAX/index.htm.

39. Garvan I. Available at: http://garvan.org.au/promotions/bone-fracture-risk/calculator/. Accessed 2011-11-07.

40. van Geel TA, van den Bergh JP, Dinant GJ, et al. Individualizing fracture risk prediction. Maturitas 2010; 65(2):143-8. 
41. Tinetti ME. Clinical practice. Preventing falls in elderly persons. The New England journal of medicine 2003; 348(1):42-9.

42. Tinetti ME, Doucette J, Claus E, et al. Risk factors for serious injury during falls by older persons in the community. Journal of the American Geriatrics Society 1995; 43(11):1214-21.

43. CBO kvdg. Preventie van valincidenten bij ouderen 2004. . available at: http:// wwwcbonl/product/richtlijnen/folder20021023121843/val-richtlijn2004pdf/view; accessed june 5, 2006.

44. Holt G, Smith R, Duncan K, et al. Outcome after sequential hip fracture in the elderly. The Journal of bone and joint surgery. American volume 2012; 94(19):1801-8.

45. Mackey DC, Black DM, Bauer DC, et al. Effects of antiresorptive treatment on nonvertebral fracture outcomes. Journal of bone and mineral research : the official journal of the American Society for Bone and Mineral Research 2011; 26(10):2411-8.

46. Sambrook PN, Cameron ID, Chen JS, et al. Oral bisphosphonates are associated with reduced mortality in frail older people: a prospective five-year study. Osteoporosis international : a journal established as result of cooperation between the European Foundation for Osteoporosis and the National Osteoporosis Foundation of the USA 2011; 22(9):2551-6.

47. Beaupre LA, Morrish DW, Hanley DA, et al. Oral bisphosphonates are associated with reduced mortality after hip fracture. Osteoporosis international : a journal established as result of cooperation between the European Foundation for Osteoporosis and the National Osteoporosis Foundation of the USA 2011; 22(3):983-91.

48. Colon-Emeric CS, Mesenbrink P, Lyles KW, et al. Potential mediators of the mortality reduction with zoledronic acid after hip fracture. Journal of bone and mineral research : the official journal of the American Society for Bone and Mineral Research 2010; 25(1):91-7.

49. Center JR, Bliuc D, Nguyen ND, et al. Osteoporosis medication and reduced mortality risk in elderly women and men. The Journal of clinical endocrinology and metabolism 2011; 96(4):1006-14.

50. Nurmi-Luthje I, Sund R, Juntunen $M$, et al. Post-hip fracture use of prescribed calcium plus vitamin $\mathrm{D}$ or vitamin $\mathrm{D}$ supplements and antiosteoporotic drugs is associated with lower mortality: a nationwide study in Finland. Journal of bone and mineral research : the official journal of the American Society for Bone and Mineral Research 2011; 26(8):1845-53.

51. Bolland MJ, Grey AB, Gamble GD, et al. Effect of osteoporosis treatment on mortality: a meta-analysis. The Journal of clinical endocrinology and metabolism 2010; 95(3):1174-81.

52. Chang JT, Morton SC, Rubenstein LZ, et al. Interventions for the prevention of falls in older adults: systematic review and meta-analysis of randomised clinical trials. BMJ 2004; 328(7441):680. 
53. Gillespie LD, Robertson MC, Gillespie WJ, et al. Interventions for preventing falls in older people living in the community. Cochrane database of systematic reviews 2012; 9:CDoo7146. 



\section{Part I}

Subsequent fracture risk in patients with a recent non-vertebral fracture 



\section{Chapter 2}

\section{Risk of subsequent fracture and mortality within 5 years after a non-vertebral fracture}

Kirsten MB Huntjens, Sevginur Kosar, Tineke ACM van Geel, Piet P Geusens, Paul Willems, Alfons Kessels, Bjorn Winkens, Peter RG Brink, Svenhjalmar van Helden 


\section{ABSTRACT}

\section{Introduction}

Non-vertebral fractures (NVFs) are the most frequent clinical fractures in patients presenting at the emergency unit because of a clinical fracture. The aim of the study was to determine the 5 -year absolute risk (AR) of subsequent NVF and mortality in patients at the time they present with a NVF.

\section{Methods}

Between 1999 and 2001, 1921 consecutive patients 50+ years from a level-one trauma centre were included. All NVFs were confirmed on radiograph reports and mortality was checked in the national obituary database. Available potential risk factors for a subsequent NVF and mortality (age, sex and baseline fracture location: major: hip, pelvis, multiple ribs, proximal tibia/humerus, distal femur; minor: all other) were expressed as hazard ratio's (HR) with 95\% confidence intervals $(\mathrm{Cl})$ using multivariable Cox regression analysis.

\section{Results}

The AR for a subsequent NVF was $17.6 \%$ and was related to age (HR per decade:1.44;95\%Cl:1.29-1.60). The AR for mortality was $32.3 \%$ and was related to age (HR per decade:2.59;95\%Cl:2.37-2.84), male sex (HR:1.74;95\%Cl:1.44-2.10), major fracture at baseline (HR:5.56;95\%Cl:3.48-8.88; not constant over time) and subsequent fracture (HR:1.65;95\%Cl:1.33-2.05). The highest risks were found within the first year (NVFs: 6.4\%, mortality: $12.2 \%$ ) and were related to age, and in addition, to baseline fracture location for mortality.

\section{Conclusions}

Within 5 years after an initial NVF, nearly one in five patients sustained a subsequent NVF and one in three died. One third of subsequent NVFs and mortality occurred within one year, indicating the need to study which reversible factors can be targeted to immediately prevent subsequent fractures and mortality. 


\section{INTRODUCTION}

A history of non-vertebral fracture (NVF) is associated with a doubling of the risk of a subsequent fracture, and the subsequent fracture risk is quadrupled after a vertebral fracture ${ }^{1,2}$. This subsequent fracture risk is not constant over time and is driven by the high, 3- to 5-fold increase in the years immediately after a first fracture, followed by a gradual waning off later on ${ }^{3}$. This has been shown for repeat morphometric vertebral fractures ${ }^{4}$, subsequent clinical spine, forearm and hip fractures in patients who were hospitalised with a vertebral fracture ${ }^{5}$, repeat low trauma fractures in subjects older than 60 years ${ }^{6}$, repeat clinical vertebral and non-vertebral fractures from menopause onwards $3,7,8$ and repeat hip fractures 9. As a result, it has been shown in long-term follow up studies that 40 to $50 \%$ of all subsequent fractures occur within 3 to 5 years after a first fracture. The clinical implication is that patients older than 50 years presenting with a fracture need immediate attention to reduce reversible risk factors of a subsequent fracture. This indicates to undertake immediate care in fracture patients is necessary, such as the Fracture Liaison Service, the involvement of a fracture nurse and other initiatives in the field of post-fracture care ${ }^{10-13}$. It also indicates that treatment, which has been shown to reduce fracture risk within short term, should be started as soon as possible in patients with a high fracture risk ${ }^{14}$.

An increased risk of mortality has been documented after hip, vertebral and several non-hip-non-vertebral fractures ${ }^{15}$. Similar to subsequent fracture risk, this increase in mortality is higher immediately after fracture than later on. In women and men older than 60 years, nearly $90 \%$ of excess deaths related to fracture over the 18 years of observation occurred in the first 5 years.

Of the 5 -year post-fracture excess mortality, approximately one-third of deaths were associated to hip, vertebral, and non-hip-non-vertebral fractures, respectively. The major causes of death were related to cardiovascular and respiratory co-morbidity and infections ${ }^{15}$.

NVFs are the most frequent fractures in patients presenting at the emergency unit because of a clinical fracture ${ }^{8}$. There is therefore an increasing interest on the role of drug intervention to reduce the risk of NVFs ${ }^{16}$ and subsequent mortality ${ }^{17}$. To our knowledge, this is the first study analyzing all consecutive patients older than 50 years of age presenting with a NVF during a 5 year follow-up. The aim of 
the present study was to determine the 5 -year absolute risk (AR) of subsequent NVF and mortality after a NVF.

\section{MATERIALS AND METHODS}

\section{Recruitment of patients}

In this retrospective study, the hospital database code (ICD9) for fractures was used to recruit patients. All fractures reported in the patients' medical files were radiographically confirmed. Only subsequent fractures that are reported in the same hospital database were used for the follow-up analyses. Whether patients were deceased during follow-up was confirmed using the national obituary database. Inclusion criteria for this study were the following: 1 / age $\geq 50$ years; 2/ a recent non- vertebral fracture (NVF) between January 1999 and December 2001; and 3/ living in the postal code area of Maastricht. Patients were excluded if they had sustained a pathological fracture. Vertebral fractures were not taken into consideration. The International Classification of Disease (ICD-9) was used to classify clinical fractures into 15 categories: skull, vertebra, clavicle, thorax, pelvis, humerus, forearm, wrist, hand, hip, femur, patella, tibia/fibula, ankle or foot. These fractures were further analysed according to fracture location (humerus, wrist, hip) and grouping of several locations: other, multiple simultaneous, fractures belonging to the 6 main NVFs (wrist, leg, humerus, hip, pelvis or clavicle) or not ${ }^{16}$ and into major fractures (hip, pelvis, proximal tibia or humerus, multiple ribs and distal femur) and minor fractures (all other fractures) ${ }^{18}$. All groups are mutually exclusive and included all patients.

Available potential risk factors for subsequent fracture and mortality included age, sex and baseline fracture locations ${ }^{6,15}$. In this paper we only showed the Kaplan Meier and Cox regression analyses with major vs. minor fractures as baseline fracture location. To create table 1 we used the other classifications as mentioned above.

\section{Statistical analysis}

Univariable Kaplan-Meier curves, univariable, multivariable and time-dependent Cox regression analyses were performed to determine the contribution of risk factors (age, sex and location of the baseline fracture) to the incidence of subse- 
quent NVFs and mortality. Follow-up time was defined as time between first fracture and subsequent fracture, death or end of the study period of 5 years. With respect to mortality the follow-up time was defined as time between first fracture and death or end of the study period. Hazard Ratios (HR) and 95\% Confidence intervals $(95 \% \mathrm{Cl}$ ) were reported. Two-tailed $P<0.05$ was considered significant. The Schoenfeld residuals were used to check the assumptions of proportionality. If violated, then we used the time-dependent Cox regression analysis to represent the profile of the HR over time. Linearity was checked for age. SPSS 15.0 for windows (SPSS Inc., Illinois, USA) was used to process the data.

\section{RESULTS}

A total of 1921 patients aged over 50 years were included, 1433 women and 488 men. Women were significantly older than men (women: $73.5 \pm 11.5$ years and men $67.1 \pm 12.2$ years, $P<0.001$ ). The majority of the baseline fractures occurred at the ulna/radius (number of patients $=502 ; 26.1 \%$ ), hip (number of patients $=469$; 24.4\%) and other (number of patients $=561 ; 29.2 \%$ ) (Table 1 ).

The patients can be categorized in the following four groups: patients who died without $(n=509)$ or after a subsequent NVF $(n=111)$ and patients still alive after 5

\begin{tabular}{llll}
\hline Baseline fracture location & $\begin{array}{l}\text { Men } \\
\mathbf{N = 4 8 8} \\
(\%)\end{array}$ & $\begin{array}{l}\text { Women } \\
\mathbf{N = 1 4 3 3} \\
(\%)\end{array}$ & $\begin{array}{l}\text { All } \\
\mathbf{N}=1921 \\
(\%)\end{array}$ \\
\hline Humerus & $38(7.8)$ & $184(12.8)$ & $222(11.6)$ \\
Wrist & $69(14.1)$ & $433(30.2)$ & $502(26.1)$ \\
Hip & $115(23.6)$ & $354(24.7)$ & $469(24.4)$ \\
Other & $203(41.6)$ & $358(25.0)$ & $561(29.2)$ \\
Multiple & $63(12.9)$ & $104(7.3)$ & $167(8.7)$ \\
6 main NVFs & & $1211(84.5)$ & $1552(80.8)$ \\
No main NVFs & $341(69.9)$ & $222(15.5)$ & $369(19.2)$ \\
Major & $147(30.1)$ & $651(45.4)$ & $865(45.0)$ \\
Minor & $214(43.9)$ & $782(54.6)$ & $1056(55.0)$ \\
\hline
\end{tabular}

Table 1.

Patients according to baseline fracture location 


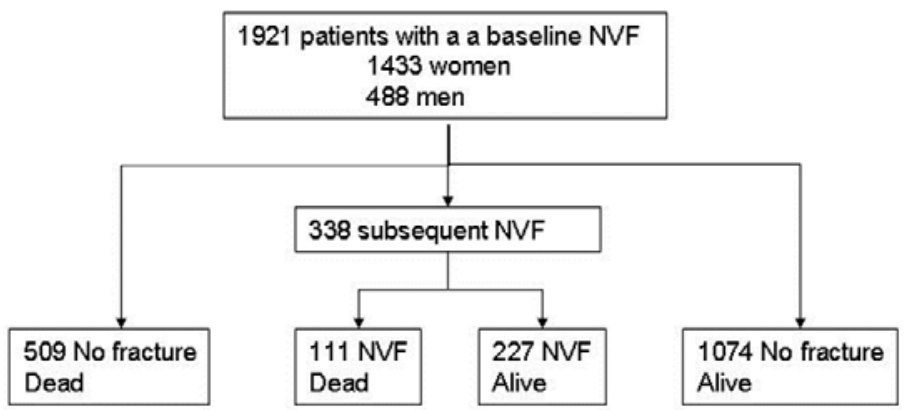

Figure 1.

Flow chart of patients included in the study

years of follow-up with ( $n=227)$ or without a subsequent NVF ( $n=1074)$ (Figure 1), during a total of 7685 patient-years. Clearly, the most common outcome 5 years after a NVF is to be alive without a subsequent fracture (in $55.9 \%$ of patients) (Figure 1).

\section{Subsequent fractures}

During the 5-year follow-up period, 338 patients had 379 subsequent NVFs, indicating an absolute risk (AR) of $17.6 \%$ (95\% Cl: 15.9-19.3) (Table 2).

In univariable analysis, women sustained significantly more subsequent fractures than men (19.3\% vs. 12.7\%, $P=0.001 ; \mathrm{HR}: 1.54 ; 95 \% \mathrm{Cl}: 1.17-2.03)$. Also increasing age (HR per decade: 1.49; 95\% Cl: 1.36-1.64) and major baseline fracture location (HR 1.60; 95\% Cl: 1.29-1.98) contributed in univariable analysis to subsequent fracture risk. (Figure 2).

Hazard ratio's were similar when baseline finger and toe fractures were excluded in the analysis (data not shown). In multivariable analysis only age (HR per decade:1.44; 95\% Cl: 1.29-1.60) remained a significant contributor.

\section{Mortality}

During 5 year follow-up a total of 620 patients died, indicating an AR of $32.2 \%$ (95\%Cl: 30.1-34.3). This number consisted of 468 (32.7\%) women and 152 men (31.1\%). Univariable analysis showed a significant contribution of age and baseline fracture location to mortality incidence $(P<0.001$; Figure 2$)$. To evaluate whether patients with a subsequent fracture had an increased risk on mortality compared with patients without a subsequent fracture, we used the time dependent Cox 


\section{Subsequent fracture incidence}
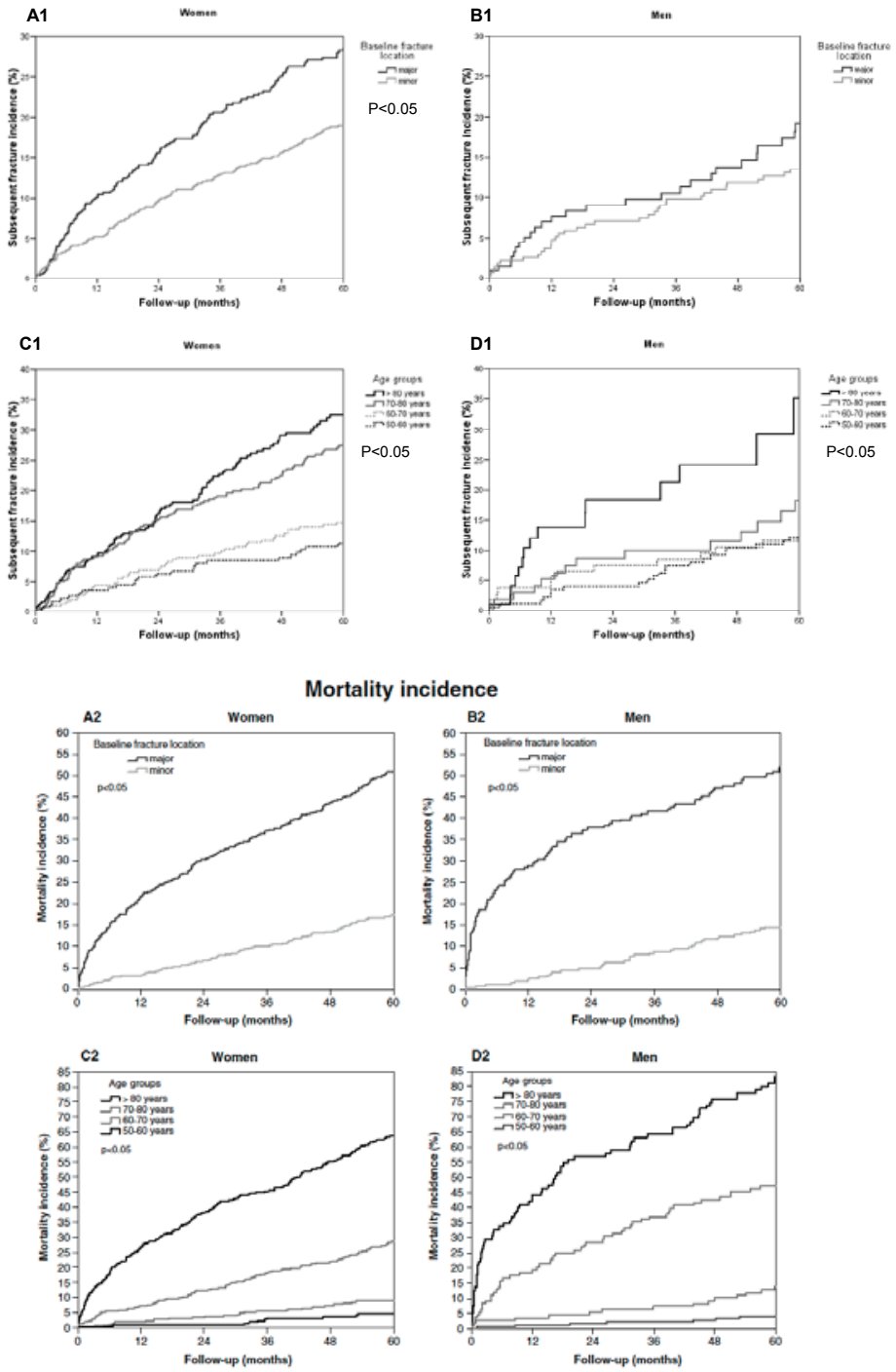

Figure 2. Kaplan Meier curves stratified by sex (univariable analysis) A1-B1 Subsequent fracture incidence by baseline fracture location C1-D1 Subsequent fracture incidence by age in groups A2-B2 Mortality incidence according to baseline fracture location C2-D2 Mortality incidence according to age in groups P-values for all comparisons were calculated with the use of the log-rank test 


\begin{tabular}{|c|c|c|c|}
\hline Variable & Hazard Ratio & $95 \% \mathrm{Cl}$ & P-value \\
\hline \multicolumn{4}{|l|}{ Sex } \\
\hline Men vs. women & 1.74 & $1.44-2.10$ & $<0.001$ \\
\hline Age (per decade) & 2.59 & $2.37-2.84$ & $<0.001$ \\
\hline \multicolumn{4}{|l|}{$\begin{array}{l}\text { Baseline fracture location } \\
\text { (major vs. minor) }\end{array}$} \\
\hline 0 months & 5.56 & $3.48-8.88$ & $<0.001$ \\
\hline 12 months & 2.44 & $1.90-3.14$ & $<0.001$ \\
\hline 24 months & 1.49 & $1.13-1.96$ & 0.004 \\
\hline 36 months & 1.27 & $0.97-1.66$ & 0.083 \\
\hline 48 months & 1.50 & $1.14-1.97$ & 0.004 \\
\hline 60 months & 2.47 & $1.41-4.33$ & 0.002 \\
\hline $\begin{array}{l}\text { Patients with a subsequent } \\
\text { fracture vs. patients without a } \\
\text { subsequent fracture }\end{array}$ & 1.65 & $1.33-2.05$ & $<0.001$ \\
\hline
\end{tabular}

\section{Table 2.}

Mortality incidence: Multivariable Cox regression analysis with time-dependent covariates

regression analysis. This showed, in univariable analysis, an association (HR 2.48 95\% Cl: 2.00-3.07) between patients with a subsequent fracture and mortality compared with patients without a subsequent fracture.

In multivariable analysis, the incidence of mortality was higher in men (HR: 1.74; 95\% Cl: 1.44-2.10) compared with women, corrected for age and baseline fracture location. The HR of baseline fracture location (major/minor) was not consistent over time. Using time dependent Cox regression, immediately after the baseline fracture, HR was 5.56 (95\% Cl:3.48-8.88) and declined at 37 months follow-up to HR 1.27 (95\% Cl: $0.97-1.66 ; p=0.077)$ and increased slightly thereafter to approximately the HR at 12 months (Table 2). Overall results of Cox regression showed that age, male gender, a major fracture and a subsequent fracture at baseline were independent risk factors for mortality (Table 2).

\section{Timing of subsequent NVF and mortality}

Risk of subsequent NVF and mortality significantly changed over time (Figure 4). The AR for subsequent NVF was $6.4 \%$ and progressively decreased to $3.3 \%$ in the $5^{\text {th }}$ year (Figure 3 ).

Of all the patients with a subsequent NVF, 36.4\% sustained a NVF within in the first year. Clustering of fractures was found at all ages, in women and men and in all subgroups of fractures. 
The incidence of mortality was highest in the first year following the baseline fracture (12.2\%) and declined to $6.9 \%$ in the fifth year (Figure 3). Of all subsequent mortality, $37.9 \%$ occurred within the $1^{\text {st }}$ year. Of the patients who sustained a hip fracture, the 1-year mortality was $40 \%$ in men and $29 \%$ in women. At the end of the follow-up period $302(65 \%)$ of the hip fracture patients at baseline were deceased.

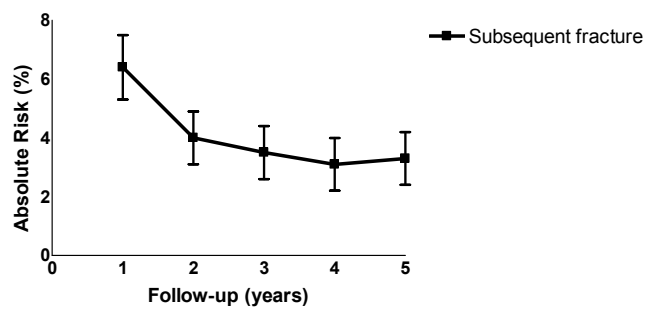

\begin{tabular}{lcccccl}
\hline Follow-up (year) & $\mathbf{0 - 1}$ & $\mathbf{1 - 2}$ & $\mathbf{2 - 3}$ & $\mathbf{3 - 4}$ & $\mathbf{4 - 5}$ & Total Follow-up \\
\hline Number of patients at risk & 1921 & 1686 & 1578 & 1487 & 1398 & 1301 \\
\hline Subsequent fracture $(\mathbf{n})$ & 123 & 68 & 55 & 46 & 46 & 338 \\
\hline$\%$ & 6.4 & 4.0 & 3.5 & 3.1 & 3.3 & 17.6 \\
\hline
\end{tabular}

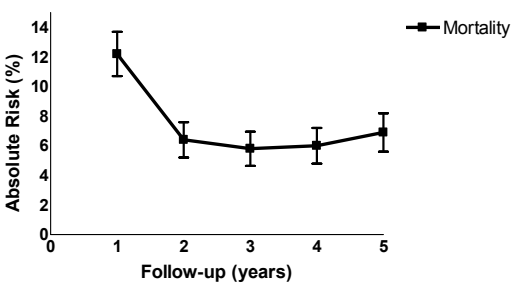

\begin{tabular}{|c|c|c|c|c|c|c|c|}
\hline Follow-up (year) & & $0-1$ & $1-2$ & $2-3$ & $3-4$ & 4-5 & Total Follow-up \\
\hline Number of patients at risk & 1921 & 1686 & 1578 & 1487 & 1398 & 1301 & \\
\hline Mortality (n) & & 235 & 108 & 91 & 89 & 97 & 620 \\
\hline$\%$ & & 12.2 & 6.4 & 5.8 & 6.0 & 6.9 & 32.3 \\
\hline
\end{tabular}

Figure 3. Subsequent risk of fracture and mortality cluster in time Patients at risk divided into 5 years of the follow-up period Fractures per year were cumulative in survivors 


\section{DISCUSSION}

Based on hospital databases for radiographically diagnosed fractures to ascertain fractures and the national obituary, the AR of sustaining a new NVF within five years after a NVF was $17.6 \%$ and $32.3 \%$ for mortality. Until today, there have not been data published regarding subsequent fracture risk and mortality in a patient population with all clinical fractures (NVF) of 50 years and over with a five year follow-up period. Moreover, there are no guidelines which recommend to evaluate all these patients we investigated in this research.

Remarkably, after multivariable analysis patients sustaining a minor fracture had a similar risk to a subsequent fracture as patients with a major fracture at baseline, even after a hip fracture. In addition, the same was true between sexes: after correction for age subsequent fracture rate was similar between men and women, as found by Center ${ }^{6}$. Even patients with a wrist fracture at baseline had an AR of a subsequent fracture of $17.9 \%$ within 5 years follow-up. From a clinical point of view these results indicate that fracture prevention should be considered after any fracture. Increasing age was the most important factor for a subsequent fracture corrected for sex and baseline fracture location. Only three variables (age, gender and fracture location) were available and not surprisingly age was the most predictive factor as in most other fracture prediction models. Over one third (36.4\%) of the patients sustained a subsequent NVF within the first year after their baseline fracture. Previous studies reported similar findings. In our own previous study we found an absolute risk of $10.8 \%$ for sustaining any clinical subsequent fracture within 2 years after baseline fracture, with $60 \%$ occurring in the first year after the baseline fracture ${ }^{8}$. Van Geel et al. found a RR of 5.3 of subsequent fracture compared with patients without a subsequent fracture ${ }^{3}$

Similar results were reported after vertebral fractures ${ }^{19}$. Center et al. showed that $41 \%$ of the women and $52 \%$ of the men sustained their subsequent fracture within the first two years after the initial fracture. The aim of this study was not to compare subsequent fracture incidence with first fracture incidence, as we already have shown in a population based study in post menopausal women between age 45 and 90 years old from the same region, that the one year incidence of all first fractures was $1.0 \%$. We recalculated the risk of only a first NVF, which was $0.9 \%$ (excluding all patients with vertebral fractures). In that study the first year subsequent fracture incidence was $6.0 \%$ almost equal as in our study $(6.8 \%)^{3}$. 
During the study almost one in three patients died. Our results confirm previous findings by others that mortality is associated with increasing age, male gender and baseline fracture location in a multivariable model, even at the age of 50 years and over ${ }^{15,18,20-27}$.

There are some potential limitations to this study. First, due to the retrospective design of this study, we could have missed subsequent fractures, which had occurred outside the recruitment region of the hospital. In an earlier study less than $1 \%$ of all patients presenting at the Emergency Department were from outside the hospital region indicating that less than $1 \%$ of fractures could have been missed ${ }^{8}$. All fractures in the hospital are coded (ICD-9) and stored in the hospital database. Second, vertebral fractures were excluded because of difficulty with verification of timing of these fractures. Third, we have no data on the trauma mechanism. In earlier studies we have shown that about $20 \%$ of clinical fractures are not resulting from a fall from maximum standing height or lesser trauma ${ }^{28}$. However, Mackay et al. has shown that the risk of subsequent fractures is similar after high and low energy trauma ${ }^{29}$. There are no data available for mortality after high and low energy trauma in fractures.

Fourth, there are no data on the cause of death. We therefore can not correlate if these deaths are directly related to the previous fracture or the subsequent fracture. The enhanced mortality could be a sign of poor health or other underlying conditions. Further studies will be necessary to examine to what degree bone and extraskeletal risks are predictive for subsequent fractures and mortality. Others have shown that bone, fall and general health related factors could be involved ${ }^{15}$.

In conclusion, we found that within 5 years after an initial NVF, nearly one in five patients sustained a subsequent NVF and one in three died. One third of subsequent NVFs and mortality occurred within one year, indicating the need to study which reversible factors can be targeted to immediately prevent subsequent fractures and mortality. 


\section{REFERENCES}

1. Kanis JA, Johnell O, De Laet C, Johansson H, Oden A, Delmas P, Eisman J, Fujiwara $\mathrm{S}$, Garnero P, Kroger H, McCloskey EV, Mellstrom D, Melton LJ, Pols H, Reeve J, Silman A, Tenenhouse A (2004) A meta-analysis of previous fracture and subsequent fracture risk. Bone 35:375-382.

2. Klotzbuecher CM, Ross PD, Landsman PB, Abbott TA, 3rd, Berger M (2000) Patients with prior fractures have an increased risk of future fractures: a summary of the literature and statistical synthesis. J Bone Miner Res 15:721-739.

3. van Geel TA, van Helden S, Geusens PP, Winkens B, Dinant GJ (2008) Clinical subsequent fractures cluster in time after first fractures. Annals of the rheumatic diseases.

4. Lindsay R, Silverman SL, Cooper C, Hanley DA, Barton I, Broy SB, Licata A, Benhamou L, Geusens P, Flowers K, Stracke H, Seeman E (2001) Risk of new vertebral fracture in the year following a fracture. Jama 285:320-323.

5. Johnell O, Oden A, Caulin F, Kanis JA (2001) Acute and long-term increase in fracture risk after hospitalization for vertebral fracture. Osteoporos Int 12:207-214.

6. Center JR, Bliuc D, Nguyen TV, Eisman JA (2007) Risk of subsequent fracture after low-trauma fracture in men and women. Jama 297:387-394.

7. van Geel AC, Geusens PP, Nagtzaam IF, Schreurs CM, van der Voort DJ, Rinkens PE, Kester AD, Dinant GJ (2006) Timing and risk factors for clinical fractures among postmenopausal women: a 5-year prospective study. BMC medicine 4:24.

8. van Helden S, Cals J, Kessels F, Brink P, Dinant GJ, Geusens P (2006) Risk of new clinical fractures within 2 years following a fracture. Osteoporos Int 17:348-354.

9. Ryg J, Rejnmark L, Overgaard S, Brixen K, Vestergaard P (2009) Hip Fracture Patients at Risk of Second Hip Fracture-A Nationwide Population-Based Cohort Study of 169,145 Cases During 1977-2001. J Bone Miner Res.

10. Chevalley T, Hoffmeyer P, Bonjour JP, Rizzoli R (2002) An osteoporosis clinical pathway for the medical management of patients with low-trauma fracture. Osteoporos Int 13:450-455.

11. Gallacher SJ, Gallagher AP, McQuillian C, Mitchell PJ, Dixon T (2007) The prevalence of vertebral fracture amongst patients presenting with non-vertebral fractures. Osteoporos Int 18:185-192.

12. van Helden S, Cauberg E, Geusens P, Winkes B, van der Weijden T, Brink P (2007) The fracture and osteoporosis outpatient clinic: an effective strategy for improving implementation of an osteoporosis guideline. Journal of evaluation in clinical practice 13:801-805.

13. van Helden S, van Geel AC, Geusens PP, Kessels A, Nieuwenhuijzen Kruseman AC, Brink PR (2008) Bone and fall-related fracture risks in women and men with a recent clinical fracture. J Bone Joint Surg Am 90:241-248. 
14. Geusens PP, Roux CH, Reid DM, Lems WF, Adami S, Adachi JD, Sambrook PN, Saag KG, Lane NE, Hochberg MC (2008) Drug Insight: choosing a drug treatment strategy for women with osteoporosis-an evidence--based clinical perspective. Nature clinical practice 4:240-248.

15. Bliuc D, Nguyen ND, Milch VE, Nguyen TV, Eisman JA, Center JR (2009) Mortality risk associated with low-trauma osteoporotic fracture and subsequent fracture in men and women. Jama 301:513-521.

16. Sebba A (2009) Comparing non-vertebral fracture risk reduction with osteoporosis therapies: looking beneath the surface. Osteoporos Int 20:675-686.

17. Lyles KW, Colon-Emeric CS, Magaziner JS, Adachi JD, Pieper CF, Mautalen C, Hyldstrup L, Recknor C, Nordsletten L, Moore KA, Lavecchia C, Zhang J, Mesenbrink P, Hodgson PK, Abrams K, Orloff JJ, Horowitz Z, Eriksen EF, Boonen S (2007) Zoledronic acid and clinical fractures and mortality after hip fracture. The New England journal of medicine 357:1799-1809.

18. Center JR, Nguyen TV, Schneider D, Sambrook PN, Eisman JA (1999) Mortality after all major types of osteoporotic fracture in men and women: an observational study. Lancet 353:878-882.

19. Johnell O, Kanis JA, Oden A, Sernbo I, Redlund-Johnell I, Petterson C, De Laet C, Jonsson B (2004) Fracture risk following an osteoporotic fracture. Osteoporos Int 15:175-179.

20. Cooper C, Atkinson EJ, Jacobsen SJ, O'Fallon WM, Melton LJ, 3rd (1993) Populationbased study of survival after osteoporotic fractures. American journal of epidemiology 137:1001-1005.

21. Johnell O, Kanis JA, Oden A, Sernbo I, Redlund-Johnell I, Petterson C, De Laet C, Jonsson B (2004) Mortality after osteoporotic fractures. Osteoporos Int 15:38-42.

22. Cauley JA, Thompson DE, Ensrud KC, Scott JC, Black D (2000) Risk of mortality following clinical fractures. Osteoporos Int 11:556-561.

23. Cummings SR, Melton LJ (2002) Epidemiology and outcomes of osteoporotic fractures. Lancet 359:1761-1767.

24. Browner WS, Pressman AR, Nevitt MC, Cummings SR (1996) Mortality following fractures in older women. The study of osteoporotic fractures. Archives of internal medicine 156:1521-1525.

25. Shortt NL, Robinson CM (2005) Mortality after low-energy fractures in patients aged at least 45 years old. Journal of orthopaedic trauma 19:396-400.

26. Piirtola M, Vahlberg T, Lopponen M, Raiha I, Isoaho R, Kivela SL (2008) Fractures as predictors of excess mortality in the aged-a population-based study with a 12-year follow-up. European journal of epidemiology 23:747-755.

27. Ensrud KE, Ewing SK, Taylor BC, Fink HA, Stone KL, Cauley JA, Tracy JK, Hochberg MC, Rodondi N, Cawthon PM (2007) Frailty and risk of falls, fracture, and mortality 
in older women: the study of osteoporotic fractures. The journals of gerontology 62:744-751.

28. Dumitrescu B, van Helden $S$, ten Broeke R, Nieuwenhuijzen-Kruseman A, Wyers $C$, Udrea G, van der Linden S, Geusens P (2008) Evaluation of patients with a recent clinical fracture and osteoporosis, a multidisciplinary approach. BMC musculoskeletal disorders 9:109.

29. Mackey DC, Lui LY, Cawthon PM, Bauer DC, Nevitt MC, Cauley JA, Hillier TA, Lewis CE, Barrett-Connor E, Cummings SR (2007) High-trauma fractures and low bone mineral density in older women and men. Jama 298:2381-2388. 


\section{Chapter 3}

\section{Timing of subsequent fractures after an initial fracture}

Tineke ACM van Geel, Kirsten MB Huntjens, Joop PW van den Bergh, Geert-Jan Dinant, Piet P Geusens 


\begin{abstract}
A prior fracture is a well documented risk factor for a subsequent fracture and it doubles the risk of subsequent fractures. Few studies have investigated the time that elapses between the initial and subsequent fracture. These studies show that the subsequent fracture risk is not constant, but fluctuates over time. The risk of subsequent vertebral, hip and non-vertebral non-hip fractures is highest immediately after initial hip, clinical and radiographic vertebral fractures and non-vertebral fractures and declines afterwards, regardless of gender, age and initial fracture location. These studies all indicate the need for early action after an initial fracture with medical interventions that have an effect within a shortterm to reduce the preventable risks of subsequent fractures.
\end{abstract}




\section{INTRODUCTION}

In terms of fractures, osteoporosis is one of the leading health problem in de Western world according to the World Health Organisation (WHO) and is a growing problem due to the ageing population ${ }^{1,2}$. However, in terms of BMD T-score $<-2.5$, osteoporosis is only one of the many risk factors for fractures

A prior fracture is yet another well known risk factor for a subsequent fracture, independent of $\mathrm{BMD}^{3}$. The risk of a subsequent fracture is doubled in the presence of a prior fracture (pooled relative risk (RR) of 2.0) ${ }^{3}$.

However, several studies have shown that the risk of subsequent fracture is not constant over time, but fluctuates over time, being highest immediately after the initial fracture ${ }^{4-8}$.

One of the earliest studies on the timing between first and subsequent fractures focused on patients who had been hospitalized because of a clinical vertebral fracture and in whom the risk of all subsequent fractures was highest within the first year following hospitalization for vertebral fracture in both women and men.

Lindsay et al (2001) found that within one year after an incident radiographic vertebral fracture, $20 \%$ of patients had a new radiographic vertebral fracture ${ }^{7}$.

These observations had a growing impact on further research on timing of subsequent fractures in relation to a first fracture, and focused on all fractures or specific initial or subsequent fracture locations. Indeed, if subsequent fractures cluster in time, this has as a clinical consequence the need for immediate attention for fracture patients in order to decrease the risk of subsequent fracture. Furthermore, if fractures cluster in time, algorithms for case finding should take into account the variable risk of subsequent fracture over time.

Several studies have meanwhile studied the time relation between fractures. However, the time relation between fractures has been reported in several ways in terms of relative risk (RR), absolute risk (AR), as percentages of all subsequent fractures that occurred over short and long term follow up, and as survival or cumulative curves. First and subsequent fractures were studied at variable fracture locations (vertebral, non-vertebral, major, minor and hip fractures).

We reviewed these aspects in the literature on studies that reported the time relation between fractures and, as far as reported, review the RR, AR and percent of subsequent fractures, according to baseline and subsequent fracture location. 


\section{CLUSTERING IN TIME OF FRACTURES AFTER A VERTEBRAL FRACTURE}

Morphometric vertebral fractures are the most frequent osteoporosis-related fractures, but only around one third come to clinical attention with the classical signs and symptoms of an acute fracture. Therefore, studies on vertebral fractures differ in including only clinical vertebral fractures or in systematic performance of radiographs of the thoracic and lumbar spine.

\section{Repeat morphometric vertebral fractures}

Only one study is available on repeat radiographic vertebral fractures and was performed by analyzing placebo-treated patients $(n=2725)$, pooled from several fracture studies with risedronate ${ }^{8}$. These women had either prevalent vertebral fractures ${ }^{9,10}$ low femoral neck BMD, or risk factors for hip fracture ${ }^{11}$. All subjects received calcium supplementation $(1000 \mathrm{mg} / \mathrm{d})$. Women with serum 25 -hydroxyvitamin D levels of less than $16 \mathrm{ng} / \mathrm{mL}$ ( $40 \mathrm{nmol} / \mathrm{L}$ ) at baseline also received vitamin D supplementation (up to $500 \mathrm{IU} / \mathrm{d}$ ).

In this study, the one-year incidence of radiographic vertebral fractures could be analysed in three groups of patients: 1 / patients without a prevalent fracture, 2/ patients with a prevalent radiographic vertebral fracture before the start of the follow up, and of which the timing of the previous radiographic vertebral fracture was unknown, and 3/ patients who developed a new radiographic vertebral fracture during the study and who were followed yearly for the development of subsequent radiographic vertebral fractures.

The cumulative incidence of new radiographic vertebral fractures in the first year of the study follow up (i.e. the AR for new radiographic vertebral fractures in patients with and without previous radiographic vertebral fracture of unknown timing) was $6.6 \%$ in the total group (Figure 1$)^{8}$.

In patients with of one or more radiographic vertebral fractures at baseline, in whom the timing of fractures was unknown, the risk of sustaining a radiographic vertebral fracture increased by 5 -fold during the initial year of the study compared with the incidence in subjects without prevalent radiographic vertebral fractures at baseline (relative risk [RR], 5.1; 95\% confidence interval [Cl], 3.1-8.4; $\mathrm{p}$ $<0.001$ ). The 1-year AR for a first radiographic vertebral fracture was 1.9\%, 4.6\% in the presence of one vertebral fracture of unknown radiographic vertebral frac- 


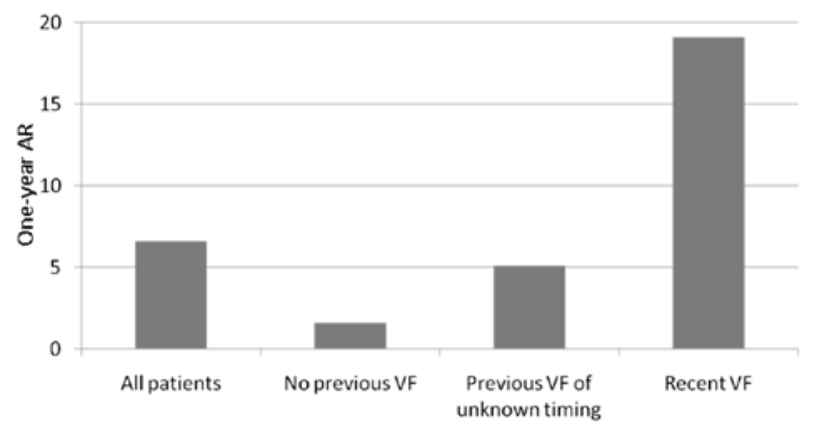

Figure 1. One-year absolute risk (AR) for first and repeat radiographic vertebral fractures $(\mathrm{VF})^{8}$

ture and $9.9 \%$ and $12.5 \%$ in the presence of more than one or two radiographic vertebral fractures of unknown timing at baseline, respectively ${ }^{8}$.

Among the 381 participants who developed an incident radiographic vertebral fracture during the study follow up, the incidence of a new radiographic vertebral fracture in the subsequent year was $19.2 \%(95 \% \mathrm{Cl}, 13.6-24.8){ }^{8}$. In summary, this study indicated that the 1-year AR for subsequent radiographic vertebral fractures is $1.9 \%$ for a first radiographic vertebral fracture, $4.6 \%$ in the presence of a radiographic vertebral fracture of unknown timing and $19.2 \%$ within one year after a radiographic vertebral fracture had occurred. This study clearly showed that the risk of repeat radiographic vertebral fractures is highest during the first year after a radiographic vertebral fracture.

\section{Fractures after clinical vertebral fractures}

A study focused on the magnitude and time course of the increase in risk of further fractures during a mean follow up of 2.4 years (maximum 8 years) in patients who were hospitalized for vertebral fracture $(n=28,869)^{7}$. It has been shown that there was a marked increase in subsequent incidence of hip and all fractures within the first year following hospitalization for vertebral fracture in both men and women. Thereafter, fracture incidence declined toward, but did not attain baseline risk. The increase in fracture risk was more marked following low-energy vertebral fracture than following high-energy trauma. The RR for an incident fracture (compared with the general population) was at any age higher at 6 months (3.9 to 48.7 , according to age) than at 4 years (1.4 to 15.2, according 

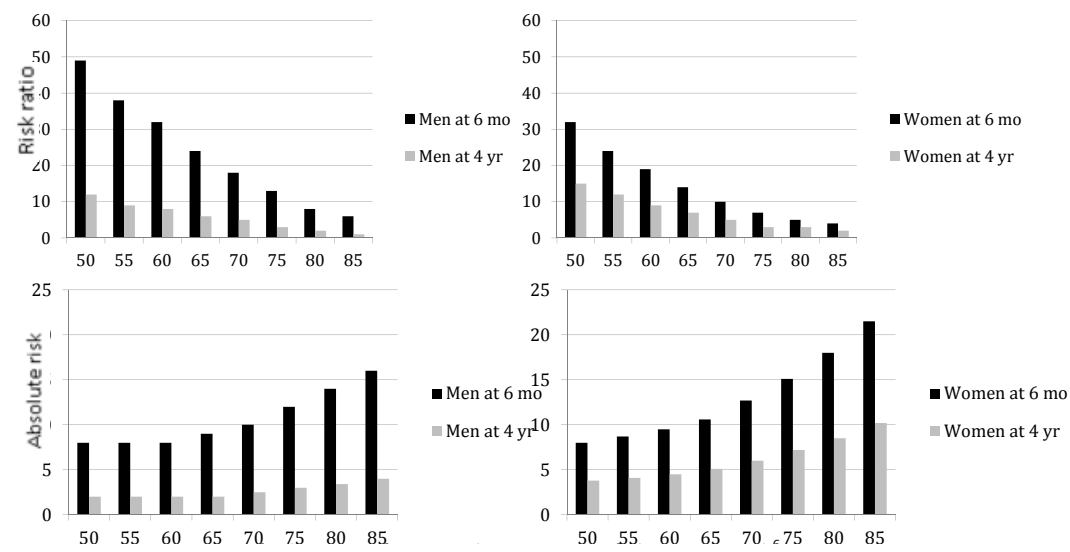

Figure 2. Risk ratio and absolute risk of subsequent fracture ${ }^{6}$

to age), was higher in men (5.6 to 48.7 , according to age) than in women (3.9 to 32.0, according to age), and was higher in younger than in older patients (Figure 2). The $A R$, expressed as the incidence of all subsequent fractures, was higher at 6 months ( $7.8 \%$ to $21.5 \%$, according to age) than at 4 years ( $1.9 \%$ to $10.2 \%$, according to age) and higher in women ( $8.0 \%$ to $21.5 \%$, according to age) than in men $(7.8 \%$ to $16.0 \%$, according to age) ${ }^{7}$. The timing of the percentage of fracture according to time of follow up was not mentioned.

\section{CLUSTERING IN TIME OF FRACTURES AFTER A HIP FRACTURE}

A total of 799 patients were followed during a mean follow up of 22 years after their initial hip fracture. After the initial hip fracture, $27 \%$ of all subsequent fractures (mean number of subsequent fractures per patient: 2.3, range 1 to 11 fractures/patient) occurred within 2 years and $73 \%$ within 5 years ${ }^{12}$. The AR over 22 years was $45 \%$ in the total group and $86 \%$ in survivors. This indicates that the 2-year AR was $\sim 12 \%$ in the total group and $\sim 23 \%$ in survivors and that the 5 -year AR was $33 \%$ and $63 \%$, respectively ${ }^{12}$.

A study in elderly living in a nursing home $(n=184)$ showed the same trend. The AR of the subsequent fractures was $12 \%$ within one year and $21 \%$ within 5 years 
indicating that more than half of subsequent fractures during 5 years follow up occurred within one year after a hip fracture ${ }^{13}$.

In a study that included $>170,000$ men and women with an initial hip fracture almost 28,000 patients sustained a subsequent hip fracture during 25 years follow up (mean follow up: 3.8 years). After a first hip fracture, the cumulative incidence of subsequent hip fracture was $9 \%$ within 1 year and $20 \%$ within 5 years, compared to $2 \%$ and $12 \%$, respectively, in subjects without a hip fracture. Thus, nearly half of all subsequent hip fractures during 5 years follow up occurred within 1 year. The RR for a second hip fracture was 11.8 at 1 month, decreasing exponentially to 3.0 at 6 months and 2.2 at 1 year, and did not normalise until after 15 years ${ }^{14}$. Risk factors for a second hip fracture were female sex, age, alcoholism, any prior fracture, living alone and having a higher income ${ }^{14}$.

Similar results were reported in other studies ${ }^{15,16}$. In addition, almost all fractures after the initial hip fracture were caused by low-energy traumatic accidents (e.g. fall from standing height or less, fall from a chair or fall out of bed) ${ }^{12-16}$.

\section{CLUSTERING IN TIME AFTER CLINICAL FRACTURES}

One study focused on the risk of hip, forearm, clinical vertebral or shoulder fractures in women and men between 60 and 80 years from the time they had a hip, clinical vertebral or shoulder fracture in both outpatients and hospitalised patients ${ }^{6}$. Of all subsequent hip, clinical vertebral, forearm or shoulder fractures during a follow up of 5 years, $34 \%$ occurred within the first year after the initial fracture (range $31-45 \%$ ) and progressively decreased to $9 \%$ during the $5^{\text {th }}$ year (Figure 3$)^{6}$.

We published a population based study focusing on all clinical fractures (including high-energy or low-energy trauma fractures) in postmenopausal women ${ }^{5}$. During a follow up of 20 years (mean: 9 years), $23 \%$ of all subsequent fractures were sustained within one year after the initial fracture and $54 \%$ within 5 years. After 15 years the subsequent fracture risk was no longer higher than the initial fracture risk ${ }^{5}$.

In the DUBBO study in Australia, in community-dwelling men and women older than 60 years, the absolute risk of subsequent low-energy trauma fracture was similar for men and women ${ }^{4}$. About $41 \%$ of the subsequent fractures in women 


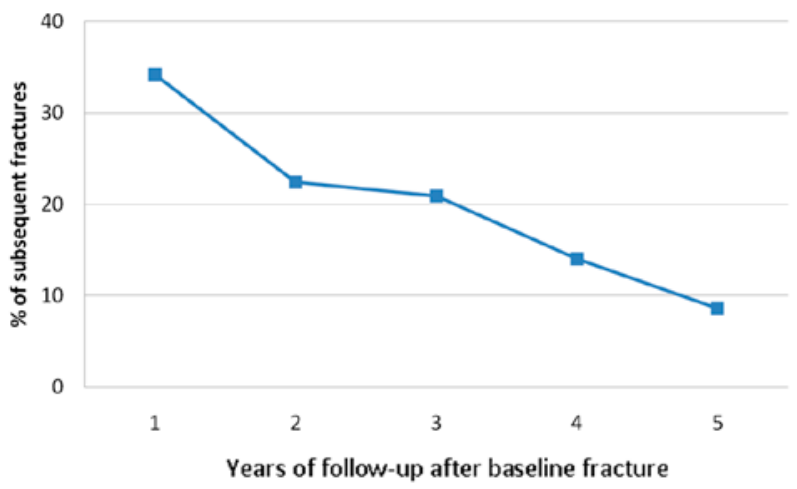

Figure 3. Percentage of subsequent fractures during a 5-year follow-up period ${ }^{6}$

and $52 \%$ in men occurred within two years after the initial fracture during a follow up of 16 years. This clustering of fractures occurred regardless of the initial fracture location. However, with the expected increase in initial fracture risk with age, the excess risk decreased over time from initial fracture $(p=0.003$ and $P=.001$ for women and men, respectively). After 10 years of follow-up, the subsequent absolute fracture risk was no longer elevated compared with the risk of a first fracture.

In a retrospective study, the time relation between fractures was studied between the time of prior fracture $(n=>8,000)$ and the time a BMD measurement was performed, and the risk of subsequent fracture $(n=>1700)$ during a follow up for a maximum of 10 years after the index BMD measurement ${ }^{17}$. The RR after major fractures was 1.9 (95\% Cl: 1.6-2.3) after the BMD measurement in patients who had a fracture history $<1$ year before the BMD measurement, decreasing towards 1.6 (95\% Cl: 1.3-2.1) if the previous fracture had occurred $>10$ years ago $(p<0.001$ for trend). After minor fractures, the RR was 1.49 (95\% Cl: 1.1-1.9) and 1.1 (95\%Cl: 0.81.5), respectively ${ }^{17}$. However, this study did not report the exact timing between fractures as the timing from BMD measurement and subsequent fracture was not reported. In view of the large database in that study, more detailed analysis of the time relation between fractures would be of interest.

The aetiology of clustering of fractures needs further investigation in terms of bone-related (e.g. cortical and trabecular bone loss due to immobility), fallrelated risk factors (e.g. immobility, postural instability, muscle strength, plaster- 
ing, use of walking device) and post-fracture care for morbidity (e.g. locomotor revalidation after lower limb fractures).

\section{CONCLUSION}

The clustering of fractures in time indicates the need for immediate attention in both men and women who sustain a first fracture to prevent the occurrence of a subsequent fracture. The high increase of subsequent fractures immediately after a first fracture creates a window of opportunity to prevent subsequent fractures. However, no studies are available on fracture prevention immediately after a fracture. Such studies will be needed in view of the immediate burden of subsequent fractures in patients with a first fracture, who can easily be identified clinically.

In addition, when treatment with osteoporosis medication is considered, such treatment should be chosen on the basis of proven short-term efficacy in the reduction of vertebral and non-vertebral fractures. How far additional fall prevention strategies would further decrease subsequent fracture risk is unknown and a field for further clinical research. 


\section{REFERENCES}

1. World Health Organisation WHO. Prevention and Management of Osteoporosis. Report of a WHO Scientific Group WHO Technical Report Series 2003; No 921

2. World Health Organisation WHO. WHO Scientific Group on the assessment of osteoporosis at primary health care level 2007. Available at: http://www.who.int/chp/ topics/Osteoporosis.pdf. Accessed 19 Nov 2007.

3. Klotzbuecher CM, Ross PD, Landsman PB, et al. Patients with prior fractures have an increased risk of future fractures: a summary of the literature and statistical synthesis. J Bone Miner Res 2000; 15(4):721-727.

4. Center JR, Bliuc D, Nguyen TV, et al. Risk of subsequent fracture after low-trauma fracture in men and women. JAMA 2007; 297(4):387-94.

5. Geel van TACM, Helden van S, Geusens PP, et al. Clinical subsequent fractures cluster in time after first fractures. Ann Rheum Dis 2009; 68(1):99-102. Epub 2008 Aug 3.

6. Johnell O, Kanis JA, Oden A, et al. Fracture risk following an osteoporotic fracture. Osteoporos Int 2004; 15(3):175-9.

7. Johnell O, Oden A, Caulin F, et al. Acute and long-term increase in fracture risk after hospitalization for vertebral fracture. Osteoporos Int. 2001; 12(3):207-214.

8. Lindsay RL, Silverman SL, Cooper C, et al. Risk of new vertebral fracture in the year following a fracture. JAMA 2001; 285(3):320-323.

9. Harris ST, Watts NB, Genant HK, et al. Effects of risedronate treatment on vertebral and nonvertebral fractures in women with postmenopausal osteoporosis: a randomized controlled trial. Vertebral Efficacy With Risedronate Therapy (VERT) Study Group. JAMA the journal of the American Medical Association 1999; 282(14):1344-52.

10. Reginster J, Minne HW, Sorensen $\mathrm{OH}$, et al. Randomized trial of the effects of risedronate on vertebral fractures in women with established postmenopausal osteoporosis. Vertebral Efficacy with Risedronate Therapy (VERT) Study Group. Osteoporos Int 2000; 11(1):83-91.

11. McClung MR, Geusens P, Miller PD, et al. Effect of risedronate on the risk of hip fracture in elderly women. Hip Intervention Program Study Group. N Engl J Med 2001; 344(5):333-340.

12. Friesendorff von M, Besjakov J, Akesson K. Long-term survival and fracture risk after hip fracture: a 22-year follow-up in women. J Bone Miner Res 2008; 23(11):1832-41.

13. Berry SD, Samelson EJ, Ngo L, et al. Subsequent fracture in nursing home residents with a hip fracture: a competing risks approach. J Am Geriatr Soc 2008; 56(10):188792.

14. Ryg J, Rejnmark L, Overgaard S, et al. Hip Fracture Patients at Risk of Second Hip Fracture-A Nationwide Population-Based Cohort Study of 169,145 Cases During 1977-2001. J Bone Miner Res 2009. 
15. Mitani S, Shimizu M, Abo M, et al. Risk factors for second hip fractures among elderly patients. J Orthop Sci 2010; 15(2):192-7.

16. Lawrence TM, Wenn R, Boulton CT, et al. Age-specific incidence of first and second fractures of the hip. J Bone Joint Surg Br 2010; 92(2):258-61.

17. Giangregorio L, Leslie W. Time since prior fracture is a risk modifier for ten year osteoporotic fractures. J Bone Miner Res 2010. 


\section{Bulleted and annotated references}

** Center, J.R., D. Bliuc, T.V. Nguyen, and J.A. Eisman, Risk of subsequent fracture after low-trauma fracture in men and women. JAMA 2007;297(4): 387-94.

This study examined the subsequent risk of all fracture types, except fingers and toes, after an initial low-energy trauma fracture in men and women aged 60 years and over taking into account the time relation between fractures. The risk of subsequent fracture was highest immediately after the initial fracture, but was no longer higher than the risk for individuals without a fracture 10-years after the initial fracture ( $41 \%$ of the subsequent fractures occurred within two years).

* Berry, S.D., E.J. Samelson, L. Ngo, et al., Subsequent fracture in nursing home residents with a hip fracture: a competing risks approach. J Am Geriatr Soc 2008;56(10): 1887-92.

In long-term care residents with a surgically repaired hip fracture, $21 \%$ sustained a subsequent fracture: $6 \%$ of residents experienced a subsequent fracture within six months, $12 \%$ within one year, and $21 \%$ within five years.

** Geel van, T.A.C.M., S. Helden van, P.P. Geusens, et al., Clinical subsequent fractures cluster in time after first fractures. Ann Rheum Dis 2009;68(1): 99-102.

The results of this study, extend the observations of Center et al. to all clinical vertebral and non-vertebral fractures, in women from menopause onwards, and for both low- and high-energy trauma fractures. The initial fracture type was no predictor for subsequent fractures. The subsequent fracture risk remained higher, compared with initial fracture risk, for 15 years after the initial fracture ( $23 \%$ of the subsequent fractures occurred within one year).

** Ryg, J., L. Rejnmark, S. Overgaard, et al., Hip Fracture Patients at Risk of Second Hip Fracture-A Nationwide Population-Based Cohort Study of 169,145 Cases During 1977-2001. J Bone Miner Res 2009.

Approximately 170.000 patients with an initial hip fracture were included in this 25 year follow-up study. The cumulative incidence showed that $9 \%$ of the subsequent hip fractures were suffered within one year and $20 \%$ within five years. The risk for a subsequent fracture remained significantly higher than the risk for individuals without a fracture for 15 years after the initial fracture. 


\section{Part II}

Fracture Liaison Service: risk evaluation 



\section{Chapter 4}

\section{The role of the combination of bone and fall related risk factors on short-term subsequent fracture risk and mortality}

Kirsten MB Huntjens, Tineke ACM van Geel, Svenhjalmar van Helden, Joop PW van den Bergh, Paul Willems, Bjorn Winkens, Piet P Geusens, Peter RG Brink

BMC Musculoskeletal (2013) 14:121 


\section{ABSTRACT}

\section{Introduction}

We analysed whether a combination of bone- and fall-related risk factors (RFs) in addition to a recent non-vertebral fracture (NVF) contributed to subsequent NVF risk and mortality during 2-years in patients who were offered fall and fracture prevention according to Dutch fracture- and fall-prevention guidelines.

\section{Methods}

834 consecutive patients aged $\geq 50$ years with a recent NVF who were included. We compared subgroups of patients according to the presence of bone RFs and/ or fall RFs (group 1: only bone RFs; group 2: combination of bone and fall RFs; group 3: only fall RFs; group 4: no additional RFs). Univariable and multivariable Cox regression analyses were performed adjusted for age, sex and baseline fracture location (major or minor).

\section{Results}

$57(6.8 \%)$ had a subsequent NVF and 29 (3.5\%) died within 2-years. Univariable Cox regression analysis showed that patients with the combination of bone and fall RFs had a $99 \%$ higher risk in subsequent fracture risk compared to all others (Hazard Ratio (HR) 1.99; 95\% Confidence Interval (CI) 1.18-3.36) Multivariable analyses this was borderline not significant (HR 1.70; 95\% Cl: 0.99-2.93). No significant differences in mortality were found between the groups.

\section{Conclusion}

Evaluation of fall RFs contributes to identifying patients with bone RFs at highest immediate risk of subsequent NVF in spite of guideline-based treatment. It should be further studied whether earlier and immediate prevention following a NVF can decrease fracture risk in patients with a combination of bone and fall RFs. 


\section{INTRODUCTION}

For persons above fifty years of age, a history of fracture doubles the risk of a subsequent fracture 1 . This risk is highest immediately after the fracture, with a 5- to 25 -fold increase of subsequent fracture risk within the first months and years ${ }^{1-6}$. In patients with a recent fracture, other bone-related clinical risk factors, low bone mineral density (BMD) and fall-related risk factors are often present ${ }^{7}$. These risk factors are independently related to fracture risk and are used in algorithms to calculate fracture risk, like $F R A X^{\circ}{ }^{8}$ and Garvan Fracture Risk calculator ${ }^{9}$. In addition, fall-related risk factors predict not only the risk of subsequent falls, but also of fractures. Therefore, these risk factors are sometimes integrated in fracture prediction algorithms ${ }^{9}$.

Fracture risk reduction has only been shown with specific anti-osteoporosis medication such as bisphosphonates, denosumab, raloxifene and recombinant PTH $^{4,10-17}$. Fall prevention strategies decrease the risk of falls, however in these studies prevention of fractures was not demonstrated ${ }^{18}$.

In the field of post fracture care, a Fracture Liaison Service is one of the initiatives to integrate evaluation of bone- and fall-related risk factors in patients attending the hospital with a recent clinical fracture ${ }^{19}$.

The aim of the Fracture Liaison Service is to evaluate bone- and fall-related risk factors, to initiate fall prevention programs, adequate calcium and vitamin $D$ supplementation and specific anti-osteoporosis medication when needed in order to reduce subsequent falls, fractures and mortality 4,6, 11, 19-21.

In this study, patients with a recent clinical fracture were assessed at the FLS at Maastricht University Medical Center for bone- and fall related risk factors and we hypothesised that over a 2-year follow-up period the subsequent fracture risk and mortality would be highest in patients with a combination of bone- and fall- related risk factors, even though these patients received anti-osteoporosis treatment and/or fall prevention. 


\section{METHODS}

\section{Study design}

The Fracture Liaison Service is a collaboration between the department of surgery, orthopaedics and internal medicine (rheumatology and endocrinology) and is based on the consensus guideline osteoporosis of the Dutch Institute for Health Care Improvement (CBO) ${ }^{20}$. The Fracture Liaison Service is coordinated by a specialised and dedicated fracture nurse.

Between September 2004 and September 2006 all consecutive patients older than 50 years with a recent non-vertebral fracture, who entered the level one trauma centre in the south of the Netherlands were invited to participate. Patients with pathological or vertebral fractures or living outside the postal area were excluded. All patients were prospectively followed for two years. The hospital database was searched for radiographically confirmed first and subsequent NVF, fracture location and date of occurrence. All NVFs (baseline and subsequent) were categorised according to International Classification of Disease (ICD)-9 and then pooled into 2 groups: major (hip, pelvis, proximal humerus, proximal tibia, multiple ribs or distal femur fracture), and minor (all other) fractures ${ }^{3}$. All groups were mutually exclusive. First and subsequent fractures were classified according to the main fracture. The national obituary database was searched to investigate whether patients were deceased.

The study was approved by the medical ethical committee of the hospital (MEC 03-194).

\section{Measurements}

All patients, who were able and agreed to evaluate their fracture risk assessment, were invited to attend the Fracture Liaison Service. Medical history, current and past medication use, living situation, conditions concerning the occurrence of the fracture, dietary calcium and vitamin D intake were assessed. Additionally, bone- and fall- related risk factors were systematically assessed, and bone mineral density was measured by dual energy X-ray absorptiometry (DXA, Hologic QDR 4500) at the lumbar spine and femoral neck. Based on criteria of the World Health Organisation osteoporosis was classified as T-score of $\leq-2.5$, osteopenia as T-score between -1.0 and -2.5, and normal BMD as T-score of >-1.0. 
According to the national osteoporosis guideline the following bone- and fallrelated risk factors were evaluated: a history of clinical fracture after the age of 50 years, family history of hip fracture, low body weight ( $<60 \mathrm{~kg}$ ), glucocorticoid use and immobility ( $<4$ hours per day) ${ }^{20}$. Vertebral fractures were excluded from this study, since the exact date of occurrence is often unclear. Patients were categorised as having a bone-related risk factor if they had osteoporosis or at least one of the above mentioned risk factors.

According to the national guideline on fall prevention the following fall-related risk factors were evaluated: a previous falls in the last 12 months (the fall leading to the current fracture was excluded), the presence of Parkinson's disease, current use of psycho-active medication, urinary incontinence (defined as involuntary loss of urine) and articular complaints ${ }^{18}$. Additionally, the Groningen Activity Restriction Scale (GARS) was used to estimate the disability in activities of daily living $(A D L)^{21}$. Patients were categorised as having a fall-related risk factor if at least one of the risk factors mentioned above was present or the GARS showed low ADL.

According to the Dutch guidelines on osteoporosis and fall prevention patients started with Calcium and Vitamin D or a bisphosphonate in the presence of osteoporosis.

For the analyses, patients were categorised into subgroups according to the presence, combination or absence of bone- and fall-related risk factors: (1) patients with only bone-related risk factors, (2) patients with combination of bone- and fall-related risk factors, (3) patients with only fall-related risk factors, and (4) patients without bone- or fall-related risk factors. The rationale behind these groups is that there is a known treatable risk factor in group 1 and 2 , but not in group 3 because in fracture prevention only bone targeted therapy has shown to reduce fracture risk and not fall targeted therapies.

\section{Statistical analysis}

Differences between the groups were analysed using the chi-square or Fisher's exact test for categorical variables. ANOVA and independent samples t-test for numerical variables. Kaplan-Meier and multivariable Cox regression analyses were performed using subsequent fracture and mortality as dependent variables (events), adjusted for age, sex and baseline fracture location (major/minor). For subsequent fracture as dependent variable, follow-up time started at time of 
current fracture (time $=0$ ) and was defined as time between current fracture and subsequent fracture (= event), death or end of 2-year follow-up period (= censored). For mortality, follow-up time was calculated as time between current fracture and death (= event) or end of 2-year follow-up period (= censored). Schoenfeld residuals were used to check the proportional hazards assumption and, if violated, time-dependent Cox regression was used. Linearity was checked for continuous variables and, if violated, centered quadratic terms were included. A two-sided $p$-value $\leq 0.05$ was considered statistically significant. All analyses were performed using SPSS for Mac (version 18.0.0; SPSS Inc., Illinois, USA).

\section{RESULTS}

In total 834 patients with a NVF were included. Fifty-seven $(6.8 \%)$ patients sustained a subsequent NVF and 29 (3.5\%) died within two years.

Table 1 shows the patient characteristics for the total studied population, and for patients with $(n=57)$ and without a subsequent non-vertebral fracture within 2 years $(n=777)$. In total, $51.2 \%$ of patients had least one bone- and $60.4 \%$ had at least one fall-related risk factor. One in four patients had a previous clinical fracture at 50+ years, almost one in five had a low body weight ( $<60 \mathrm{~kg}$ ) or a family history with a previous hip fracture. The most common Fall-related risk factors were articular complaints (31.3\%), >1 fall in the preceding year (26.0\%) and exposure to psychopharmaca (22.2\%). Compared to patients without a subsequent fracture, patients with a subsequent fracture were significantly older (70.3 vs. 67.1 years), more patients had impaired mobility (10.5\% vs. $3.9 \%$ ) and a previous fracture after the age of 50 (38.6\% vs. $25.2 \%)$, but less often had urinary incontinence $(24.6 \%$ vs. $13.6 \%)$. Additionally, patients with a subsequent fracture had more often a combination of at least one bone-and one fall-related risk factor (group $2,56.1 \%$ vs. $38.9 \%, p<0.01)$ compared to patients without a subsequent fracture.

\section{Subsequent fracture risk}

\section{Comparison of subgroups}

Table 2 shows the results all patients according to the pre-specified groups. Patients with the combination of bone- and fall related risk factors (group 2, n = 334) 


\begin{tabular}{|c|c|c|c|c|c|}
\hline & & $\begin{array}{l}\text { Total } \\
(n=834)\end{array}$ & $\begin{array}{l}\begin{array}{l}\text { Subsequent } \\
\text { fracture } \\
(n=57 ; 6.8 \%)\end{array} \\
\end{array}$ & $\begin{array}{l}\text { No subsequent } \\
\text { fracture } \\
(n=777 ; 93.2 \%)\end{array}$ & P-value \\
\hline Age (SD) & & $67.3(10.4)$ & $70.3(11.1)$ & $67.1(10.3)$ & 0.023 \\
\hline \multirow[t]{3}{*}{ Sex n (\%) } & & & & & 0.022 \\
\hline & Women & $608(72.9)$ & $49(86.0)$ & $559(71.9)$ & \\
\hline & Men & $226(27.1)$ & $8(14.0)$ & $218(28.1)$ & \\
\hline \multirow[t]{3}{*}{ Fracture location $n(\%)$} & & & & & 0.874 \\
\hline & Major & $286(34.3)$ & $19(33.3)$ & $267(32.0)$ & \\
\hline & Minor & $548(65.7)$ & $38(67.7)$ & $510(68.0)$ & \\
\hline \multicolumn{6}{|l|}{ Bone RFs (\%) } \\
\hline Fracture $50+y r s$ & & $218(26.1)$ & $22(38.6)$ & $196(25.2)$ & 0.027 \\
\hline$<60 \mathrm{~kg}$ & & $149(17.9)$ & $11(19.3)$ & $138(17.8)$ & 0.770 \\
\hline Positive family history & & $144(17.3)$ & $12(21.1)$ & $132(17.0)$ & 0.433 \\
\hline Immobility & & $36(4.3)$ & $6(10.5)$ & $30(3.9)$ & 0.017 \\
\hline On glucocorticoids & & $7(0.8)$ & $0(0)$ & $7(0.9)$ & 1.000 \\
\hline At least 1 bone RF & & $427(51.2)$ & $36(63.2)$ & $391(50.3)$ & 0.061 \\
\hline \multicolumn{6}{|l|}{ Fall RFs (\%) } \\
\hline$>1$ fall last year & & $217(26.0)$ & $21(36.8)$ & $196(25.2)$ & 0.054 \\
\hline On psychopharmaca & & $185(22.2)$ & $18(31.6)$ & $167(21.5)$ & 0.077 \\
\hline Low ADL (before fracture) & & $61(7.3)$ & $8(14.0)$ & $53(6.8)$ & 0.043 \\
\hline Articular complaints & & $261(31.3)$ & $17(29.8)$ & $244(31.4)$ & 0.804 \\
\hline Urinary incontinence & & $120(14.4)$ & $14(24.6)$ & $106(13.6)$ & 0.023 \\
\hline Parkinson's disease & & $5(0.6)$ & $0(0)$ & $5(0.6)$ & 1.000 \\
\hline At least 1 of the fall RF & & $504(60.4)$ & $39(68.4)$ & $465(59.8)$ & 0.201 \\
\hline
\end{tabular}

Table 1. Comparison of characteristics of patients with and without a subsequent fracture P-value refers to differences between patients with and without subsequent fracture Chi-square and Fisher's exact tests were used for categorical variables and independent-samples t-tests for numerical variables.

Abbreviations: ADL: activity of daily living

were significantly older (70.0 years) compared with group 1 ( $n=183,65.6$ years), group $3(n=170,67.6$ years) and group $4(n=147,63.0$ years), and were more often females ( $83.2 \% ; 69.4 \%$ for group $1 ; 70.6 \%$ for group 3 , and $6.5 \%$ for group 4$)$. They had also sustained more often a major fracture $(42.8 \%)$ at baseline compared to the other groups (group 1: 33.3\%; group 3:27.6\%; group 4: 23.8\%, respectively). In absolute terms, no significant difference was found in absolute subsequent fracture risk between the groups ( $p=0.069$ ) (Figure 1, 2 and Table 2). 


\begin{tabular}{|c|c|c|c|c|c|c|c|}
\hline & & Total & $\begin{array}{l}\text { Group } 1 \\
\text { BRF }\end{array}$ & $\begin{array}{l}\text { Group } 2 \\
\text { Combination } \\
\text { of RFs }\end{array}$ & $\begin{array}{l}\text { Group } 3 \\
\text { FRF }\end{array}$ & $\begin{array}{l}\text { Group } 4 \\
\text { No RFs }\end{array}$ & P value \\
\hline Age (SD) & & $67.3(10.4)$ & $65.6(9.5)$ & $70.0(10.4)$ & $67.6(10.8)$ & $63.0(8.7)$ & \\
\hline \multirow[t]{3}{*}{ Sex n (\%) } & & & & & & & $<0.001$ \\
\hline & Women & $608(72.9)$ & $127(69.4)$ & $278(83.2)$ & $120(70.6)$ & $83(56.5)$ & \\
\hline & Men & $226(27.1)$ & $56(30.6)$ & $56(16.8)$ & $50(29.4)$ & $64(43.5)$ & \\
\hline \multirow[t]{3}{*}{ Fracture location $\mathbf{n}(\%)$} & & & & & & & $<0.001$ \\
\hline & Major & $286(34.3)$ & $61(33.3)$ & $143(42.8)$ & $47(27.6)$ & $35(23.8)$ & \\
\hline & Minor & $548(65.7)$ & $122(66.7)$ & $191(57.2)$ & $123(72.4)$ & $112(76.2)$ & \\
\hline \multirow[t]{3}{*}{ Subsequent fracture $\mathrm{n}(\%)$} & Total & $57(6.8)$ & $9(4.9)$ & $32(9.6)$ & $7(4.1)$ & $9(6.1)$ & 0.069 \\
\hline & $1^{\text {st }}$ year & 34 (59.6) & $3(33.3)$ & $22(68.8)$ & $3(42.9)$ & $6(66.7)$ & \\
\hline & $2^{\text {nd }}$ year & $23(40.4)$ & $6(67.7)$ & $10(31.2)$ & $4(57.1)$ & $3(33.3)$ & \\
\hline Mortality n (\%) & & $29(3.5)$ & $6(3.3)$ & $13(3.9)$ & $7(4.1)$ & $3(2.0)$ & 0.728 \\
\hline
\end{tabular}

Table 2. Comparison of all patients according to their pre-specified groups

Chi-square and Fisher's exact tests were used for categorical variables and ANOVA F-tests for numerical variables.
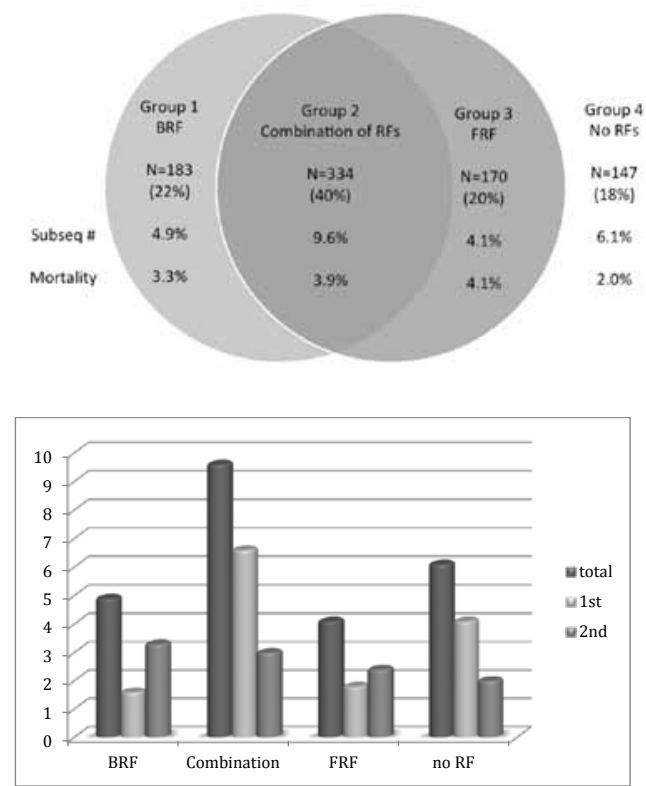

Figure 1. All patients according to their pre-specified groups

A Venn diagram

B Histogram 


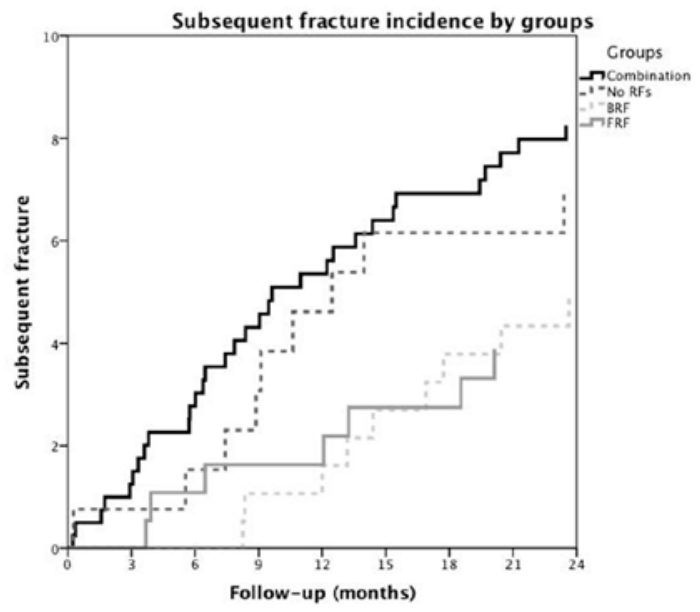

Figure 2. Multivariable Cox regression.

Analyses stratified by groups

Patients with a combination of bone- and fall-related risk factors versus all other patients

Univariable Cox analysis showed that patients with a combination of risk factors had a significantly higher subsequent fracture risk than all other patients (HR: 1.99, 95\%Cl: 1.18-3.36 p=0.010) (Figure 3). However, after adjusting for age, sex and baseline fracture location (multivariable model) the subsequent fracture risk was not significantly higher (borderline) in the multivariable model ( $\mathrm{HR} 1.70,95 \% \mathrm{Cl}$ : 0.99-2.93; $p=0.055)$. 


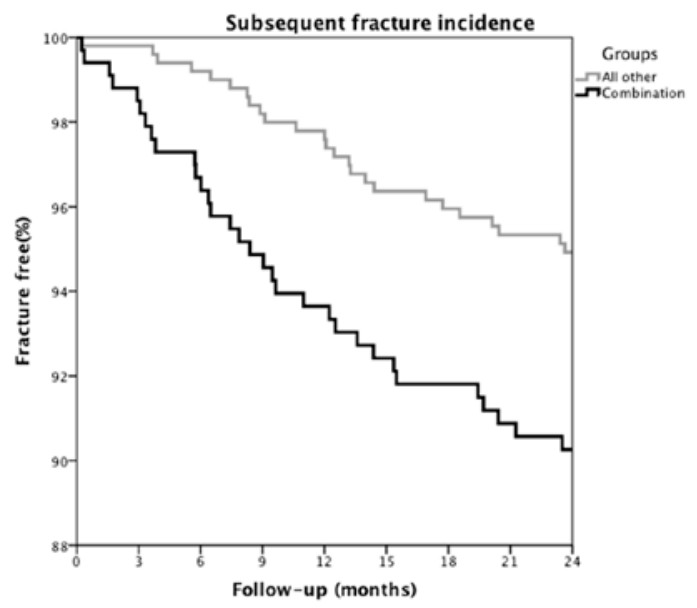

Figure 3. Kaplan Maier curve

Cumulative subsequent fracture incidence in patients with the combination of risk factors (group 2) compared with all other patients (group 1, 3 and 4)

Patients with a combination of risk factors compared to group 1 (only bonerelated risk factors)

Patients with the combination of risk factors did not have a significantly higher subsequent fracture risk than patients with only bone-related risk factors in univariable (HR 2.04; 95\%Cl: 0.97-4.27) or multivariable analyses (HR 1.67; 95\%Cl: 0.79-3.54). However, the plot of the Kaplan-Meier curves indicated that the subsequent fractures occurred immediately after the current fracture in the combination group, while this was not the case for the patients with only bone-related risk factors (Figure 4). This time-dependency was confirmed by the Schoenfeld residuals and the time-dependent Cox regression model $(p=0.024)$. However, the number of events is too low to draw reliable conclusions. 


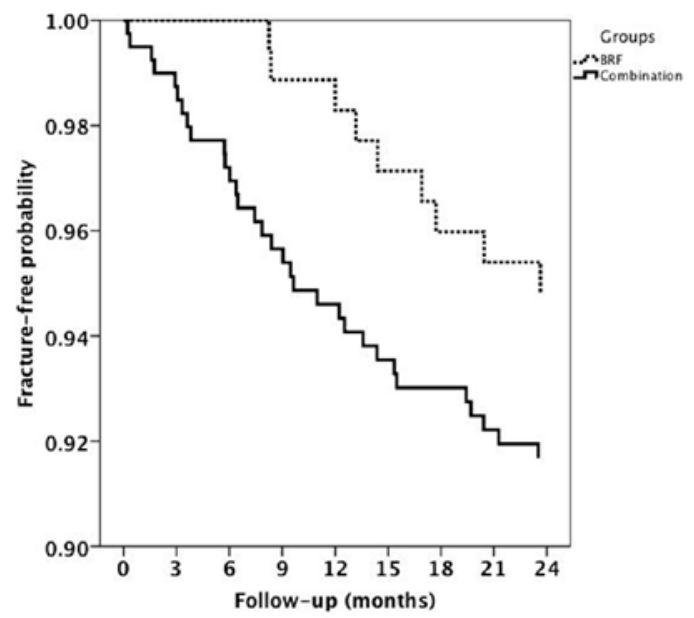

Figure 4. Kaplan Maier curve

Fracture free probability of the combination versus BRF, adjusted for age, sex and baseline fracture location.

Patients with a combination of risk factors compared to group 3 (only fall-related risk factors)

In univariable analysis, patients with the combination of risk factors had a higher risk of subsequent fractures compared with patients with only fall-related risk factors (HR 2.41,95\% Cl: 1.06-6.46). In the multivariable model, the subsequent fracture risk was no longer significantly higher (HR 2.05; 95\%Cl: 0.90-4.69).

Patients with a combination of risk factors compared to group 4 (no bone- or fallrelated risk factors)

No significant differences were found between the groups on subsequent fracture risk within 2-years after univariable ( $\mathrm{HR} 1.61 ; 95 \% \mathrm{Cl}$ : 0.77-3.38) and multivariable cox regression analyses (HR 1.16; 95\% Cl: 0.53-2.55).

\section{Mortality}

Within two years after baseline fracture 26 patients were deceased (3.5\%). In univariable Cox regression analysis, no significant difference was found between patients with a combination of bone- and fall-related risk factors (group 2) and all other groups, as well as between group 2 and all groups separately. Due to 
the small number of deceased patients in the present study, no multivariable regression analyses were performed. However, this only reflects the very selected nature of our cohort, as the majority of patients were still alive within 2 years after their baseline fracture.

\section{DISCUSSION}

\section{Subsequent fracture incidence}

The subsequent non-vertebral fracture risk in patients with a combination of bone- and fall-related risk factors was nearly double the risk of all other patients in univariable analysis (HR 1.99 (95\% Cl: 1.18-3.36). In multivariable analysis this tendency was also shown, but it did not reach significance (HR 1.70; 95\%Cl: 0.992.93). This is partly explained by the low event rate. There was a time-dependency when comparing patients with a combination of risk factors to patients with only bone-related risk factors (data not shown). This indicates that, in spite of Fracture Liaison Service assessment, patients with a combination of risk factors still had a high fracture risk at short term. Many studies have shown that the risk of subsequent fracture is highest immediately after a fracture, such as repeat vertebral, hip and non-vertebral fractures 3,6,22,23. However, the event rate was lower in our research compared to other published articles. In a study among patients aged 60 years and over a relative risk of subsequent fracture incidence of 1.95 in women and 3.45 in men was found ${ }^{3}$. A subsequent fracture risk of $10.8 \%$ was found within 2-years after a fracture, and of $17.6 \%$ in patients of $50+$ years who sustained a NVF after a NVF, 5 . The two retrospective studies were performed according to intention-to-treat, and therefore, a difference in subsequent fracture rate and mortality could be found. Mortality is known to be increased after a fracture, especially after a hip fracture ${ }^{24}$. A recent study showed an increased risk of mortality especially within 5 -years after the fracture ${ }^{11}$. In the described studies, $3,4,5,24,11$ not all patients were treated at a Fracture Liaison Service. This might explain the lower subsequent fracture (6.8\%) and mortality rate $(3.5 \%)$ in our study compared with the studies mentioned above (due to a possible treatment effect). In addition, the minimum age of inclusion was different, and only patients who did attend the Fracture Liaison Service were included. 
There was a time-dependency with regard to subsequent fracture risk in patients who had both bone- and fall-related risk factors with the highest risk immediately after the initial fracture. This might be caused by (new) falls and, since the bone is already vulnerable due to the initial fracture, subsequent fractures mostly occur in this subgroup short-term after the initial fracture.

Therefore, patients with a combination of bone- and fall-related risk factors, are definitely candidates for immediate fracture prevention combined with fall prevention.

However, of the patients without additional risk factors $6.1 \%$ had a subsequent fracture within 2-years of follow-up. Presumably other risk factors that are not captured by the bone- and fall- related risk assessment in this study play a role in the occurrence of subsequent fractures. On the other hand, all patients in this study had a recent fracture, which is by itself a major independent risk factor for subsequent fractures. As a consequence, this might imply that all patients with an initial NVF, whether or not additional risk factors are present, deserve subsequent fracture prevention regardless of other risk factors. This is also proposed in the UK guideline ${ }^{25}$.

\section{Mortality}

No difference was found between the groups for mortality rate. This could be the result of the low mortality rate $(n=29)$ in this study in combination with the relatively short follow-up period (two years). A study with a longer follow-up period in a larger population is necessary to further study these findings. Treatment of osteoporosis with bisphosphonates might reduce mortality rate. The mechanism by which this operates remains unclear, but its effect on subsequent fracture risk or on extra skeletal sites might be two possibilities ${ }^{11,26,27}$. Integrating guidelines on prevention of falls, fractures and identification and treatment of osteoporosis is recommended to optimise post fracture care. However, integrating these services is difficult and still has to be achieved in many centers ${ }^{28}$.

\section{Strengths and limitations}

The strength of this study is that all consecutive patients with a recent nonvertebral fracture who attended the Fracture Liaison Service were included in the analyses. Furthermore, a dedicated fracture nurse performed the assessments of 
well-defined clinical, bone- and fall-related risk factors according to the national Osteoporosis and Fall Prevention Guidelines ${ }^{20,21}$.

A limitation of this study is that there are no data on prescription and adherence of the proposed osteoporosis treatment and fall prevention. Persistence might be low, as has been shown in a recent publication for oral anti-osteoporosis medications in the Netherlands ${ }^{29}$. Due to the low mortality rate, no in depth analysis of the role of risk factors could be performed. However, this could also be a strength, since one of the effects of the Fracture Liaison Service might be mortality risk reduction.

\section{Conclusions}

In patients with a recent non-vertebral fracture who had a combination of boneand fall-related risk factors, the risk of subsequent fractures was almost doubled compared with the other patients. These patients also had a higher subsequent fracture risk immediately after the initial fracture compared with patients in whom only bone-related risk factors were present.

Therefore, not only bone- but also fall-related risk factors should be assessed in order to identify patients at highest immediate risk of subsequent NVF. 


\section{REFERENCES}

1. Klotzbuecher CM, Ross PD, Landsman PB, et al. Patients with prior fractures have an increased risk of future fractures: a summary of the literature and statistical synthesis. J Bone Miner Res 2000; 15(4):721-39.

2. Johnell O, Kanis JA, Oden A, et al. Fracture risk following an osteoporotic fracture. Osteoporos Int 2004; 15(3):175-9.

3. Center JR, Bliuc D, Nguyen TV, et al. Risk of subsequent fracture after low-trauma fracture in men and women. JAMA : the journal of the American Medical Association 2007; 297(4):387-94.

4. Huntjens KM, Kosar S, van Geel TA, et al. Risk of subsequent fracture and mortality within 5 years after a non-vertebral fracture. Osteoporosis international : a journal established as result of cooperation between the European Foundation for Osteoporosis and the National Osteoporosis Foundation of the USA 2010; 21(12):2075-82.

5. van Helden S, Cals J, Kessels F, et al. Risk of new clinical fractures within 2 years following a fracture. Osteoporos Int 2006; 17(3):348-54.

6. van Geel TA, van Helden S, Geusens PP, et al. Clinical subsequent fractures cluster in time after first fractures. Ann Rheum Dis 2008.

7. van Helden S, van Geel AC, Geusens PP, et al. Bone and fall-related fracture risks in women and men with a recent clinical fracture. The Journal of bone and joint surgery. American volume 2008; 90(2):241-8.

8. WHO, Kanis JA. http://www.shef.ac.uk/FRAX/?lang=en. Available at: http://www. shef.ac.uk/FRAX/index.htm.

9. Garvan I. Available at: http://garvan.org.au/promotions/bone-fracture-risk/calculator/. Accessed 2011-11-07.

10. Johnell O, Kanis JA, Oden A, et al. Mortality after osteoporotic fractures. Osteoporosis international : a journal established as result of cooperation between the European Foundation for Osteoporosis and the National Osteoporosis Foundation of the USA 2004; 15(1):38-42.

11. Bliuc D, Nguyen ND, Milch VE, et al. Mortality risk associated with low-trauma osteoporotic fracture and subsequent fracture in men and women. JAMA : the journal of the American Medical Association 2009; 301(5):513-21.

12. Harris ST. Bisphosphonates for the treatment of postmenopausal osteoporosis: clinical studies of etidronate and alendronate. Osteoporosis international : a journal established as result of cooperation between the European Foundation for Osteoporosis and the National Osteoporosis Foundation of the USA 2001; 12 Suppl 3:S11-6.

13. Boonen S, Laan RF, Barton IP, et al. Effect of osteoporosis treatments on risk of non-vertebral fractures: review and meta-analysis of intention-to-treat studies. Osteoporos Int 2005; 16(10):1291-8. 
14. Cummings SR, San Martin J, McClung MR, et al. Denosumab for prevention of fractures in postmenopausal women with osteoporosis. The New England journal of medicine 2009; 361(8):756-65.

15. Black DM, Delmas PD, Eastell R, et al. Once-yearly zoledronic acid for treatment of postmenopausal osteoporosis. N Engl J Med 2007; 356(18):1809-22.

16. Black DM, Thompson DE, Bauer DC, et al. Fracture risk reduction with alendronate in women with osteoporosis: the Fracture Intervention Trial. FIT Research Group. J Clin Endocrinol Metab 2000; 85(11):4118-24.

17. Reginster J, Minne HW, Sorensen $\mathrm{OH}$, et al. Randomized trial of the effects of risedronate on vertebral fractures in women with established postmenopausal osteoporosis. Vertebral Efficacy with Risedronate Therapy (VERT) Study Group. Osteoporosis international : a journal established as result of cooperation between the European Foundation for Osteoporosis and the National Osteoporosis Foundation of the USA 2000; 11(1):83-91.

18. Bischoff-Ferrari HA. The role of falls in fracture prediction. Current osteoporosis reports 2011; 9(3):116-21.

19. Eisman JA, Bogoch ER, Dell R, et al. Making the first fracture the last fracture: ASBMR task force report on secondary fracture prevention. Journal of bone and mineral research : the official journal of the American Society for Bone and Mineral Research 2012; 27(10):2039-46.

20. CBO KvdG. Osteoporose, tweede herziene richtlijn. Van Zuiden Communications 2002.

21. CBO. Preventie van valincidenten bij ouderen 2004. Available at: http://www.cbo.nl/ thema/richtlijnen/overzicht-richtlijnen/geriatrie/.

22. Lindsay R, Silverman SL, Cooper C, et al. Risk of new vertebral fracture in the year following a fracture. Jama 2001; 285(3):320-3.

23. Ryg J, Rejnmark L, Overgaard S, et al. Hip fracture patients at risk of second hip fracture: a nationwide population-based cohort study of 169,145 cases during 19772001. Journal of bone and mineral research : the official journal of the American Society for Bone and Mineral Research 2009; 24(7):1299-307.

24. Center JR, Nguyen TV, Schneider D, et al. Mortality after all major types of osteoporotic fracture in men and women: an observational study. Lancet 1999; 353(9156):878-82.

25. Compston J, Cooper A, Cooper C, et al. Guidelines for the diagnosis and management of osteoporosis in postmenopausal women and men from the age of 50 years in the UK. Maturitas 2009; 62(2):105-8.

26. Huntjens KM, van Geel TC, Geusens PP, et al. Impact of guideline implementation by a fracture nurse on subsequent fractures and mortality in patients presenting with non-vertebral fractures. Injury 2011; 42 Suppl 4:S39-43. 
27. Center JR, Bliuc D, Nguyen ND, et al. Osteoporosis medication and reduced mortality risk in elderly women and men. The Journal of clinical endocrinology and metabolism 2011; 96(4):1006-14.

28. Huntjens KM, van Geel TA, Blonk MC, et al. Implementation of osteoporosis guidelines: a survey of five large fracture liaison services in the Netherlands. Osteoporosis international : a journal established as result of cooperation between the European Foundation for Osteoporosis and the National Osteoporosis Foundation of the USA 2011; 22(7):2129-35.

29. Diez-Perez A, Hooven FH, Adachi JD, et al. Regional differences in treatment for osteoporosis. The Global Longitudinal Study of Osteoporosis in Women (GLOW). Bone 2011; 49(3):493-8. 



\section{Chapter 5}

\section{Implementation of osteoporosis guidelines: a survey of five large Fracture Liaison Services in the Netherlands}

Kirsten MB Huntjens, Tineke ACM van Geel, Marion C Blonk, Han JH Hegeman, Maarten van der Elst, Paul Willems, Piet P Geusens, Bjorn Winkens, Peter RG Brink, Svenhjalmar van Helden 


\section{ABSTRACT}

\section{Introduction}

The aim of the study was to evaluate the implementation of case finding according to guidelines for osteoporosis in fracture patients presenting at Fracture Liaison Services (FLSs) in The Netherlands.

\section{Methods}

Five FLSs were contacted to participate in this prospective study. Patients older than 50 years with a recent clinical fracture who were able and were willing to participate in fracture risk evaluation were included. Performance was evaluated by criteria for patient recruitment, patient characteristics, nurse time, evaluated clinical risk factors (CRFs), bone mineral density (BMD) and laboratory testing and results of CRFs and BMD are presented. Differences between FLSs were analysed for performance (by chi square and Student t-test) and for prevalence of CRFs (by relative risks (RR)).

\section{Results}

All FLSs had a dedicated nurse, spending 0.9 to 1.7 hours per patient. During 39 to 58 months follow up, 7199 patients were evaluated (15 to 47 patients/centre/ month, mean age $67 \mathrm{yrs}, 77 \%$ women). Major differences were found between FLSs in performance of patient recruitment, evaluation of CRFs, BMD and laboratory testing, varying between o and $100 \%$. The prevalence of CRFs and osteoporosis varied significantly between FLSs (RR between 1.7 and 37.0, depending on the risk factor).

\section{Conclusion}

All five participating FLSs with a dedicated fracture nurse differed in performance of patient selection, CRFs and in the prevalence of CRFs, indicating the need for more concrete and standardised guidelines to organise evaluation of patients at the time of fracture in daily practice. 


\section{INTRODUCTION}

Osteoporotic fractures represent a major growing public health issue. The number of fractures in the elderly is expected to increase mainly due to the world's ageing population '. Bone mineral density (BMD) measured by Dual Energy X-ray Absorptiometry (DXA) scan alone is not sufficient to provide an accurate prediction of fracture risk. Other clinical, non-BMD risk factors are known to be important for estimating an adequate probability of fracture ${ }^{2,3}$. A previous fracture doubles the risk for future fractures and vertebral fractures quadruple this risk ${ }^{4,5}$, and even more so at short term ${ }^{6-10}$. Recently, the World Health Organization (WHO) developed a Fracture Risk Assessment (FRAX) tool to evaluate the 10year fracture risk of patients ${ }^{11}$. The FRAX tool integrated clinical risk factors (CRFs) and BMD to predict the 10-year risk of a major osteoporotic and hip fracture, but does not include evaluation of fall risks.

Current Guidelines on Osteoporosis in the Netherlands (developed in 2002) recommend that all female patients over 50 years of age with a minimal trauma fracture should be investigated by DXA and treated, when having, for osteoporosis ${ }^{12}$. Moreover, women aged sixty years and over, with all three known risk factors for fractures: a family history of fractures, low body weight $(<67 \mathrm{~kg})$ or immobility, should be investigated by DXA scan for osteoporosis. Women over the age of 70 merely require two of these risk factors ${ }^{12}$.

A Fracture Liaison Service (FLS) is one of the initiatives in the field of post fracture care to integrate osteoporosis assessment ${ }^{13-16}$. An evaluation of FLSs allowed to identify similarities and differences in performance of evidence based medicine and prevalence of CRFs, and can be helpful to detect strengths and weaknesses of guideline advices and their implementation. The results of previous studies encouraged the start of several FLSs throughout the Netherlands $13-15,17,18$.

The aim of the present study was to identify $1 /$ similarities and differences in performance, and 2/ the prevalence of CRFs in patients presented at FLSs in five large hospitals in The Netherlands. 


\section{MATERIAL AND METHODS}

\section{Study design}

This prospective, observational study was conducted in five FLSs of hospitals in the Netherlands, one university hospital and four general hospitals. These FLSs agreed to respond to an extensive questionnaire on organisational aspects, performance and results of examinations about patients who were older than 50 years of age and who were examined shortly after they presented with a recent clinical fracture, in order to prevent subsequent fractures. The results were reported by the FLSs in a standardised database.

\section{FLS procedures}

Several organisational aspects were examined: number of patients, in- and exclusion criteria, patient recruitment, fracture location, nurse time, performed examinations (CRFs, DXA, laboratory examinations, circumstances of injury) and results of CRFs and DXA. All fractures were categorised using ICD-9 classification (skull, spine, clavicle, thorax, pelvis, humerus, radius/ulna, hand, hip, femur, patella, tibia/fibula, ankle, foot, multiple, other) and classified as major (pelvis, vertebra, distal femur, proximal tibia, multiple ribs and proximal humerus), minor (all other excluding major fractures, hip and fingers/toes fractures), hip and fingers/toes, according to Center et $\mathrm{al}^{6}$. Fractures were also divided into hip, humerus, distal radius/ulna and tibia/fibula fractures. To evaluate all patients in the analysis all remaining fractures were analysed as "other fractures".

\section{Statistical analysis}

FLS characteristics were analysed with Pearson Chi square for dichotomous variables and independent-samples t-test and analysis of variance (ANOVA) for continuous variables. Dichotomous variables were presented as percentages or mean with standard deviation (SD). Variability of presence of CRFs between FLSs were calculated as relative risks (RR), i.e. as the relative difference between highest and lowest prevalence. A p-value $\leq 0.05$ was considered as statistically significant. All statistical analyses were performed using SPSS software 15.0 for Windows (SPSS Inc. Illinois, USA). 


\section{RESULTS}

\section{Implementation of the national osteoporosis guideline at the FLSs}

\section{Performance}

During a follow-up between 39 to 58 months, depending on the FLS, 7199 patients over the age of 50 years were examined at the FLS (range: 847 to 2224 per FLS) (Table 1).

All five FLS took initiatives to implement the Guideline on Osteoporosis from 2002 onwards and had a dedicated nurse, of whom one had specialised training as a nurse practitioner (registered nurse with specific advanced nursing education) (Table 1). All FLSs reported to consider all patients older than 50 years with any fracture for examination. Exclusion criteria differed between FLSs: 4 excluded patients with pathological fractures and 4 with high energetic trauma (HET).

Counselling of the fracture nurse was performed by the trauma-surgeon in two FLSs, by an endocrinologist in three or by a rheumatologist or general internist in one FLS.

Baseline characteristics (age, sex and CRFs) were screened during the visit at the FLSs by questionnaire before their visit to the FLS in 3 centres and by personal contact with the nurse in two centres. In 3 centres the patient filled in the questionnaire and discussed this at the outpatient clinic, in two centres all questions were asked by the nurse.

CRFs were examined in all, but recording varied between FLSs. Whether patients had a history of fracture after the age of 50 years, a family history of hip fracture or used glucocorticoids was recorded in $>97 \%$ of all patients. A history of vertebral fracture was asked for in all patients in 4 centres, and in $65 \%$ of one centre. Low body weight was recorded as a CRF in $>94 \%$ of patients in 4 centres, and in $69 \%$ of patients in one centre. A fall during the past year was asked for in $>99 \%$ of patients in 3 centres and in $44 \%$ in one centre. In one centre the nurse inquired into previous falls in the preceding 6 months (data not shown). DXA examinations were performed in 83 up to $>99 \%$ of patients. Criteria for laboratory examinations differed between FLSs: in all patients $(n=1)$, only in men $(n=1)$, in men younger than 65 years $(n=2)$, in patients with a T-score $<-2.0(n=1)$, and in women depending on age and T-score $(n=2)$ (Table 1$)$. 


\begin{tabular}{|c|c|c|c|c|c|}
\hline $\begin{array}{l}\text { FLS } \\
\% \text { (number of } \\
\text { patients) }\end{array}$ & $\begin{array}{l}1 \\
30.9 \%(n=2224)\end{array}$ & $\begin{array}{l}2 \\
11.8 \%(n=847)\end{array}$ & $\begin{array}{l}3 \\
19.6 \%(n=1409)\end{array}$ & $\begin{array}{l}4 \\
23.6 \% n=1699)\end{array}$ & $\begin{array}{l}5 \\
14.2 \%(n=1020)\end{array}$ \\
\hline $\begin{array}{l}\text { Time period } \\
\text { studied (months) }\end{array}$ & 47 months & 58 months & 52 months & 54 months & 39 months \\
\hline Patients/month & 47 & 15 & 27 & 31 & 26 \\
\hline Inclusion criteria & $\begin{array}{l}\geq 50 \text { years } \\
\text { All fracture types }\end{array}$ & $\begin{array}{l}\geq 50 \text { years } \\
\text { All fracture types }\end{array}$ & $\begin{array}{l}\geq 50 \text { years } \\
\text { All fracture types }\end{array}$ & $\begin{array}{l}\geq 50 \text { years } \\
\text { All fracture types }\end{array}$ & $\begin{array}{l}\geq 50 \text { years } \\
\text { All fracture types }\end{array}$ \\
\hline Exclusion criteria & $\begin{array}{l}\text { Dementia } \\
\text { Pathological } \\
\text { fracture }\end{array}$ & $\begin{array}{l}\text { Dementia } \\
\text { HET }\end{array}$ & $\begin{array}{l}\text { Dementia } \\
\text { Pathological } \\
\text { fracture } \\
\text { HET }\end{array}$ & $\begin{array}{l}\text { Dementia } \\
\text { Pathological } \\
\text { fracture } \\
\text { HET }\end{array}$ & $\begin{array}{l}\text { Dementia } \\
\text { Pathological } \\
\text { fracture }\end{array}$ \\
\hline $\begin{array}{l}\text { Patient } \\
\text { recruitment }\end{array}$ & $\begin{array}{l}\text { E-care system ED } \\
\text { Outpatient clinic, } \\
\text { cast clinic }\end{array}$ & $\begin{array}{l}\text { Outpatient clinic, } \\
\text { cast clinic } \\
\text { E-care system ED }\end{array}$ & $\begin{array}{l}\text { Through } \\
\text { radiology reports } \\
\text { and thereafter } \\
\text { contacted by } \\
\text { phone }\end{array}$ & $\begin{array}{l}\text { Through } \\
\text { radiology reports } \\
\text { and thereafter } \\
\text { contacted by } \\
\text { phone }\end{array}$ & $\begin{array}{l}\text { ED nurse and in } \\
\text { hospital patients } \\
\text { via surgeon/ } \\
\text { orthopedic } \\
\text { surgeon }\end{array}$ \\
\hline $\begin{array}{l}\text { Fracture location } \\
\text { unknown (\%) }\end{array}$ & 3.3 & 4.5 & 0.1 & 0.4 & 0.5 \\
\hline $\begin{array}{l}\text { Nurse } \\
\text { practitioner }\end{array}$ & No & Yes & No & No & No \\
\hline Nurse & Yes & No & Yes & Yes & Yes \\
\hline $\begin{array}{l}\text { Time per week } \\
\text { (hrs) }\end{array}$ & $7 \times 4$ & $4 \times 4$ & $2 \times 8$ & $2 \times 8 ; 1 \times 4$ & $3 \times 8$ \\
\hline Counselling & $\begin{array}{l}\text { Trauma- surgeon } \\
\text { Orthopaedic } \\
\text { surgeon } \\
\text { Internist- } \\
\text { rheumatologist }\end{array}$ & $\begin{array}{l}\text { Internist- } \\
\text { endocrinologist } \\
\text { (by phone) }\end{array}$ & $\begin{array}{l}\text { Internist- } \\
\text { endocrinologist }\end{array}$ & $\begin{array}{l}\text { Internist- } \\
\text { endocrinologist }\end{array}$ & $\begin{array}{l}\text { Internist } \\
\text { Trauma-surgeon }\end{array}$ \\
\hline DXA scan & $\begin{array}{l}\text { Yes } \\
\text { After } 1^{\text {st }} \text { visit }\end{array}$ & $\begin{array}{l}\text { Yes } \\
\text { Before } 1^{\text {st }} \text { visit }\end{array}$ & $\begin{array}{l}\text { Yes } \\
\text { Before } 1^{\text {st }} \text { visit }\end{array}$ & $\begin{array}{l}\text { Yes } \\
\text { Before } 1^{\text {st }} \text { visit }\end{array}$ & $\begin{array}{l}\text { Yes } \\
\text { Before } 1^{\text {st }} \text { visit }\end{array}$ \\
\hline $\begin{array}{l}\text { No DXA scan } \\
\text { results (\%) }\end{array}$ & 12.1 & 17.0 & 1.0 & 0.4 & 9.8 \\
\hline $\begin{array}{l}\text { Blood } \\
\text { examination }\end{array}$ & Men & $\begin{array}{l}\text { T-score }<-2.0 \\
\text { Osteoporosis }\end{array}$ & $\begin{array}{l}\text { Men }<65 \text { years } \\
\text { and } T \text { score } \leq-2.5 \\
\text { Women/Men }<70 \\
\text { years and T-score } \\
\leq-3.0\end{array}$ & $\begin{array}{l}\text { Men }<65 \text { years } \\
\text { and } T \text { score } \leq-2.5 \\
\text { Women/Men }<70 \\
\text { years and T-score } \\
\leq-3.0\end{array}$ & All patients \\
\hline $\begin{array}{l}\text { Questionnaire } \\
\text { CRFs missing (\%) }\end{array}$ & Nurse & Patient & Patient & Patient & Nurse \\
\hline $\begin{array}{l}\text { Previous fracture } \\
\geq 50 \text { years }\end{array}$ & 0 & 0 & 0.3 & 0 & 0 \\
\hline $\begin{array}{l}\text { Previous } \\
\text { vertebral } \\
\text { fracture }\end{array}$ & 0 & 34.6 & 0 & 0 & 0 \\
\hline $\begin{array}{l}\text { Family history of } \\
\text { hip fracture }\end{array}$ & 0 & 1.7 & 0 & 0 & 0 \\
\hline
\end{tabular}




\begin{tabular}{|c|c|c|c|c|c|}
\hline Immobility & 0 & 48.4 & 0 & 0 & 0 \\
\hline $\begin{array}{l}\text { Low body weight } \\
(<60 \mathrm{~kg})\end{array}$ & 30.5 & 2.5 & 1.6 & 5.7 & 5.3 \\
\hline $\begin{array}{l}\text { Use of } \\
\text { corticosteroids }\end{array}$ & 0 & 2.5 & 0 & 0 & 0 \\
\hline $\begin{array}{l}\text { Fall risks missing } \\
(\%)\end{array}$ & & & & & \\
\hline $\begin{array}{l}\text { Fall in preceding } \\
12 \text { months }\end{array}$ & 0 & 56.2 & 0.3 & 0.1 & $100 *$ \\
\hline $\begin{array}{l}\text { Fracture due } \\
\text { to fall from } \\
\text { standing height }\end{array}$ & 0 & 48.4 & 0 & 0 & 0 \\
\hline
\end{tabular}

Table 1. Overview of performance and procedures in the 5 FLSs

Abbreviations:

HET: high energetic trauma; ED: Emergency Department; BMD: bone mineral density; DXA: dual energy

X-ray absorptiometry

* One FLS inquired into fall risk assessment with a different question

The acute circumstances of trauma were specified in all FLS, but extensively in 4 (Table 2).

\section{Patient characteristics}

Of the 7199 patients, $76.7 \%$ were women. Mean age was 66.7 years (SD 10.0).The number of patients included varied between 15 and $47 / \mathrm{month} / \mathrm{centre}$. The fracture nurse spend between 16 and 24 hours/week at the FLS and therefore the time per patient varied between 0.9 and 1.7 hours per patient. Data on fracture locations were only available for patients seen at the FLS. No records were available on patients who did not consult the FLS. The majority of examined patients sustained a distal radius/ulna fracture $(n=1828,26.1 \%)$. Hip and tibia/fibula fractures occurred in 397 (5.7\%) and 900 (12.9\%) patients, respectively, and humerus fractures in 854 $(12.2 \%)$. Most frequent fractures in women were radius/ulna fractures $(n=1582$; $29.5 \%)$, humerus fractures $(n=702 ; 13.1 \%)$ and fractures of the foot $(n=634 ; 11.8 \%)$ (Table 3). Men sustained primarily hand fractures $(n=264 ; 16.1 \%)$, radius/ulna fractures $(n=246 ; 15.0 \%)$ and foot fractures $(n=186 ; 11.3 \%)$ (Table 3 ).

Significant differences between FLSs were found for major fractures (13.4$18.1 \%)$, minor fractures $(65.5-78.5 \%)$, hip fractures (1.0-7.6\%) and fractures of fingers or toes (0.9-12.6\%) ( $p<0.001$ between FLSs) (Table 2).

The acute circumstances of injury were extensively reported by 4 FLSs. Trauma's occurred at home in 28.2 to $58.4 \%$ of patients and at work in 0.2 to $2.0 \%$. An injury 


\begin{tabular}{|c|c|c|c|c|c|c|c|c|}
\hline & 1 & 2 & 3 & 4 & 5 & All & $\mathbf{R} \mathbf{R}^{*}$ & P-value** \\
\hline Age (SD) & $67.5(10.7)$ & $69.0(10.5)$ & $65.6(9.3)$ & $65.4(9.2)$ & $67.0(10.2)$ & $66.7(10.0)$ & & $<0.001$ \\
\hline Sex (\%) & & & & & & & & $<0.001$ \\
\hline Women & 74.2 & 88.2 & 70.0 & 79.9 & 77.0 & 76.7 & & \\
\hline Men & 25.8 & 11.8 & 30.0 & 20.1 & 23.0 & 23.3 & & \\
\hline Fracture location (\%) & & & & & & & & $<0.001$ \\
\hline Major & 18.1 & 15.3 & 13.4 & 14.6 & 14.8 & 15.5 & & \\
\hline Minor & 70.3 & 78.5 & 66.3 & 65.5 & 75.9 & 70.1 & & \\
\hline Hip & 5.5 & 5.3 & 7.6 & 7.3 & 1.0 & 5.7 & & \\
\hline Fingers/Toes & 6.1 & 0.9 & 12.6 & 12.6 & 8.4 & 8.7 & & \\
\hline Hip & 5.5 & 5.3 & 7.6 & 7.3 & 1.0 & 5.7 & & \\
\hline Humerus & 13.7 & 12.3 & 9.9 & 11.0 & 14.3 & 12.2 & & \\
\hline Distal radius/ulna & 25.8 & 22.4 & 26.8 & 26.9 & 27.2 & 26.1 & & \\
\hline Tibia/fibula & 12.7 & 12.8 & 13.3 & 12.7 & 12.8 & 12.9 & & \\
\hline Other & 42.3 & 47.1 & 42.4 & 42.1 & 44.7 & 43.2 & & \\
\hline BMD (\%) & & & & & & & & $<0.001$ \\
\hline Normal BMD & 23.7 & 5.0 & 26.6 & 15.5 & 30.3 & 21.2 & & \\
\hline Osteopenia & 44.7 & 54.3 & 46.2 & 45.5 & 47.5 & 46.6 & & \\
\hline Osteoporosis & 31.6 & 40.7 & 27.2 & 39.0 & 22.2 & 32.2 & & \\
\hline \multicolumn{9}{|l|}{ CRF (\%) } \\
\hline Previous fracture $\geq 50$ years & 25.9 & 12.6 & 21.4 & 16.4 & 23.9 & 20.9 & 2.1 & $<0.001$ \\
\hline Previous vertebral fracture & 6.8 & 9.6 & 6.0 & 5.8 & 9.3 & 7.0 & 1.7 & $<0.001$ \\
\hline Family history of hip fracture & 15.4 & 7.3 & 8.9 & 18.6 & 26.9 & 15.6 & 3.7 & $<0.001$ \\
\hline Immobility & 3.0 & 0.7 & 0.4 & 0.9 & 10.7 & 2.9 & 26.8 & $<0.001$ \\
\hline Low body weight $(<60 \mathrm{~kg})$ & 19.0 & 17.0 & 13.1 & 13.8 & 8.6 & 14.4 & 2.2 & $<0.001$ \\
\hline Use of corticosteroids & 0.7 & 7.4 & 0.2 & 1.6 & 5.0 & 2.2 & 37.0 & $<0.001$ \\
\hline \multicolumn{9}{|l|}{ Fall risk (\%) } \\
\hline Fall in preceding 12 months & 20.5 & 21.8 & 3.7 & 14.4 & No data $\wedge$ & 14.1 & 5.9 & $<0.001$ \\
\hline $\begin{array}{l}\text { Fracture due to fall from } \\
\text { standing height }\end{array}$ & 80.6 & 91.1 & 81.5 & 81.3 & 51.0 & 77.2 & 1.8 & $<0.001$ \\
\hline \multicolumn{9}{|l|}{$\begin{array}{l}\text { Prevalence etiology of the } \\
\text { fracture (\%) }\end{array}$} \\
\hline Accident at home & 28.2 & 58.4 & 31.5 & 34.9 & 42.8 & 34.7 & 2.1 & $<0.001$ \\
\hline Accident at work & 1.6 & 0.2 & 1.4 & 2.0 & 2.6 & 1.7 & 10.0 & 0.021 \\
\hline Fall accident & 80.6 & 91.1 & 81.5 & 81.3 & 51.0 & 77.2 & 5.9 & $<0.001$ \\
\hline Traffic accident & 11.0 & 23.3 & 14.4 & 26.9 & 7.7 & 16.0 & 3.5 & $<0.001$ \\
\hline Sport accident & 4.0 & 3.0 & 5.7 & 7.1 & 4.5 & 5.1 & 2.4 & $<0.001$ \\
\hline Etiology unknown & 4.7 & 8.0 & 3.8 & 2.1 & 1.6 & 3.6 & 5.0 & $<0.001$ \\
\hline Etiology other & 6.8 & 0.5 & 17.5 & 6.6 & 2.8 & 7.9 & 35.0 & $<0.001$ \\
\hline
\end{tabular}




\section{Table 2.}

Prevalence of CRFs, falls and circumstances of trauma in all patient cohort and according to the different FLSS

* RR is calculated as a ratio between the highest en the lowest prevalence of CRFs, fall risk and prevalence of etiology of the fracture

** P-value is calculated by using chi square, student $t$-test and ANOVA, and refers to a comparison between the $5 \mathrm{FLSS}$

$\wedge$ One FLS inquired into fall risk assessment with a different question

was reported to be a fall in 51.0 to $91.1 \%$, a traffic accident in 11.0 to $26.9 \%$ and a sport injury in 3.0 to $7.1 \%$. Overall, $77.2 \%$ of all fractures were caused by a fall (Table 2).

\section{Prevalence}

Significant differences were found in the prevalence of CRFs between FLSs ( $p<0.001$ for all CRFs). A history of fracture after the age of 50 years was reported by 12.6 to $25.9 \%$ of patients, a previous vertebral fracture in 5.8 to $9.6 \%$, a family history of hip fracture by 7.3 to $26.9 \%$, immobility by 0.4 to $10.7 \%$, low body weight by 8.6 to $19.0 \%$, use of glucocorticoids by 0.2 to $5.0 \%$ and a fall during 12 months before the current fracture by 3.7 to $21.8 \%$. The majority of patients had osteopenia ( $n=3107,46.6 \%)$ and nearly one in three patients had osteoporosis $(n=2147,32.3 \%)$. More women than men were diagnosed with osteoporosis $(35.2 \%$ vs. $22.9 \% ; p<0.001$ ) or osteopenia ( $45.9 \%$ vs. $48.5 \% ; p<0.001$ ) (Figure 1). Significant

\begin{tabular}{lllll}
\hline & Women & Men & All & P-value \\
\hline Fracture sites (\%) & & & & $<0.001$ \\
Major & 15.6 & 15.6 & 15.6 & \\
Minor & 71.6 & 65.1 & 70.1 & \\
Hip & 5.3 & 7.0 & 5.7 & \\
Fingers/Toes & 7.6 & 12.3 & 8.7 & \\
& & & & $<0.001$ \\
Hip & 5.3 & 7.0 & 5.7 & \\
Humerus & 13.1 & 9.3 & 12.2 & \\
Distal radius/ulna & 29.5 & 15.0 & 26.1 & \\
Tibia/fibula & 12.2 & 15.1 & 12.9 & \\
Other & 40.0 & 53.6 & 43.2 & \\
\hline
\end{tabular}

Table 3.

Frequencies of fracture according to gender 


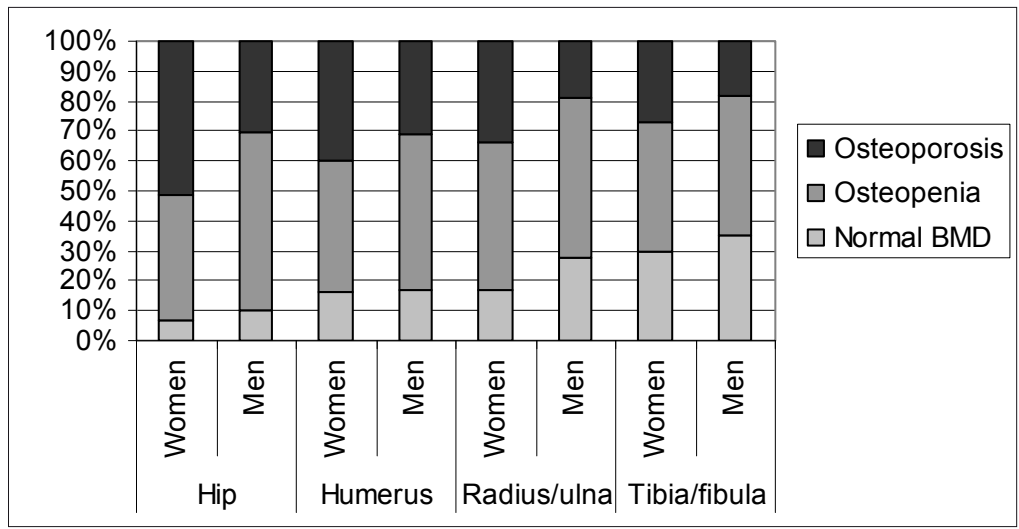

Figure 1.

Bone mineral density according to sex and fracture location

Only patients with hip, humerus, distal radius/ulna and tibia/fibula fractures are evaluated in this figure.

differences between FLSs were found in the prevalence of osteoporosis (in 22.2 to 40.7\%), osteopenia (in 44.7 to $54.3 \%$ ) and normal BMD (in 5.0 to $30.3 \%$ ) ( $p<0.001$ ).

Variability, expressed as RR between the CRFs, ranged from RR 1.7 to 37.0, depending on the risk factor, lowest variability in previous vertebral fracture (RR 1.7), highest in use of corticosteroids (RR 37.0)(Table 2).

\section{DISCUSSION}

In this prospective study in patients older than 50 years presenting with a recent clinical fracture at 5 large FLSs in The Netherlands, a dedicated fracture nurse was the central responsible coordinator to identify fracture patients, to evaluate risk factors for subsequent fractures and to organise secondary fracture prevention after counselling by the surgeon, endocrinologist or rheumatologist. Nearly 150 patients were examined per month resulting in nearly 7,200 evaluated patients during 250 months in total. This indicates that specialists in these hospitals made a major effort to implement the guidelines of case finding of osteoporosis and fall prevention in daily practice.

The fracture nurse did spend 0.9 to 1.7 hours per patient, indicating that organisation of post-fracture care is labour-intensive. It should be further investigated 
which components of this work (such as patient contact, administrative tasks for appointments, reporting to the GP) are the most time consuming and how this time spending can be optimalised.

\section{$1 /$ Performance}

Most CRFs that were mentioned in the questionnaire to the FLSs were recorded, with the exception previous vertebral fracture, immobility, low body weight and a fall in the preceding 12 months in one centre. Bone densitometry was performed in most patients. Reasons for not performing a DXA were not mentioned, but is often the result of patients (or their family) who do not agree or not able to perform further examinations ${ }^{17}$.

Criteria for laboratory investigations were highly variable between FLSs and were performed according to age, gender, and BMD as criteria. This variability can be the result of the lack of specific guidelines on the role of laboratory investigations in fracture patients ${ }^{12}$. However, several studies indicate that contributors to secondary osteoporosis are often present in patients with osteoporosis, with and without a history of recent fracture ${ }^{19,20}$. Clearly, more data are necessary about the prevalence of contributors to secondary osteoporosis and bone loss in fracture patients with and without osteoporosis to specify which laboratory examinations should be performed.

The age and sex of patients and fracture location were significantly different between FLSs, but less significant from a clinical point of view (differences of 4.5 years for age, $5.7 \%$ for female sex, $4.7 \%$ for major fractures), indicating that patient selection was quite similar between FLSs.

Of interest is the finding that most fractures resulted from a fall (77.2\%), and a minority as a result of a traffic or sport accident, as found by others ${ }^{20}$. In spite of the exclusion of HET, $11 \%$ to $27 \%$ of traffic accidents were still interpreted as a lowenergy trauma. There is a need to specify which traumas are considered minor or major. On the one hand, the definition of 'fragility' or 'osteoporotic' fractures is heterogeneous in the literature ${ }^{21}$. On the other hand, however, high-energy trauma fractures are as predictive for subsequent fracture risk as low-trauma fractures ${ }^{22}$. In addition, 5-year subsequent fracture risk is similar after a finger or hip fracture, but 5-year mortality is different, being higher after a hip fracture than after a finger fracture ${ }^{10}$. Thus, in the context of case finding of subsequent 
fracture risk in patients with a recent fracture, there is presumably no need for distinction between high- and low-energy fractures and fracture locations.

\section{2/ Prevalence}

There was a high variability in the reporting of several CRFs between FLSs. The reason for this is unclear. For example for immobility, the variance between centres was very high, and could reflect the absence of a clear definition of this CRF in the guideline ${ }^{12}$. Clearly, to prevent confusion about definitions in daily practice risk factors should be specified as concrete as possible in guidelines.

Differences between FLSs were also found in T-scores and fall risks of the included patients per center. In our study, the range of prevalence of osteoporosis was $22.2 \%$ to $40.7 \%$ between centers and for fall risk (fracture due to fall from standing height or less) $51.0 \%$ to $91.1 \%$. Presumably, not all centers had the same interest of formally evaluating fall risk or did not include such evaluation in their protocol, in spite of a guideline on fall prevention in the Netherlands.

Recent literature on fracture prevention focuses more on a combination of bone and extraskeletal risks in fracture patients ${ }^{7}$. This is also expressed in the fracture risk assessment tool (FRAX), which predicts future fractures based on several CRFs with and without BMD and in the Garvan Fracture risk calculator, which also includes fall risk ${ }^{11,23}$.

This study has several limitations.

Firstly, there are no data on all patients who visited the hospitals due to a fracture and did not visit the FLS. We only have data on subjects who were able and willing to undergo evaluation of their fracture risk, and we can not give a percentage of the patients who were willing or not willing to participate. However, from previous studies is known that $50-85 \%$ of the patients at high risk for an osteoporotic fracture participate in osteoporosis assessment ${ }^{13-15,24}$.

Secondly, there is no information about the ethnicity of the participants.

Thirdly, we do not have data on subsequent fractures of these patients. It would be very informative to determine in a cohort of treated fracture patients and see whether there is an association between CRFs, BMD and fall risks on subsequent fractures and mortality. Possibly, as seen in this study, not all risk factors are evenly distributed throughout the fractured patients. 
Fourthly, almost $6 \%$ of all fractures were hip fractures compared to approximately $18-21 \%$ in other studies. It's possible that our data are not representative for hip fracture patients 9,12 .

In conclusion, when evaluating five FLSs in the Netherlands we found that there was a striking difference in prevalence of CRFs and fall risks between elderly screened for osteoporosis. Moreover, the study also showed that osteoporosis care in the Netherlands is implemented in several hospitals.

This indicates that prevention strategies to avert subsequent fractures mainly have to focus on BMD, CRFs and fall risks and potentially there are differences in the presence of risk factors between different fracture types. 


\section{REFERENCES}

1. Bliuc D, Ong CR, Eisman JA, et al. Barriers to effective management of osteoporosis in moderate and minimal trauma fractures: a prospective study. Osteoporos Int 2005; 16(8):977-82.

2. Kanis JA. Assessment of fracture risk and its application to screening for postmenopausal osteoporosis: synopsis of a WHO report. WHO Study Group. Osteoporos Int 1994; 4(6):368-81.

3. Kanis JA. Diagnosis of osteoporosis and assessment of fracture risk. Lancet 2002; 359(9321):1929-36.

4. Kanis JA, Johnell O, De Laet C, et al. A meta-analysis of previous fracture and subsequent fracture risk. Bone 2004; 35(2):375-82.

5. Klotzbuecher CM, Ross PD, Landsman PB, et al. Patients with prior fractures have an increased risk of future fractures: a summary of the literature and statistical synthesis. J Bone Miner Res 2000; 15(4):721-39.

6. Center JR, Bliuc D, Nguyen TV, et al. Risk of subsequent fracture after low-trauma fracture in men and women. Jama 2007; 297(4):387-94.

7. Bliuc D, Nguyen ND, Milch VE, et al. Mortality risk associated with low-trauma osteoporotic fracture and subsequent fracture in men and women. Jama 2009; 301(5):513-21.

8. Ryg J, Rejnmark L, Overgaard S, et al. Hip Fracture Patients at Risk of Second Hip Fracture-A Nationwide Population-Based Cohort Study of 169,145 Cases During 1977-2001. J Bone Miner Res 2009.

9. van Helden S, Cals J, Kessels F, et al. Risk of new clinical fractures within 2 years following a fracture. Osteoporos Int 2006; 17(3):348-54.

10. Huntjens KM, Kosar S, van Geel TA, et al. Risk of subsequent fracture and mortality within 5 years after a non-vertebral fracture. Osteoporos Int.

11. WHO, Kanis JA. http://www.shef.ac.uk/FRAX/?lang=en. Available at: http://www. shef.ac.uk/FRAX/index.htm.

12. CBO KvdG. Osteoporose, tweede herziene richtlijn. Van Zuiden Communications 2002.

13. McLellan AR, Gallacher SJ, Fraser M, et al. The fracture liaison service: success of a program for the evaluation and management of patients with osteoporotic fracture. Osteoporos Int 2003; 14(12):1028-34.

14. Blonk MC, Erdtsieck RJ, Wernekinck MG, et al. The fracture and osteoporosis clinic: 1-year results and 3-month compliance. Bone 2007; 40(6):1643-9.

15. Hegeman JH, Willemsen G, van Nieuwpoort J, et al. [Effective tracing of osteoporosis at a fracture and osteoporosis clinic in Groningen; an analysis of the first 100 patients]. Ned Tijdschr Geneeskd 2004; 148(44):2180-5. 
16. Chevalley $\mathrm{T}$, Hoffmeyer $\mathrm{P}$, Bonjour JP, et al. An osteoporosis clinical pathway for the medical management of patients with low-trauma fracture. Osteoporos Int 2002; 13(6):450-5.

17. van Helden $S$, van Geel AC, Geusens PP, et al. Bone and fall-related fracture risks in women and men with a recent clinical fracture. J Bone Joint Surg Am 2008; 90(2):241-8.

18. van Helden S, Cauberg E, Geusens $\mathrm{P}$, et al. The fracture and osteoporosis outpatient clinic: an effective strategy for improving implementation of an osteoporosis guideline. J Eval Clin Pract 2007; 13(5):801-5.

19. Tannenbaum C, Clark J, Schwartzman K, et al. Yield of laboratory testing to identify secondary contributors to osteoporosis in otherwise healthy women. J Clin Endocrinol Metab 2002; 87(10):4431-7.

20. Dumitrescu B, van Helden S, ten Broeke R, et al. Evaluation of patients with a recent clinical fracture and osteoporosis, a multidisciplinary approach. BMC Musculoskelet Disord 2008; 9:109.

21. Sebba A. Comparing non-vertebral fracture risk reduction with osteoporosis therapies: looking beneath the surface. Osteoporos Int 2009; 20(5):675-86.

22. Mackey DC, Lui LY, Cawthon PM, et al. High-trauma fractures and low bone mineral density in older women and men. Jama 2007; 298(20):2381-8.

23. McLellan AR, Wolowacz SE, Zimovetz EA, et al. Fracture liaison services for the evaluation and management of patients with osteoporotic fracture: a cost-effectiveness evaluation based on data collected over 8 years of service provision. Osteoporosis international : a journal established as result of cooperation between the European Foundation for Osteoporosis and the National Osteoporosis Foundation of the USA 2011; 22(7):2083-98.

24. Murray AW, McQuillan C, Kennon B, et al. Osteoporosis risk assessment and treatment intervention after hip or shoulder fracture. A comparison of two centres in the United Kingdom. Injury 2005; 36(9):1080-4. 



\section{Part III}

Fracture Liaison Service: risk reduction? 



\section{Chapter 6}

\section{Impact of guideline implementation by a fracture nurse on subsequent fractures and mortality in patients presenting with non-vertebral fractures}

Kirsten MB Huntjens, Tineke ACM van Geel, Piet P Geusens, Bjorn Winkens, Paul Willems, Joop PW van den Bergh, Peter RG Brink, Svenhjalmar van Helden 


\begin{abstract}

\section{Introduction}

Systematic implementation of guidelines in patients presenting with a fracture increases identification of patients at high risk for subsequent fractures and measures to decrease fracture risk, but its effect on prevention on the risk of subsequent fractures and mortality has not been documented. The aim of this study was to determine the impact of guideline implementation on the risk of subsequent fracture and mortality in patients presenting with a non-vertebral fracture (NVF).
\end{abstract}

\title{
Methods
}

Before-after impact analysis in consecutive patients older than 50 years who were admitted to the hospital with a NVF during 2 periods: pre-intervention group ( $n=1920$, enrolled in 1999-2001) and intervention group ( $n=1335$, enrolled in 2004-2006). The intervention consisted of a dedicated fracture nurse who systematically offered fracture risk evaluation and treatment according to available guidelines. The 2-year absolute risk (AR) and hazard ratio's (HR, with 95\% confidence interval (CI)) of subsequent NVFs and mortality were analysed between both groups after adjustment for age, sex and baseline fracture location by multivariable Cox regression and by intention-to-treat.

\section{Results}

The AR of subsequent fracture was 9.9\% before and $6.7 \%$ after intervention, indicating a decrease of $35 \%$ in the risk of subsequent fracture ( $\mathrm{HR} 0.65 ; \mathrm{Cl}: 0.51-0.84$, after adjustment for age, sex and baseline fracture location) and $17.9 \%$ and $11.6 \%$, respectively, for subsequent mortality, indicating a decrease of $33 \%$ in the risk of subsequent mortality (HR: 0.67 ; Cl:0.55-0.81, after adjustment for age, sex and baseline fracture location) .

\section{Conclusion}

Systematic implementation of guidelines for fracture prevention by a dedicated fracture nurse immediately after a NVF is associated with a significant reduction of the 2-year risk of subsequent NVF and mortality. 


\section{INTRODUCTION}

Women and men with a history of a clinical fracture have an increased risk for sustaining a subsequent fracture, already within short term ${ }^{1-4}$. Guidelines on osteoporosis advocate the evaluation of patients presenting with fractures for fracture risk, including bone densitometry by dual energy $\mathrm{X}$-ray absorptiometry (DXA) to make appropriate decisions about therapy that has been shown to reduce fracture risk ${ }^{5-7}$. Guidelines on fall prevention advocate to perform a fall risk evaluation in patients with a fracture to make decisions about targeted or multidimensional fall prevention that has been shown to reduce fall risk ${ }^{8-10}$. The Surgeon General guideline on fracture prevention promotes an integrated approach to prevent fractures, including life style advices, fall prevention and drug treatment if appropriate ${ }^{11,12}$.

However, the implementation of guidelines for osteoporosis and for falls or other validated case finding strategies is low in daily practice ${ }^{13-24}$. The reasons for deficient implementation of guidelines are not well defined, but are dependent on factors related to doctors and patients. There are several barriers against successful implementation, including cost of diagnosis and therapy, concerns about medications ${ }^{13-21,24,25}$ and the lack of clarity about who is responsible for the osteoporosis care and patient follow-up even after a fracture has occurred ${ }^{26}$.

In patients presenting with a fracture, the treating surgeon or the general practitioner can take this responsibility, but this is often not the case ${ }^{27}$. Today's surgeons show resemblance to cardiologists about ten years ago. At that time, treatment focused on the treatment of the current cardiovascular (CV) event, such as myocardial infarction and stroke. However, no efforts were made to reduce the risk for subsequent CV events, even though this risk was high. After a while it became clear that a patient recovering from a CV event and relatives are in the ideal state of mind to comply with preventive advice and prescribed medication. Therefore, the American Heart Association (AHA) launched a program called "Get With The Guidelines" (GWTG). The implementation of this program immediately after an acute myocardial infarction resulted in an increased adherence to guidelines for secondary prevention. The goal of implementing the GWTG was to achieve a $25 \%$ reduction in the risk of $\mathrm{CV}$ events over 10 years ${ }^{28}$. The parallel between cardiologists and surgeons regarding fracture care is obvious. Trauma and orthopaedic surgeons treating patients with fractures are responsible for 
optimal treatment of the fracture itself, but could also initiate a procedure to optimize prevention of a new, subsequent fracture ${ }^{29}$.

The Fracture Liaison Service (FLS) has shown that systematic approach of fracture patients increases case finding ${ }^{24,30-32}$. In addition, some data indicate that post-hip fracture care can decrease the risk of subsequent fracture and mortality. In a large prospective randomised clinical trial in 2127 patients presenting with a hip fracture, zoledronate with calcium and vitamin D decreased the risk of subsequent fractures and mortality ${ }^{33}$. In a retrospective study in 221 patients with a history of hip fracture, a potential relationship was found between reduced mortality and post-fracture use of calcium plus vitamin D supplementation and, in females, concomitant use of anti-osteoporosis drugs ${ }^{34}$.

In patients selected on the basis of presenting with a NVF, no studies are available about the impact of implementing guidelines on subsequent fracture incidence and mortality. The aim of this pre-post intervention study was to determine the impact of guideline implementation on the risk of subsequent fracture and mortality in patients presenting with a non-vertebral fracture (NVF).

\section{METHODS}

\section{Study design}

This study is a before-after impact analysis in two cohorts of patients. The group with systematic implementation of the guidelines on osteoporosis and fall prevention was prospectively studied and compared to a retrospective group of patients in the same hospital before the intervention. Both groups were compared with regard of the rate of subsequent NVF and mortality.

This study design was performed according to the Evidence-Based Medicine Working Group based on their conclusion that randomisation of individual patients is unlikely to be appropriate in the impact analysis of clinical decision rules ${ }^{35}$.

\section{Patients}

All consecutive patients older than 50 years presenting with a NVF at the emergency room and living in the postal area of Maastricht were included into two cohorts. Between January 1999 and December 2001, all patients were included in the pre-intervention group ${ }^{36}$, at the time no guidelines were available and 
no post-fracture care was organised. Between September 2004 and September 2006, all consecutive patients presenting with a NVF, were included.

In both groups, patients were excluded when presenting with a pathological fracture, a clinical vertebral fracture, or a skull fracture. For the intervention group, patients were excluded if they had participated in the pre-intervention group. All patients were included in the analysis according to the intention-to-treat (ITT) principle. Of the patients in the intervention group, $68.4 \%$ were evaluated.

\section{Decision rule}

Our study was based on the Dutch guidelines on osteoporosis and falls $5,37,38$.

Before intervention, no systematic post-fracture care was organised.

In the intervention group, a fracture nurse, trained in osteoporosis management and fall risk assessment, contacted the patients or family with a personal contact ${ }^{30}$. The aim of intervention was to evaluate subsequent fracture risk, to identify risk factors and to take measures to reduce fracture incidence. The intervention included evaluation of clinical bone related risk factors (previous fracture after the age of 50 years, mother with fracture history, body weight $<60$ $\mathrm{kg}$, severe immobility and current use of glucocorticoids), fall-related risk factors (more than one fall during the last year, use of psychoactive drugs, articular complaints, impaired vision, urine incontinence, tests for the detection of activity of daily living ( $A D L$ ) functions according to the Groningen Activity Restriction Scale (status before the fracture) ${ }^{18,39-41}$ and vision according to the Snellen eye chart ${ }^{41-44}$ ), bone mineral density (BMD) measurement of the femoral neck and lumbar spine (Hologic QDR 4500 Elite densitometer), calcium intake by a standardised questionnaire and vitamin $D$ status by anamnesis (time spent outside/day). Serum levels of vitamin D were not measured, as this was not advocated in the guideline. After evaluation, the fracture nurse instructed all participating patients about the need of adequate intake of calcium and vitamin D and provided general instructions about fall prevention, adapted to the patient's individualized fall risk profile. Patients were instructed to visit their general practitioner to discuss fall prevention strategies if the results from the fall risk assessment showed the patient was at high risk for falls. In addition, patients with BMD-osteoporosis were treated with drugs known to reduce fracture incidence, mostly a bisphosphonate in combination with calcium (500 $\mathrm{mg} / \mathrm{d}$ ) and vitamin D (400lE/d). Details about the initiation of medical therapy by the GP and on adherence are not available. 


\section{Data Collection}

Baseline data on age, sex and location of baseline fracture were available in the pre-intervention group and were compared with the intervention group. All baseline and subsequent fractures were radiographically confirmed in the hospital database. Whether and when patients had died during follow-up was checked for all patients using the national obituary database.

Fractures were classified according to the International Classification of Disease (ICD-9: clavicle, thorax, pelvis, humerus, radius and/or ulna, hand, femur, tibia, fibula and/or patella or foot categories). Fractures were than grouped into categories according to their location: major fractures (hip, pelvis, proximal tibia or humerus, multiple ribs and distal femur) and minor fractures (all other) similar to the classification of Center et al. ${ }^{45}$.

\section{Statistical analysis}

Baseline characteristics were compared between groups by chi-square for dichotomous variables and by independent samples $t$-tests for continuous variables. The absolute risk (AR) for subsequent fracture and mortality was calculated. To test differences in subsequent fracture incidence and mortality between groups, Cox regression analyses were performed with Hazard Ratio's (HR) and 95\% confidence intervals $(\mathrm{Cl})$ regarding the ITT principle (including all patients in both groups in all analyses). All HRs were calculated after adjustment for age, sex and baseline fracture location (major vs. minor). For subsequent fractures, follow-up time was defined as time between first fracture and subsequent fracture, death or end of the study. For mortality, follow-up time was defined as time between first fracture and death or end of the study period. Kaplan Meier curves were plotted and analysed by the log rank test ${ }^{33}$. To evaluate whether a subsequent fracture also had an effect on mortality, we performed the time-dependent Cox regression analysis with patients with a subsequent fracture as a new variable. Variables were considered significant if $p$-value was $<0.05$ (two tailed). Statistical analysis was performed using SPSS for Windows (version 15.0; SPSS Inc. Chicago, IL, USA).

\section{Ethics}

This study was approved by the medical ethical committee of the hospital (MEC 03-194). The pre-intervention group consisted of patients retrospectively 
collected from the hospital database and therefore it is not necessary to obtain ethical approval for these subjects according to local guidelines.

\section{Source of funding}

The authors did not receive any outside funding or grants in support of their research for or preparation of this work. Neither they nor a member of their immediate families received payments or other benefits or a commitment or agreement to provide such benefits from a commercial entity.

\section{RESULTS}

In the pre-intervention group 1920 patients participated and 1335 in the intervention group (Figure 1). Patients in the intervention were younger (70.8 versus 71.9 years, $\mathrm{p}<0.05$ ) and had more major baseline fractures ( 45.0 versus $40.1 \%, \mathrm{p}<0.05$ ). Sex distribution was similar ( 74.6 versus $72.5 \%$ women). Results on the effect of intervention on subsequent fracture risk and mortality were therefore adjusted for these differences using multivariable Cox regression. All patients were analysed according to the ITT principle.

\section{Subsequent fracture}

In the pre-intervention group 191 patients (9.9\%) sustained a subsequent fracture, and 89 patients $(6.7 \%)$ in the intervention group ( $p=0.001)$ (Figure 1 and 2 ), indicating a significant fracture risk reduction of 35\% (HR $0.65 ; 95 \% \mathrm{Cl}: 0.51-0.84$ ) after adjustment for age, sex and baseline fracture location.

\section{Mortality}

By the ITT analysis, 343 patients (17.9\%) deceased in the pre-intervention group and 155 patients $(11.6 \%)$ in the intervention group $(p<0.001)$ (Figure 1 and 2 ), indicating a significant mortality risk reduction of $33 \%$ (HR $0.67 ; 95 \% \mathrm{Cl}: 0.55-0.81$ ) after adjustment for age, sex and baseline fracture location.

The risk of mortality was increased in patients with a subsequent fracture by 93\% (HR 1.93; 95\% Cl: 1.41-2.64) as compared to patients without a subsequent fracture. 


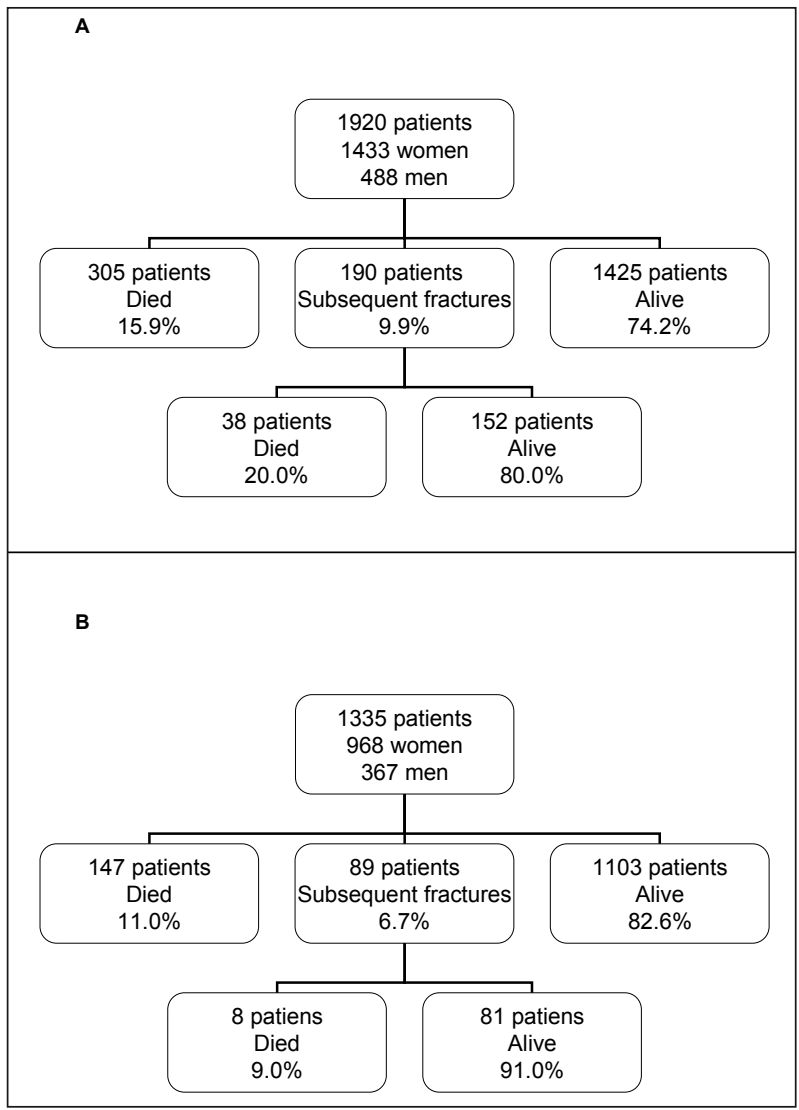

Figure 1. Flow chart

Flow chart of pre-intervention group (A) and intervention group (B) divided into subsequent fractures and mortality within 2 years 
A

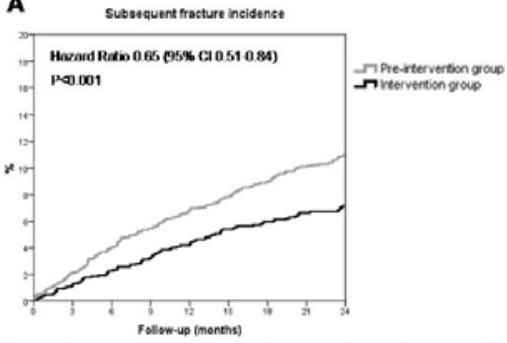

B

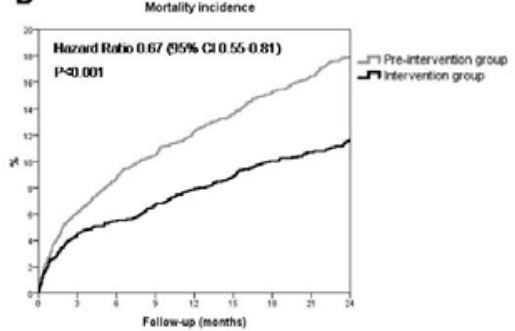

Figure 2. Kaplan Meier curves

Figure 2A Subsequent fracture incidence within 2 years after baseline fracture between the intervention and pre-intervention group

Figure 2B Mortality incidence within 2 years after baseline fracture between the intervention and preintervention group

Hazard ratio's were calculated by multivariable Cox regression analysis with adjustment for age, sex and baseline fracture location

\section{DISCUSSION}

Systematic implementation of previously validated guidelines for osteoporosis and fall prevention resulted in a significant $35 \%$ reduction of subsequent fracture incidence within two years and a $33 \%$ reduction in subsequent mortality, after adjustment for age, sex and baseline fracture location. Previous studies on systematic implementation of guidelines in fracture patients have shown that this increases identification of patients at highest risk for fractures, but they did not report on post-fracture outcomes ${ }^{24,32,46-49}$. Zoledronate, calcium and vitamin D supplements given within 3 months after a hip fracture decreased the risk of subsequent fracture and mortality ${ }^{33}$. Post-fracture use of calcium plus vitamin D supplementation and, in females, concomitant use of anti-osteoporosis drugs were potentially related to reduced mortality ${ }^{34}$.

To our knowledge this is the first study on the effect of guideline implementation on the risk of subsequent fracture and mortality in patients with a NVF. In spite of a lower mortality after intervention, which potentially puts more patients at risk for subsequent fractures, subsequent fracture risk was significantly decreased after intervention.

The $35 \%$ lower subsequent fracture incidence is most probably an effect of several contributors including counselling, calcium and vitamin D supplements, drug treatment of osteoporosis and fall prevention measures. 
The reduction in mortality is also probably an effect of several of these contributors. In addition, the reduction in mortality can be partly explained by the reduction in overall mortality in subjects older than 50 years in The Netherlands during this study period from $2.7 \%$ to $2.4 \%{ }^{50}$. Therefore, further implementation studies will need to include population mortality background data, as has been done in the prospective population-based Dubbo Osteoporosis Epidemiology Study (DOES), in which post-fracture mortality was prospectively compared with mortality in subjects without fractures ${ }^{51}$.

Reduced mortality has been documented in a prospective randomised double-blind placebo-controlled study during treatment with zoledronate given within 3 months after a hip fracture ${ }^{33}$. The reason for this reduced mortality compared to placebo is still unknown. Only $8 \%$ of this reduced mortality was attributable to a demonstrated effect on subsequent fracture risk reduction ${ }^{52}$. However, our results and those of the zoledronate study, indicate that measures to prevent fractures also reduce mortality. This finding strengthens the view that post-fracture care does not only have an effect on subsequent fracture risk, but also on other adverse outcomes like mortality.

This study has several limitations. Firstly, $31.6 \%$ of patients did not want to participate in the intervention program. This might be because the non-responders were older and sustained significantly more major fractures, including hip fractures. Several studies showed that only $50-85 \%$ of the patients at high risk of an osteoporotic fracture participate in a prevention program 475332 and that compliance regarding the intake of prescribed drugs is suboptimal ${ }^{54}$. The reduction of subsequent fracture and mortality risk could be demonstrated by ITT which included all patients, also those who did not fully participated in the intervention. Thus, even with $68.4 \%$ of the patients of the intervention group participating in the intervention, as in our study, a risk reduction could be demonstrated after adjustment for age, sex and baseline fracture location. However, implementation of a fracture prevention program by a specialised nurse will probably not reach the optimal result until the issue of non-response (about one third of patients with a NVF) will be resolved.

Secondly, the external validity of this approach needs broad verification. In a small study we have already shown that case finding using DXA is 10-fold higher than in the surrounding hospitals without a fracture nurse ${ }^{55}$. This confirms that the pres- 
ence of a fracture nurse increases case finding ${ }^{24} 32$,but no comparison is currently available about the two-year fracture incidence in these surrounding hospitals ${ }^{55}$.

Thirdly, due to the study design, it is not possible to point out which components of the intervention contributed to this effect and to what degree. Changes in other components of post-fracture care (anaesthesia, wound healing care) or improved post-fracture care by physicians who applied the guidelines could be involved.

Fourthly, an impact study would ideally be a randomised study with and without application of guidelines. However, randomisation of individual patients is unlikely to be appropriate because it is expected that participating clinicians incorporate the guidelines into the care of all patients, and it would be considered unethical to withdraw treatment in the presence of existing guidelines for subsequent fracture prevention. A well-accepted design for implementation of guidelines in cardiovascular studies is the pre- post-intervention study design, which we therefore have applied in this study ${ }^{35}$.

Fifthly, the pre- and post intervention groups differed slightly in age and baseline fracture locations. However, this could be resolved by using multivariable Cox regression with adjustments for these variables.

We conclude that systematic implementation of guidelines for osteoporosis and fall prevention, by a dedicated fracture nurse, shortly after a NVF is associated with a significant risk reduction of subsequent fractures and mortality. Therefore, we suggest implementation of such guidelines in services taking care of patients with a recent NVF. Further studies are needed to analyse which components of the intervention are most effective or whether it is the combination of bone and fall-related evaluation and intervention that is contributing to fracture and mortality reduction.

\section{Acknowledgement and affiliations}

We would like to express our gratitude to Mrs Gittie Willems, fracture nurse, who contributed substantially to the data acquisition. 


\section{REFERENCES}

1. Klotzbuecher CM, Ross PD, Landsman PB, et al.: Patients with prior fractures have an increased risk of future fractures: a summary of the literature and statistical synthesis. : J Bone Miner Res 2000; 15(4):721-39.

2. Kanis JA, Borgstrom F, De Laet C, et al. Assessment of fracture risk. Osteoporos Int 2005; 16(6):581-9.

3. Center JR, Bliuc D, Nguyen TV, et al. Risk of subsequent fracture after low-trauma fracture in men and women. Jama 2007; 297(4):387-94.

4. van Helden S, Cals J, Kessels F, et al. Risk of new clinical fractures within 2 years following a fracture. Osteoporos Int 2006; 17(3):348-54.

5. Geusens PP, Lems WF, Verhaar HJ, et al. Review and evaluation of the Dutch guidelines for osteoporosis. J Eval Clin Pract 2006; 12(5):539-48.

6. Geusens PP. Review of guidelines for testing and treatment of osteoporosis. Curr Osteoporos Rep 2003; 1(2):59-65.

7. Sambrook P, Cooper C. Osteoporosis. Lancet 2006; 367(9527):2010-8.

8. Oliver D, Britton M, Seed P, et al. Development and evaluation of evidence based risk assessment tool (STRATIFY) to predict which elderly inpatients will fall: case-control and cohort studies. Bmj 1997; 315(7115):1049-53.

9. Chang JT, Morton SC, Rubenstein LZ, et al. Interventions for the prevention of falls in older adults: systematic review and meta-analysis of randomised clinical trials. BMJ 2004; 328(7441):680.

10. Stenvall $M$, Olofsson B, Lundstrom $M$, et al. A multidisciplinary, multifactorial intervention program reduces postoperative falls and injuries after femoral neck fracture. Osteoporos Int 2007; 18(2):167-75.

11. Bone Health and Osteoporosis: A Report of the Surgeon General. US Department of Health and Human Services 2004; rockville, MD:http://www.surgeongeneral.gov/ library.

12. Geusens PP, Roux $\mathrm{CH}$, Reid DM, et al. Drug Insight: choosing a drug treatment strategy for women with osteoporosis-an evidence-based clinical perspective. Nat Clin Pract Rheumatol 2008.

13. Bliuc D, Ong CR, Eisman JA, et al. Barriers to effective management of osteoporosis in moderate and minimal trauma fractures: a prospective study. Osteoporos Int 2005; 16(8):977-82.

14. Solomon DH, Brookhart MA, Gandhi TK, et al. Adherence with osteoporosis practice guidelines: a multilevel analysis of patient, physician, and practice setting characteristics. Am J Med 2004; 117(12):919-24.

15. Solomon DH, Connelly MT, Rosen CJ, et al. Factors related to the use of bone densitometry: survey responses of 494 primary care physicians in New England. Osteoporos Int 2003; 14(2):123-9. 
16. Feldstein AC, Nichols GA, Elmer PJ, et al. Older women with fractures: patients falling through the cracks of guideline-recommended osteoporosis screening and treatment. J Bone Joint Surg Am 2003; 85-A(12):2294-302.

17. Feldstein $\mathrm{A}$, Elmer PJ, Orwoll $\mathrm{E}$, et al. Bone mineral density measurement and treatment for osteoporosis in older individuals with fractures: a gap in evidence-based practice guideline implementation. Arch Intern Med 2003; 163(18):2165-72.

18. Jaglal SB, Mclsaac WJ, Hawker G, et al. Information needs in the management of osteoporosis in family practice: an illustration of the failure of the current guideline implementation process. Osteoporos Int 2003; 14(8):672-6.

19. Siris ES, Bilezikian JP, Rubin MR, et al. Pins and plaster aren't enough: a call for the evaluation and treatment of patients with osteoporotic fractures. J Clin Endocrinol Metab 2003; 88(8):3482-6.

20. Taylor JC, Sterkel B, Utley M, et al. Opinions and experiences in general practice on osteoporosis prevention, diagnosis and management. Osteoporos Int 2001; 12(10):844-8.

21. Mauck KF, Cuddihy MT, Atkinson EJ, et al. Use of clinical prediction rules in detecting osteoporosis in a population-based sample of postmenopausal women. Arch Intern Med 2005; 165(5):530-6.

22. Elliott ME, Drinka PJ, Krause $\mathrm{P}$, et al. Osteoporosis assessment strategies for male nursing home residents. Maturitas 2004; 48(3):225-33.

23. Streeten EA, Mohamed A, Gandhi A, et al. The inpatient consultation approach to osteoporosis treatment in patients with a fracture. Is automatic consultation needed? J Bone Joint Surg Am 2006; 88(9):1968-74.

24. Chevalley $\mathrm{T}$, Hoffmeyer $\mathrm{P}$, Bonjour JP, et al. An osteoporosis clinical pathway for the medical management of patients with low-trauma fracture. Osteoporos Int 2002; 13(6):450-5.

25. Elliott ME, Meek PD, Kanous NL, et al. Osteoporosis screening by community pharmacists: use of National Osteoporosis Foundation resources. J Am Pharm Assoc (Wash) 2002; 42(1):101-10; quiz 110-1.

26. Elliot-Gibson V, Bogoch ER, Jamal SA, et al. Practice patterns in the diagnosis and treatment of osteoporosis after a fragility fracture: a systematic review. Osteoporos Int 2004; 15(10):767-78.

27. Skedros JG, Holyoak JD, Pitts TC. Knowledge and opinions of orthopaedic surgeons concerning medical evaluation and treatment of patients with osteoporotic fracture. J Bone Joint Surg Am 2006; 88(1):18-24.

28. Smaha LA. The American Heart Association Get With The Guidelines program. Am Heart J 2004; 148(5 Suppl):S46-8.

29. Boden SD, Einhorn TA, Morgan TS, et al. An AOA critical issue. The future of the orthopaedic surgeon-proceduralist or keeper of the musculoskeletal system? J Bone Joint Surg Am 2005; 87(12):2812-21. 
30. van Helden S, van Geel AC, Geusens PP, et al. Bone and fall-related fracture risks in women and men with a recent clinical fracture. J Bone Joint Surg Am 2008; 90(2):241-8.

31. Hegeman JH, Willemsen G, van Nieuwpoort J, et al. [Effective tracing of osteoporosis at a fracture and osteoporosis clinic in Groningen; an analysis of the first 100 patients]. Ned Tijdschr Geneeskd 2004; 148(44):2180-5.

32. McLellan AR, Gallacher SJ, Fraser M, et al. The fracture liaison service: success of a program for the evaluation and management of patients with osteoporotic fracture. Osteoporos Int 2003; 14(12):1028-34.

33. Lyles KW, Colon-Emeric CS, Magaziner JS, et al. Zoledronic acid and clinical fractures and mortality after hip fracture. N Engl J Med 2007; 357(18):1799-809.

34. Nurmi-Luthje I, Luthje P, Kaukonen JP, et al. Post-fracture prescribed calcium and vitamin $\mathrm{D}$ supplements alone or, in females, with concomitant anti-osteoporotic drugs is associated with lower mortality in elderly hip fracture patients: a prospective analysis. Drugs Aging 2009; 26(5):409-21.

35. McGinn TG, Guyatt GH, Wyer PC, et al. Users' guides to the medical literature: XXII: how to use articles about clinical decision rules. Evidence-Based Medicine Working Group. Jama 2000; 284(1):79-84.

36. Huntjens KM, Kosar S, van Geel TA, et al. Risk of subsequent fracture and mortality within 5 years after a non-vertebral fracture. Osteoporos Int.

37. CBO kvdg. Osteoporose. Tweede herziene richtlijn 2002. available at : http://wwwcbonl/product/richtlijnen/folder20021023121843/osteoporosepdf/view; accessed august 17, 2005.

38. CBO kvdg. Preventie van valincidenten bij ouderen 2004. . available at: http:// wwwcbonl/product/richtlijnen/folder20021023121843/val-richtlijn2004pdf/view; accessed june 5, 2006.

39. Tinetti ME, Speechley M, Ginter SF. Risk factors for falls among elderly persons living in the community. N Engl J Med 1988; 319(26):1701-7.

40. O'Loughlin JL, Robitaille $\mathrm{Y}$, Boivin JF, et al. Incidence of and risk factors for falls and injurious falls among the community-dwelling elderly. Am J Epidemiol 1993; 137(3):342-54.

41. Tromp AM, Pluijm SM, Smit JH, et al. Fall-risk screening test: a prospective study on predictors for falls in community-dwelling elderly. J Clin Epidemiol 2001; 54(8):83744.

42. Nevitt MC, Cummings SR, Kidd S, et al. Risk factors for recurrent nonsyncopal falls. A prospective study. Jama 1989; 261(18):2663-8.

43. Northridge ME, Nevitt MC, Kelsey JL. Non-syncopal falls in the elderly in relation to home environments. Osteoporos Int 1996; 6(3):249-55.

44. Lord SR, Dayhew J. Visual risk factors for falls in older people. J Am Geriatr Soc 2001; 49(5):508-15. 
45. Center JR, Nguyen TV, Schneider D, et al. Mortality after all major types of osteoporotic fracture in men and women: an observational study. Lancet 1999; 353(9156):878-82.

46. Bogoch ER, Elliot-Gibson V, Beaton DE, et al. Effective initiation of osteoporosis diagnosis and treatment for patients with a fragility fracture in an orthopaedic environment. J Bone Joint Surg Am 2006; 88(1):25-34.

47. Hegeman JH, Willemsen $\mathrm{G}$, van Nieuwpoort J, et al. Effective tracing of osteoporosis at a fracture and osteoporosis clinic in Groningen; an analysis of the first 100 patients. Ned Tijdschr Geneeskd 2004; 148(44):2180-5.

48. Scott V, Votova K, Scanlan A, et al. Multifactorial and functional mobility assessment tools for fall risk among older adults in community, home-support, long-term and acute care settings. Age Ageing 2007; 36(2):130-9.

49. Geusens P, Dumitrescu B, van Geel T, et al. Impact of Systematic Implementation of a Clinical Case Finding Strategy on Diagnosis and Therapy of Postmenopausal Osteoporosis. J Bone Miner Res 2008.

50. Donaldson MG, Cawthon PM, Lui LY, et al. Estimates of the proportion of older white women who would be recommended for pharmacologic treatment by the new U.S. National Osteoporosis Foundation Guidelines. Journal of bone and mineral research : the official journal of the American Society for Bone and Mineral Research 2009; 24(4):675-80.

51. Bliuc D, Nguyen ND, Milch VE, et al. Mortality risk associated with low-trauma osteoporotic fracture and subsequent fracture in men and women. Jama 2009; 301(5):513-21.

52. Colon-Emeric CS, Mesenbrink P, Lyles KW, et al. Potential Mediators of the Mortality Reduction with Zoledronic Acid After Hip Fracture. J Bone Miner Res 2009.

53. Murray AW, McQuillan C, Kennon B, et al. Osteoporosis risk assessment and treatment intervention after hip or shoulder fracture. A comparison of two centres in the United Kingdom. Injury 2005; 36(9):1080-4.

54. Cramer JA, Gold DT, Silverman SL, et al. A systematic review of persistence and compliance with bisphosphonates for osteoporosis. Osteoporos Int 2007; 18(8):1023-31.

55. van Helden S, Cauberg E, Geusens P, et al. The fracture and osteoporosis outpatient clinic: an effective strategy for improving implementation of an osteoporosis guideline. J Eval Clin Pract 2007; 13(5):801-5. 



\section{Chapter 7}

\section{Fracture Liaison Service: impact on subsequent non-vertebral fracture incidence and mortality}

Kirsten MB Huntjens, Tineke ACM van Geel, Joop PW van den Bergh, Svenhjalmar van Helden, Paul Willems, Bjorn Winkens, John B Eisman, Piet P Geusens, Peter RG Brink 


\begin{abstract}

\section{Introduction}

A systematic Fracture Liaison Service (FLS) model of care is widely recommended and applied, but data are scarce on its effectiveness. Therefore, the risk of subsequent non-vertebral fractures and mortality within 2 years after a non-vertebral fracture was analysed in patients who attended a hospital with FLS and a hospital without FLS.
\end{abstract}

\title{
Methods
}

In 2005-2006, all consecutive patients older than 50 years presenting with a non-vertebral fracture were included. In the no-FLS, only standard fracture care procedures were followed to address proper fracture healing. In the FLS, DXA and laboratory testing were performed, and if applicable, patients were treated according to the Dutch guideline for osteoporosis. The risk for subsequent non-vertebral fracture risk and mortality was analysed using multivariable Cox regression models with adjustments for age, sex and baseline fracture location.

\section{Results}

In total, 1412 patients attended the FLS (73.2\% women, mean age: 71.1 years) and 1910 underwent standard fracture care (no FLS, 69.8\% women, mean age: 69.5 years). After adjustment for age, sex and baseline fracture location, patients who attended the FLS had a significantly lower mortality risk (Hazard Ratio (HR): 0.65, 95\%Cl: 0.53-0.79) over 2-years of follow-up. The subsequent non-vertebral fracture risk was also significantly lower in FLS patients, but this effect was timedependent with at 12 months a HR of 0.84 (95\%Cl: 0.64-1.10) and at 24 months of 0.44 (95\%Cl: 0.25-0.79).

\section{Conclusion}

Patients who attended the FLS had a significant lower mortality and subsequent non-vertebral fracture risk over 2-years follow-up, 35\% and 56\% respectively. Therefore, FLS might be a successful approach to reduce the number of subsequent fractures and premature mortality. 


\section{INTRODUCTION}

Patients with a fracture after the age of 50 years are at increased risk of sustaining a subsequent fracture, which is highest at short term after the initial fracture $(<2$ years) ${ }^{1-8}$. Fracture Liaison Services (FLSs) have been developed and implemented to identify, evaluate and treat patients with a recent fracture ${ }^{9}$, but they differ in the way they identify, assess and treat individuals at high risk of a subsequent fracture ${ }^{10-12}$. Patients with a recent fracture not only have an increased risk of subsequent fracture, but also an increased risk of mortality especially after hip and major fractures ${ }^{13}, 14$. In addition to fracture prevention, recent studies indicated that mortality could also be reduced by bisphosphonate treatment. A $28 \%$ reduction in mortality was reported after zoledronic acid therapy in patients with a recent hip fracture and a life expectancy of more than 6 months ${ }^{15}$. A significant reduction in mortality of $11 \%$ was found in a recent meta-analysis on the effect of osteoporosis medication on mortality ${ }^{16,17}$.

In a previous before-after impact study (1999-2001 vs. 2004-2006), the 2-year risk reduction of repeat non-vertebral fracture and mortality was $35 \%$ and $33 \%$, respectively ${ }^{18}$. However, it could not be ruled out that other components of postfracture care had changed over time.

Therefore, the aim of the current study was to evaluate the impact of the FLS by comparing subsequent non-vertebral fracture risk and mortality between two hospitals within the same years, one with and one without a FLS, over a two-year follow-up period in patients who presented with a non-vertebral fracture.

\section{MATERIAL AND METHODS}

\section{Study design}

This prospective study was conducted in two hospitals in the Netherlands: one university hospital with a FLS and one general hospital without a FLS ("no-FLS"). In the FLS, a dedicated fracture nurse systematically evaluated all patients aged 50 years and over, who were able and willing to participate, at the outpatient clinic after a recent NVF.

The fracture nurse checked whether all patients $>50$ years with a fracture had an appointment at the FLS using the Emergency Department computer system. 
If not, she sent an invitation by mail. All fracture patients were seen at the fracture outpatient clinic by an orthopaedic trauma surgeon._The evaluation consisted of a systematic evaluation of clinical risk factors (medical history, exposure to medication and fall-related risk factors. The clinical and fall-related risk factors are published elsewhere ${ }^{19}$. Additionally, the Groningen Activity Restriction Scale (GARS) was used to estimate the disability in activities of daily living (ADL) $)^{10,12,20}$. Bone mineral density (BMD) measurement of the femoral neck and lumbar spine was assessed using a Hologic QDR 4500 Elite densitometer. All patients with a T-score equal or less than -2.5 SD at either BMD location were advised to start treatment according to the Dutch osteoporosis guideline ${ }^{10,20}$. The evaluation consisted of two appointments: in the first one the FLS is explained and informed consent is obtained; and in the second one all risk factors and DXA results were collected. Based on the results, the fracture nurse informs the patient and advices to start treatment when necessary (anti-osteoporosis, calcium and vitamin D).

In the no FLS group patients received standard fracture care concentrated on the fracture healing, not on the possible predisposing factors.

All consecutive patients older than 50 years and living in the postal area of the FLS and no-FLS hospital that presented with a recent non-vertebral fracture in 2005 and 2006 were included in the study. Patients with pathological or vertebral fractures were excluded. Baseline and subsequent fractures were classified according to the ICD-9 International Classification of Disease and additionally categorised based on fracture location as hip, major (pelvis, proximal tibia or humerus, multiple ribs and distal femur) and minor (all remaining fractures) ${ }^{13}$. These categories were chosen, because hip and major fractures are associated with increased mortality ${ }^{1,13}$. Mortality was obtained and confirmed using the national obituary database. Date, but not cause of death is registered in this database. According to the intention-to-treat principle, patients who were unable or not willing to visit the FLS were included in the FLS group and in all analyses.

\section{Statistical analysis}

Characteristics between FLS and no-FLS were analysed with Pearson's chi-square test for dichotomous variables and independent-samples T-test for continuous variables. The effect of FLS on subsequent fracture and mortality was analyzed using multiple Cox proportional hazard models. For the death-censored analyses 

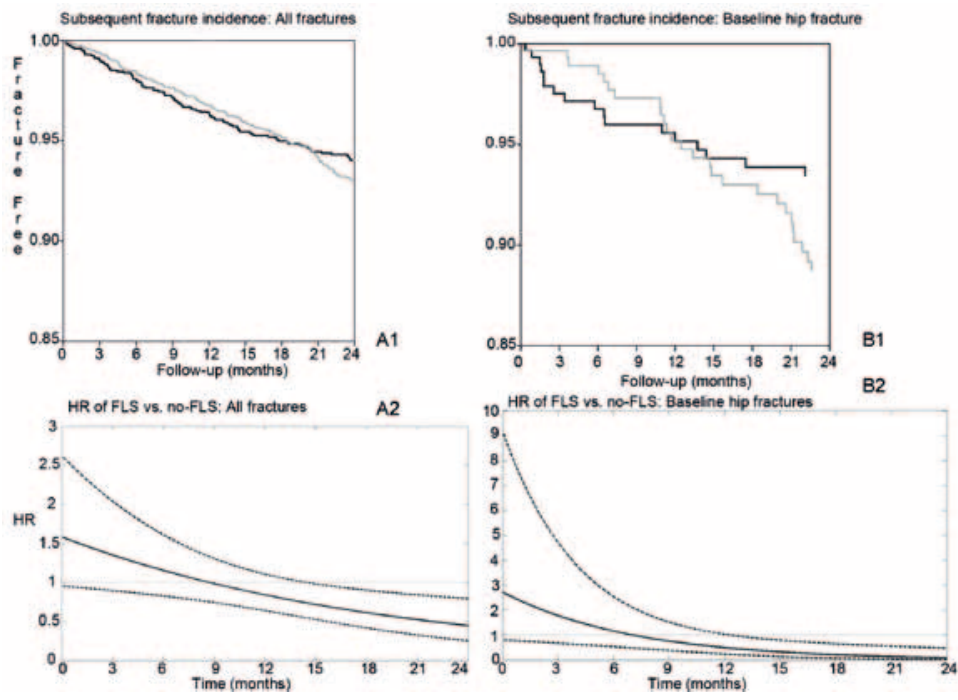

Figure 2 Subsequent fracture incidence

A1 and B1 Cumulative survival rate with subsequent fractures as event for the patients included at the university hospital with a Fracture Liaison Service (FLS; black line) and at the general hospital without a FLS (no-FLS; grey line)

A1: all fractures, B1: baseline hip fractures

A2: Hazard ratio's (continuous black line) and 95\% confidence intervals ( $95 \% \mathrm{Cl}$, black dotted lines) for subsequent fractures as event: comparing patients included at the university hospital with a Fracture Liaison Service (FLS) and at the general hospital without a FLS (no-FLS). After 15 months (HR: 0.72, 95\% Cl: 0.52-0.98) subsequent fracture hazard rate was significantly lower in the FLS.

B2: Hazard ratio's (continuous black line) and $95 \%$ confidence intervals ( $95 \% \mathrm{Cl}$, black dotted lines) for subsequent fractures as event for the subgroup with a baseline hip fracture: comparing patients included at the university hospital with a Fracture Liaison Service (FLS) and at the general hospital without a FLS (no-FLS). After 13 months (HR: 0.43, 95\%Cl: 0.20-0.94) subsequent fracture hazard rate was significantly lower in the FLS.

of subsequent fracture, follow-up time was set as time between the first and subsequent fracture, death or end of 2-year follow-up period. For the analysis with mortality as event, follow-up time was set as time between first fracture and death or end of the 2-year study period.

The proportional hazard (PH) assumption was checked using Schoenfeld residuals. If this assumption was violated, i.e. the hazard ratio (HR) is not constant over time, time-dependent Cox proportional hazard models were used. Subgroup analyses, i.e. multiple Cox PH regression, were performed for baseline fracture location and in a subgroup comparing no-FLS with FLS (divided into "shows" 
and "no-shows"). All analyses were performed with adjustments for sex, age and baseline fracture location, except the subgroup analyses in which adjustments were made for sex and age.. All statistical analyses were performed using SPSS software 18.0 for Windows (SPSS Inc., Illinois, USA). MathLab (7.10) was used to plot figures $2 \mathrm{~A} 2$ and $2 \mathrm{~B} 2$.

\section{Source of funding}

The authors declare that no external funding source played a role in this investigation.

\section{RESULTS}

\section{Patient characteristics}

In total, 3322 patients (1412 FLS and 1910 no-FLS) were included of whom $71.3 \%$ were women (Figure 1). Differences in patient characteristics between FLS and no FLS patients are shown in Table 1. Of the 1412 patients in the FLS hospital, $67.8 \%$ participated in the FLS (shows FLS). Within the FLS group, the "no shows" (patients not willing or able to participate) were significantly older (76.9 years vs. 68.3 years, $\mathrm{p}<0.001)$ and had sustained more hip fractures $(34.1 \%$ vs. $13.1 \%$, $\mathrm{p}<0.001$ ) than the "shows".

\section{Subsequent non-vertebral fractures}

In total, $225(6.8 \%)$ patients sustained a subsequent non-vertebral fracture within two years after their baseline non-vertebral fracture; 130(6.8\%) in the FLS and 95 $(6.7 \%)$ in the no-FLS hospital (Figure 1). After adjusting for sex, age and baseline

\begin{tabular}{llcccc}
\hline Baseline variable & & FLS & No-FLS & Total & P-value \\
\hline Women (n, \%) & & $1033(73.2)$ & $1334(69.8)$ & $2367(71.3)$ & 0.037 \\
Age (mean years, SD) & & $71.1(11.8)$ & $68.3(11.0)$ & $69.5(11.4)$ & $<0.001$ \\
Baseline fracture location (n, \%) & Hip & $280(19.8)$ & $303(15.9)$ & $583(17.5)$ & \\
& Major & $298(21.1)$ & $357(18.7)$ & $655(19.7)$ & $<0.001$ \\
& Minor & $834(59.1)$ & $1250(65.4)$ & $2084(62.7)$ & \\
\hline
\end{tabular}

Table 1. Baseline characteristics of patients included at the university hospital with a Fracture Liaison Service (FLS) and at the general hospital without a FLS (no-FLS). ${ }^{\text {a }}$

a. Chi-square tests and Student T-tests were used.

${ }^{\mathrm{b}}$ Major: pelvis, proximal tibia or humerus, multiple ribs and distal femur; Minor (all other fractures) 


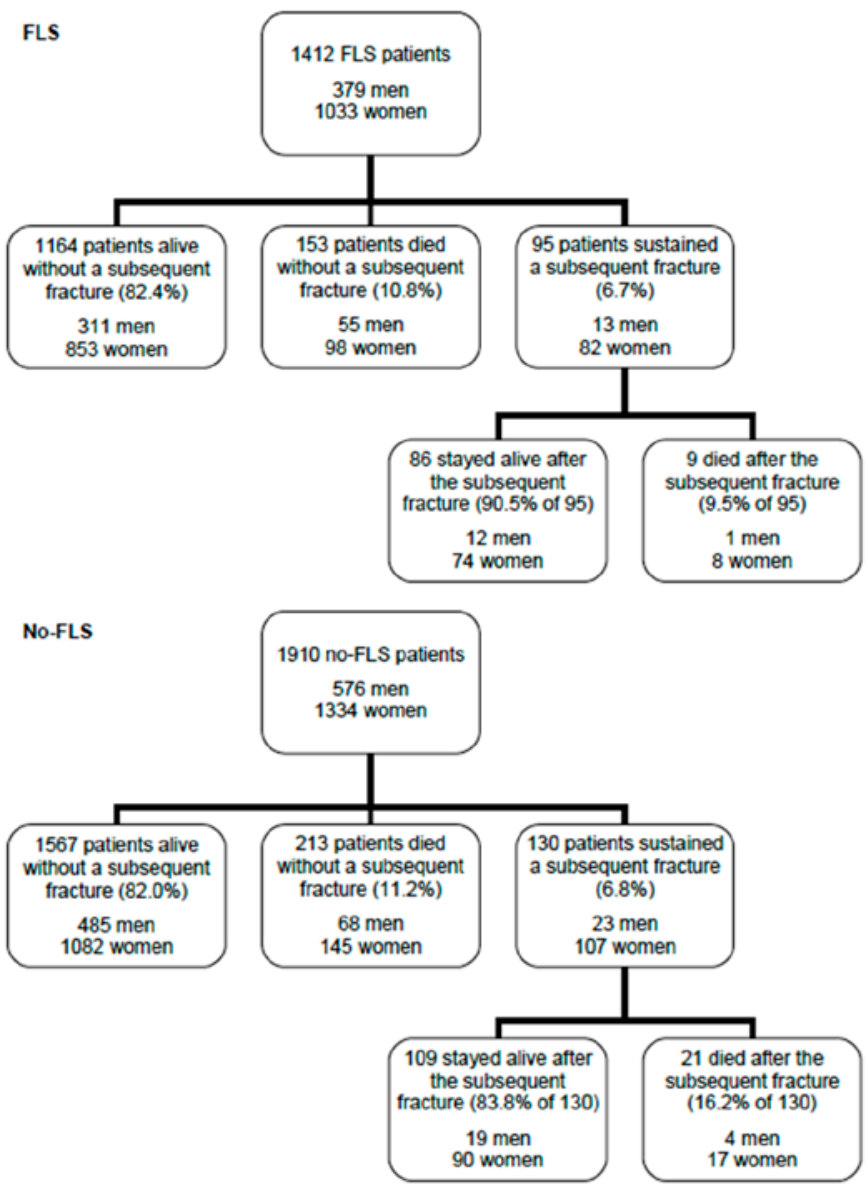

Figure 1. Flow chart

Flow chart of patient categories over a 2-year follow-up period for the university hospital with a Fracture Liaison Service (FLS) and at the general hospital without a FLS (no-FLS).

fracture location, the general Cox PH model showed no significant difference in subsequent fracture risk between the FLS and no-FLS patients (HR: $0.88,95 \%$ confidence interval (95\%Cl): 0.67-1.14) (Table 2, and Figure $2 \mathrm{~A} 1$ ).

However, since the assumption of PH was violated for FLS vs. no-FLS, the timedependent Cox model should be applied instead of the general Cox model. There were no significant lower subsequent fracture risk in the FLS compared with the 


\begin{tabular}{|c|c|c|c|c|c|c|}
\hline & $\begin{array}{l}\text { Multivariable } \\
\text { (HR; } 95 \% \mathrm{Cl})\end{array}$ & $\begin{array}{c}\text { Time } \\
\text { dependency }\end{array}$ & $\begin{array}{c}\text { Multivariable } \\
(\mathrm{HR} ; 95 \% \mathrm{Cl})\end{array}$ & $\begin{array}{c}\text { Multivariable } \\
\text { (HR; } 95 \% \mathrm{Cl})\end{array}$ & $\begin{array}{c}\text { Multivariable } \\
\text { (HR; 95\%Cl) }\end{array}$ & $\begin{array}{l}\text { Multivariable } \\
\text { (HR; 95\%Cl) }\end{array}$ \\
\hline & & & $\begin{array}{c}6 \\
\text { months }\end{array}$ & $\begin{array}{c}12 \\
\text { months }\end{array}$ & $\begin{array}{c}18 \\
\text { months }\end{array}$ & $\begin{array}{c}24 \\
\text { months }\end{array}$ \\
\hline FLS vs no-FLS * & $\begin{array}{c}0.88 \\
(0.67-1.14)\end{array}$ & Yes & $\begin{array}{c}1.15 \\
(0.85-1.60)\end{array}$ & $\begin{array}{c}0.84 \\
(0.64-1.10)\end{array}$ & $\begin{array}{c}0.61 \\
(0.42-0.90)\end{array}$ & $\begin{array}{c}0.44 \\
(0.25-0.79)\end{array}$ \\
\hline $\begin{array}{l}\text { Baseline hip } \\
\# * *\end{array}$ & $\begin{array}{c}0.63 \\
(0.34-1.18)\end{array}$ & Yes & $\begin{array}{c}1.16 \\
(0.53-2.55)\end{array}$ & $\begin{array}{c}0.50 \\
(0.24-1.04)\end{array}$ & $\begin{array}{c}0.21 \\
(0.07-0.65)\end{array}$ & $\begin{array}{c}0.09 \\
(0.02-0.48)\end{array}$ \\
\hline $\begin{array}{l}\text { Baseline } \\
\text { major \# }\end{array}$ & $\begin{array}{c}0.89 \\
(0.51-1.56)\end{array}$ & No & & & & \\
\hline \multirow[t]{2}{*}{$\begin{array}{l}\text { Baseline } \\
\text { minor \# }\end{array}$} & $\begin{array}{c}0.98 \\
(0.69-1.34) \\
\end{array}$ & No & & & & \\
\hline & $\begin{array}{l}\text { Multivariable } \\
(\mathrm{HR} ; 95 \% \mathrm{Cl})\end{array}$ & $\begin{array}{c}\text { Time } \\
\text { dependency }\end{array}$ & & & & \\
\hline FLS vs no-FLS & $\begin{array}{c}0.65 \\
(0.53-0.79)\end{array}$ & No & & & & \\
\hline Baseline hip \# & $\begin{array}{c}0.67 \\
(0.49-0.91)\end{array}$ & No & & & & \\
\hline $\begin{array}{l}\text { Baseline } \\
\text { major \# }\end{array}$ & $\begin{array}{c}0.57 \\
(0.37-0.89)\end{array}$ & No & & & & \\
\hline $\begin{array}{l}\text { Baseline } \\
\text { minor \# }\end{array}$ & $\begin{array}{c}0.74 \\
(0.51-1.07)\end{array}$ & No & & & & \\
\hline
\end{tabular}

Table 2. Multivariable Cox regression analysis on subsequent fracture incidence and mortality between FLS and no-FLS

FLS vs no-FLS adjusted for age, sex and baseline fracture location Subgroup analyses (hip, major, minor) adjusted for age and sex "significant at 15 months (HR 0.72 (0.52-0.98)) (See also figure 2) "* significant at 13 months (HR $0.43(0.20-0.94)$ ) (See also figure 2)

no-FLS after 6 months and 12 months follow-up, but there was from 15 months onwards (HR at 15 months: 0.72, 95\% Cl: 0.52-0.98; Table 2, Figure 2A2).

The subgroup analyses according to baseline fracture location showed no significant difference in subsequent non-vertebral fracture risk between FLS and no-FLS (Table 2, Figure 2B1).

However, for the hip fracture subgroup, the $\mathrm{PH}$ assumption was violated. The results of the time dependent Cox model showed no significant differences between the FLS and no-FLS at 6 months and 12 months follow-up However, from 13 months onwards the risk was significantly lower in the FLS group (HR: 0.43, 95\% Cl: 0.20-0.94), and remained lower during follow-up, Figure 2B2; Table 2). 
A subgroup analysis comparing no-FLS with FLS (divided into "shows" and "no-shows") showed no overall significant difference on subsequent fracture incidence $(p=0.085)$.
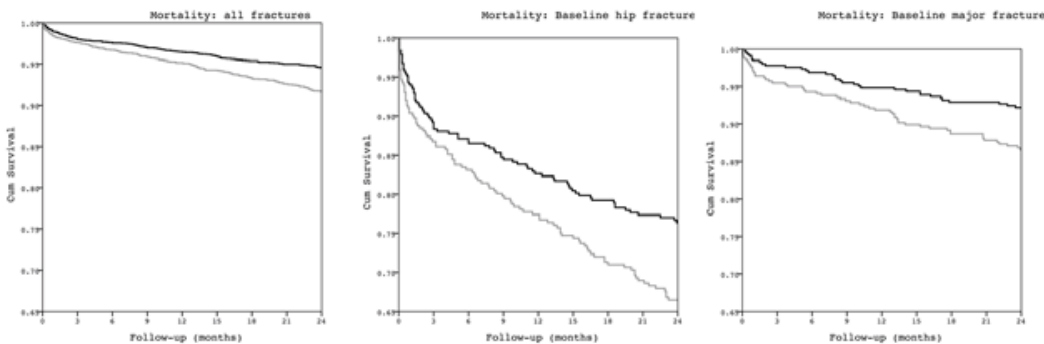

Figure 3. Mortality incidence

Cumulative survival rate with mortality as event for the patients included at the university hospital with a Fracture Liaison Service (FLS; black line) and at the general hospital without a FLS (no-FLS; grey line).

A: all fractures, B: baseline hip fractures and C: baseline major fractures

\section{Mortality}

In total, 396 patients (11.9\%) died within 2 years (Figure 1) of whom 162 (11.5\%) were FLS-patients and 234 (12.3\%) were no-FLS patients.

The $\mathrm{PH}$ assumption was not violated for mortality. Mortality risk was significantly lower in the FLS than the no-FLS hospital (Table 2, Figure 3A). Significant interaction was found between FLS and sex. Separate analyses for sex showed that women in the FLS group had a significantly lower mortality risk (HR: $0.57 ; 95 \% \mathrm{Cl}$ : 0.44-0.73). In men the difference was not significant (HR: 0.81 ; 95\% Cl: 0.57-1.16).

The subgroup analyses according to baseline fracture locationshowed that mortality risk was significantly lower in the FLS I after baseline hip fracture and after baseline major fracture, with a similar but not significant trend after baseline minor fracture (Table 2, Figure 3B-C). Again, the PH assumption was not violated. A subgroup analysis comparing FLS (divided into "shows FLS" and "noshows FLS") and no-FLS indicated that the mortality rate was significant lower in the patients that attended the FLS (shows) compared to no-shows FLS (HR: 0.42; 95\%Cl: 0.30-0.60) and no-FLS (HR: $0.40 ; 95 \% \mathrm{Cl}$ : 0.29-0.54). This effect was mainly driven by baseline hip fracture (HR hip vs. minor: $2.80 ; 95 \% \mathrm{Cl}$ : 2.18-3.58, and $\mathrm{HR}$ hip vs. major: 1.64; 95\%Cl: 1.27-2.13). 


\section{DISCUSSION}

In this study we compared subsequent fracture incidence and mortality rate in patients who had presented with a non-vertebral fracture over two years of follow-up between two hospitals; one with and one without a Fracture Liaison Service. There was a significant time-related lower subsequent non-vertebral fracture incidence after correction for age, sex and baseline fracture location in patients evaluated and treated according to the Dutch guidelines of 2002 on osteoporosis in the FLS compared to the no-FLS hospital. (CME) No significant difference in fracture rate was found during the first year, but from the second year on fracture incidence was $28 \%$ lower at 15 months and $56 \%$ lower at 2 years. These data are consistent with our previous results that showed an overall lower subsequent non-vertebral fracture incidence of $35 \%$ after the introduction of a FLS as compared to 5 years earlier without a FLS ${ }^{18}$. Subgroup analysis according to baseline fracture indicated that the time-dependent effect on subsequent non-vertebral fractures was mainly driven by the effect in patients with a baseline hip fracture, since subsequent non-vertebral fracture incidence was 57-91\% lower after a hip fracture in the FLS group, without differences after baseline major or minor non-vertebral fractures.

Mortality rate was $35 \%$ lower in the FLS compared to the no-FLS group after correction for age, sex and baseline fracture location. The difference in mortality was not time dependent. Based on subgroup analysis according to baseline fracture location, significant differences were found after baseline hip (-33\%) and major fractures $(-43 \%)$, but not after minor fractures.

Remarkably, fewer patients died in the FLS group, therefore more patients survived to be at risk for a subsequent fracture but still there was a significant reduction of subsequent non-vertebral fractures in the second year of follow-up. Also, despite the fact that patients in the no-shows FLS group were older, had more hip fractures at baseline and more risk factors for subsequent fractures and mortality, we found a lower incidence in mortality and subsequent fractures (in the second year) for the total FLS group compared to the no-FLS group. Previous studies showed similar results on subsequent fracture risk and mortality 1, 2, 5, 13,14. A recent study showed in patients $60+$ years a relative risk (RR) in women of 1.95 and 3.45 of men in subsequent fracture incidence '. Two retrospective studies showed an absolute risk of subsequent fractures of $10.8 \%$ in 2-year follow-up 
and $17.6 \%$ in 5 -year follow-up of all fracture patients older than $50^{2,5}$. Fractures increased the risk of mortality, especially after a hip fracture, e.g. ${ }^{13}$. Another study showed increased mortality risk after all types of fragility fractures that was highest within the first five years of follow-up ${ }^{14}$. However, in none of these studies was the outcome of patients in a FLS versus no-FLS hospital was compared. The findings in the present study strongly support the concept that a Fracture Liaison Service can reduce both fractures and mortality ${ }^{21}$.

Many Randomized Controlled Trials (RCTs) have included patients with a prevalent vertebral fracture of unknown date with and without BMD criterion. In these studies a reduction of subsequent hip, non-vertebral fracture and vertebral fracture has been shown, depending on treatment.

Only one RCT has demonstrated mortality reduction after treatment comparing yearly administration of the intravenous bisphosphonate, zoledronic acid, in patients with a recent hip fracture compared to placebo ${ }^{15}$. In that study, a subgroup of patients with a recent hip fracture was included who had, according to the investigator, a life expectancy of more than 6 months and without BMD restrictions. It was the first RCT in which an effect on mortality was demonstrated. Mortality decreased from 16 months on and when the first zoledronic acid infusion was given from 4- 6 weeks after the hip fracture. In contrast, we found a lower mortality rate, which was independent of time.

Several studies have meanwhile shown that anti-osteoporosis treatment can not only decrease fracture rate and increase in quality of life, but also decrease mortality. In a meta-analysis of bisphosphonate RCTs, mortality was $11 \%$ lower than in placebo ${ }^{16}$. Oral bisphosphonates in hip fracture patients showed a $27 \%$ reduction in mortality compared to non-users ${ }^{22}$. In a 3-year prospective study in 220 patients with a recent hip fracture, mortality was $60 \%$ lower in each year in patients with a T-score $<-1.5$ who received bisphosphonates ${ }^{23}$. In a prospective cohort study, treatment with bisphosphonates was associated with $69 \%$ reduction in mortality rate during longitudinal follow-up ${ }^{17}$.

The mechanisms by which mortality is reduced are still unclear and seem to be multifactorial and probably related to extra skeletal effects of bisphosphonates 17 or calcium and vitamin D or other still unclear mechanisms. One explanation could be the prevention of (subsequent) fractures. In our previous research patients with a subsequent fracture had a higher risk of mortality after subsequent fracture compared to patients without a subsequent fracture ${ }^{14,18}$. However, 
fracture prevention seems only to have a small attribution in mortality reduction. In the intravenous bisphosphonate RCT study, $8 \%$ of the overall $28 \%$ mortality reduction could be attributed to fracture risk reduction ${ }^{24}$. Vitamin D insufficiency is associated with osteoporosis and seems to be associated with other medical conditions. A recent study evaluated anti-osteoporotic treatment in hip fracture patients in a nationwide database and found an association between antiosteoporotic treatment, vitamin $\mathrm{D}$ and calcium supplements and reduced post hip fracture mortality of $38 \%$ in women ${ }^{25}$. In men this reduction was $26 \%$ and only seen after vitamin $D$ and/or calcium supplements ${ }^{25}$. Another positive effect on the patient's overall health and thereby reduce mortality might be the attention of the fracture nurse to the fracture patient. Unfortunately, we only have data on subsequent fractures, mortality, sex, age and fracture location and therefore we cannot measure this possible positive effect.

The lower mortality in the FLS group in our study can only be partly explained by treatment with bisphosphonates and calcium and vitamin $D$, since only a limited number of patients were on bisphosphonate therapy, which was given to the participating patients who had BMD defined osteoporosis (approximately $50 \%$ ). We do not have data about the percentage of patients treated with antiosteoporosis medication in the no-FLS group, but post-fracture treatment and persistence of treatment at the time of this study was known to be low ${ }^{26}$.

A strength of our study is that all consecutive patients that presented with a non-vertebral fracture in both hospitals were included in the analysis according to the intention-to-treat principle. The lower fracture and mortality rate was found in the total FLS group, in spite of inclusion of no-show patients who were significantly older and had more base-line hip fractures. A limitation of this study is that it is not a randomized controlled trial. Therefore other possible confounders could not be ruled out especially since we do not have additional information about management in the no-FLS group. Also baseline differences between the groups on sex, age and baseline fracture location is a limitation of this study, but we adjusted the cox regression analyses for these known factors. Cox regression analyses adjusted for age, sex and baseline fracture location showed a timedependent effect (Figure 2), whereas the absolute risks were comparable $(6.7 \%$ and $6.8 \%$, respectively). The difference in conclusion is due to the fact that there is a time-dependent factor, which is not taken into account in an absolute risk analysis. More specifically, the effect of the FLS is more pronounced after one year 
than during the first months. This is probably due to the effect of bone directed therapies (calcium, vitamin $\mathrm{D}$ and bisphosphonates) and therapies directed at SECOB (secondary osteoporosis and metabolic bone diseases). The intervention will continue after the visit at the FLS and was not the standard of fracture care in the non-FLS hospital.

In the Netherlands, BMD measurements and outpatient clinic visits are always covered by health care insurance. However, travel costs and parking tickets are not reimbursed. Recent cost-effectiveness analyses showed that FLSs are costeffective in fragility fracture patients for prevention of further fractures ${ }^{27,28}$. The ASBMR Task Force published recently an article about making the first fracture the last ${ }^{29}$. The authors concluded that the FLS was the most important tool for such a change in fracture patients and that implementation would still be challenging in some ways ${ }^{29}$.

In conclusion, patients with a recent non-vertebral fracture who were evaluated at the hospital with a FLS had a significantly lower mortality compared to patients in a no- FLS hospital. Subsequent fracture risk was significantly lower after 15 months and decreased by up to $56 \%$ after 2 years follow-up in the patients evaluated at the FLS hospital. These results indicate that a FLS should be considered in patients with a recent fracture, especially after a recent hip or other major fracture. 


\section{REFERENCES}

1. Center JR, Bliuc D, Nguyen TV, et al. Risk of subsequent fracture after low-trauma fracture in men and women. JAMA : the journal of the American Medical Association 2007; 297(4):387-94.

2. Huntjens KM, Kosar S, van Geel TA, et al. Risk of subsequent fracture and mortality within 5 years after a non-vertebral fracture. Osteoporosis international : a journal established as result of cooperation between the European Foundation for Osteoporosis and the National Osteoporosis Foundation of the USA 2010; 21(12):2075-82.

3. van Geel TA, Huntjens KM, van den Bergh JP, et al. Timing of subsequent fractures after an initial fracture. Current osteoporosis reports 2010; 8(3):118-22.

4. van Geel TA, van Helden S, Geusens PP, et al. Clinical subsequent fractures cluster in time after first fractures. Ann Rheum Dis 2008.

5. van Helden S, Cals J, Kessels F, et al. Risk of new clinical fractures within 2 years following a fracture. Osteoporos Int 2006; 17(3):348-54.

6. Kanis JA, Johnell O, De Laet $C$, et al. A meta-analysis of previous fracture and subsequent fracture risk. Bone 2004; 35(2):375-82.

7. Johnell O, Kanis JA, Oden A, et al. Fracture risk following an osteoporotic fracture. Osteoporos Int 2004; 15(3):175-9.

8. Klotzbuecher CM, Ross PD, Landsman PB, et al. Patients with prior fractures have an increased risk of future fractures: a summary of the literature and statistical synthesis. J Bone Miner Res 2000; 15(4):721-39.

9. McLellan AR, Gallacher SJ, Fraser M, et al. The fracture liaison service: success of a program for the evaluation and management of patients with osteoporotic fracture. Osteoporos Int 2003; 14(12):1028-34.

10. CBO KvdG. Osteoporose, tweede herziene richtlijn. Van Zuiden Communications 2002.

11. Huntjens KM, van Geel TA, Blonk MC, et al. Implementation of osteoporosis guidelines: a survey of five large fracture liaison services in the Netherlands. Osteoporosis international : a journal established as result of cooperation between the European Foundation for Osteoporosis and the National Osteoporosis Foundation of the USA 2011; 22(7):2129-35.

12. CBO. Preventie van valincidenten bij ouderen 2004. Available at: http://www.cbo.nl/ thema/richtlijnen/overzicht-richtlijnen/geriatrie/.

13. Center JR, Nguyen TV, Schneider D, et al. Mortality after all major types of osteoporotic fracture in men and women: an observational study. Lancet 1999; 353(9156):878-82.

14. Bliuc D, Nguyen ND, Milch VE, et al. Mortality risk associated with low-trauma osteoporotic fracture and subsequent fracture in men and women. JAMA : the journal of the American Medical Association 2009; 301(5):513-21. 
15. Lyles KW, Colon-Emeric CS, Magaziner JS, et al. Zoledronic acid and clinical fractures and mortality after hip fracture. N Engl J Med 2007; 357(18):1799-809.

16. Bolland MJ, Grey AB, Gamble GD, et al. Effect of osteoporosis treatment on mortality: a meta-analysis. The Journal of clinical endocrinology and metabolism 2010; 95(3):1174-81.

17. Center JR, Bliuc D, Nguyen ND, et al. Osteoporosis medication and reduced mortality risk in elderly women and men. The Journal of clinical endocrinology and metabolism 2011; 96(4):1006-14.

18. Huntjens KM, van Geel TC, Geusens PP, et al. Impact of guideline implementation by a fracture nurse on subsequent fractures and mortality in patients presenting with non-vertebral fractures. Injury 2011; 42 Suppl 4:S39-43.

19. van Helden S, van Geel AC, Geusens PP, et al. Bone and fall-related fracture risks in women and men with a recent clinical fracture. The Journal of bone and joint surgery. American volume 2008; 90(2):241-8.

20. CBO. Osteoporosis and fracture prevention 2011. Available at: http://www.cbo.nl/ thema/Richtlijnen/Overzicht-richtlijnen/Geriatrie/. Accessed 2011-11-07.

21. Lih A, Nandapalan $\mathrm{H}, \mathrm{Kim} M$, et al. Targeted intervention reduces refracture rates in patients with incident non-vertebral osteoporotic fractures: a 4-year prospective controlled study. Osteoporosis international : a journal established as result of cooperation between the European Foundation for Osteoporosis and the National Osteoporosis Foundation of the USA 2011; 22(3):849-58.

22. Sambrook PN, Cameron ID, Chen JS, et al. Oral bisphosphonates are associated with reduced mortality in frail older people: a prospective five-year study. Osteoporosis international : a journal established as result of cooperation between the European Foundation for Osteoporosis and the National Osteoporosis Foundation of the USA 2011; 22(9):2551-6.

23. Beaupre LA, Morrish DW, Hanley DA, et al. Oral bisphosphonates are associated with reduced mortality after hip fracture. Osteoporosis international : a journal established as result of cooperation between the European Foundation for Osteoporosis and the National Osteoporosis Foundation of the USA 2011; 22(3):983-91.

24. Colon-Emeric CS, Mesenbrink P, Lyles KW, et al. Potential mediators of the mortality reduction with zoledronic acid after hip fracture. Journal of bone and mineral research : the official journal of the American Society for Bone and Mineral Research 2010; 25(1):91-7.

25. Nurmi-Luthje I, Sund R, Juntunen $M$, et al. Post-hip fracture use of prescribed calcium plus vitamin $\mathrm{D}$ or vitamin $\mathrm{D}$ supplements and antiosteoporotic drugs is associated with lower mortality: a nationwide study in Finland. Journal of bone and mineral research : the official journal of the American Society for Bone and Mineral Research 2011; 26(8):1845-53. 
26. Diez-Perez A, Hooven FH, Adachi JD, et al. Regional differences in treatment for osteoporosis. The Global Longitudinal Study of Osteoporosis in Women (GLOW). Bone 2011; 49(3):493-8.

27. McLellan AR, Wolowacz SE, Zimovetz EA, et al. Fracture liaison services for the evaluation and management of patients with osteoporotic fracture: a cost-effectiveness evaluation based on data collected over 8 years of service provision. Osteoporosis international : a journal established as result of cooperation between the European Foundation for Osteoporosis and the National Osteoporosis Foundation of the USA 2011; 22(7):2083-98.

28. Cooper MS, Palmer AJ, Seibel MJ. Cost-effectiveness of the Concord Minimal Trauma Fracture Liaison service, a prospective, controlled fracture prevention study. Osteoporosis international : a journal established as result of cooperation between the European Foundation for Osteoporosis and the National Osteoporosis Foundation of the USA 2012; 23(1):97-107.

29. Eisman JA, Bogoch ER, Dell R, et al. Making the first fracture the last fracture: ASBMR task force report on secondary fracture prevention. Journal of bone and mineral research : the official journal of the American Society for Bone and Mineral Research 2012; 27(10):2039-46. 


\section{Part IV}

Summary and conclusions 



\section{Chapter 8}

Summary and conclusions 

In the field of post fracture care there has been substantial progress in identifying and recognizing patients at high-risk for subsequent fracture. In this context, there is increasing evidence that a dedicated fracture nurse under supervision of surgeons, rheumatologists or endocrinologists, can integrate osteoporosis and fall prevention guidelines at the Fracture Liaison Service (FLS). In this thesis, we studied in patients with a recent non-vertebral fracture the timing and risk factors for subsequent non-vertebral fracture and mortality, and compared subsequent fracture risk and mortality risk before and after the introduction of the FLS.

\section{PART I SUBSEQUENT FRACTURE INCIDENCE IN PATIENTS WITH A RECENT FRACTURE}

The first aim of this thesis was to evaluate the subsequent non-vertebral fracture incidence in patients with a recent non-vertebral fracture. Therefore, in chapter $\mathbf{2}$ we retrospectively investigated a cohort of fracture patients of $50+$ years of age who had sustained a recent non-vertebral fracture. The absolute risk for a subsequent non-vertebral fracture within 5 years was $17.6 \%$, and increasing age was

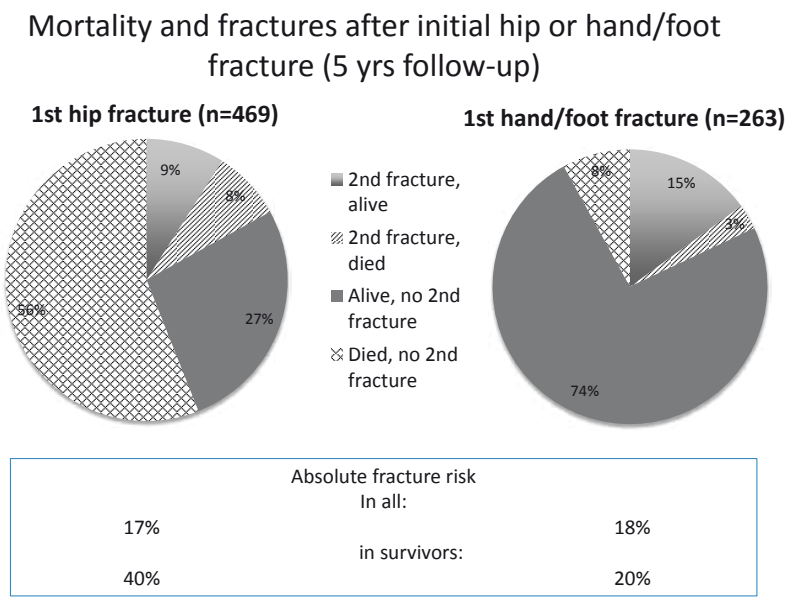

Figure 1.

Subsequent fracture incidence and mortality according to baseline fracture location. 
a significant risk factor (Figure 1). The absolute risk for mortality was 32.3\%, with increasing age, male sex, an initial major fracture (hip, pelvis, multiple ribs, proximal tibia/humerus and distal femur) and a subsequent fracture as significant risk factors. We also found a time-related effect: the risk of sustaining a subsequent fracture, as well as mortality, was highest immediately after the non-vertebral fracture. After multivariable analyses, patients with a minor fracture had a similar risk for sustaining a subsequent fracture compared to patients with an initial major fracture, but the risk for premature mortality was highest for patients with an initial major fracture. From a clinical point of view these results indicate that fracture prevention should be considered after any non-vertebral fracture and, moreover, starting immediately after the initial fracture. Still, there is the need to study which reversible factors can be targeted to prevent subsequent fractures and mortality.

In chapter 3, we reviewed studies that focused on the timing of repeat fractures, i.e. the time of subsequent fracture after an initial fracture. The RR of fractures is doubled after a fracture, but this meta-analysis could not take into account the timing of subsequent fractures, as this was not available in the included population-based studies ${ }^{1}$. However, studies that noted the timing of fractures indicate clustering of fractures in time, i.e. the risk of subsequent fracture is highest in the first years following a fracture and decreases over time after a fracture. This has been shown for repeat radiographic and clinical vertebral fractures, repeat hip fractures and repeat low-trauma fractures, and for fractures after clinical vertebral fractures and after hip fracture.

The results of a population-based study in postmenopausal women in the South of the Netherlands showed that the risk for any initial fracture was 1\% per year, and the subsequent risk of any subsequent fracture was highest within the first year (absolute risk: 6\%) and this declined exponentially (absolute risk over 20 years: $40 \%$ ). Focusing only on the patients who sustained a subsequent fracture, $23 \%$ of all subsequent fractures occurred within the first year and $54 \%$ within 5 years after the initial fracture. However, after 15 years, the subsequent fracture risk was no longer higher than the initial fracture risk² (Figure 2). 


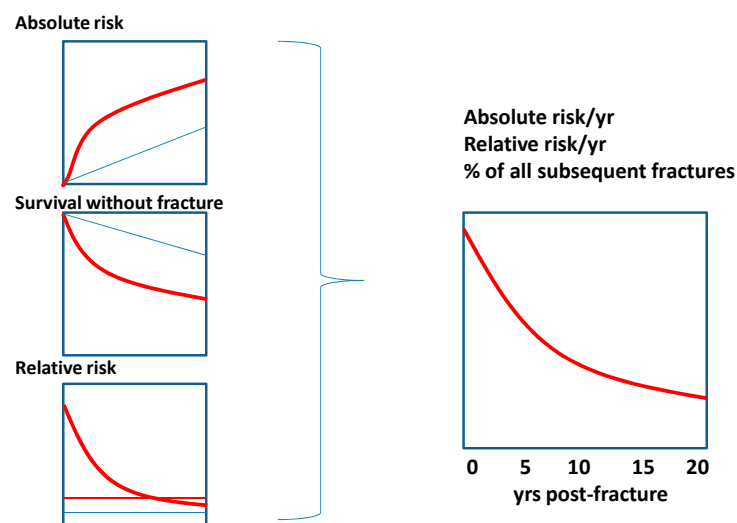

Figure 2.

Clustering of fractures in time, especially within the first years.

The clustering of fractures in time indicates the need for immediate attention to fracture patients, in order to prevent the occurrence of a subsequent fracture. When treatment with osteoporosis medication is considered, such treatment should be chosen on the basis of proven short-term efficacy in the reduction of fractures.

In conclusion, the results of part I of this thesis showed that almost one in five patients with a recent non-vertebral fracture sustained a subsequent fracture within five years of follow-up. We found that most of the fractures occurred within the first year after the initial fracture, in concordance with recent literature. In addition, mortality was also highest within the first year after the initial fracture. Therefore, immediate action after the initial fracture is necessary to reduce the risk of a subsequent fracture.

\section{PART II FRACTURE LIAISON SERVICE: RISK EVALUATION}

The second aim of this thesis was to evaluate the possible benefit of implementation of a guideline on osteoporosis and falls combined into a Fracture Liaison Service by a dedicated fracture nurse. The FLS has shown that systematic approach of fracture patients increases case identification ${ }^{3-5}$. 
In chapter 4, we analyzed risk factors in patients with a recent non-vertebral fracture over 2 years of follow-up. The hypothesis was that patients with a non-vertebral initial fracture with both bone- and fall-related risk factors were at higher risk of sustaining a subsequent non-vertebral fracture and premature mortality even if they were offered fall and fracture prevention according to the Dutch fracture- and fall-prevention guidelines ${ }^{6-8}$. Of all patients, 51\% had at least one bone-related risk factor and $60 \%$ at least one fall-related risk factor. Univariable Cox regression analysis showed a 99\% higher risk in subsequent fracture risk in patients with the combination of bone- and fall-related risk factors compared to all other patients. In multivariable analyses (including age, gender and baseline fracture location) this tendency was also shown, but it did not reach statistical significance. We also found a time-dependent effect in patients with the combination of risk factors compared with patients with only bone-related risk factors. Immediately after their initial non-vertebral fracture, patients with the combination of bone- and fall-related risk factors had a higher subsequent fracture risk until approximately 8 months after their non-vertebral fracture. However, a study with a larger number of events is necessary to confirm our findings. In univariable analysis, patients with the combination of bone- and fall-related risk factors had a significantly higher risk for a subsequent fracture compared to patients with only fall-related risk factors (Hazard Ratio (HR) 2.41; 95\% Confidence Interval (Cl) 1.06-6.46), but not in multivariable analysis. These data indicate that, in spite of a FLS assessment, patients with a combination of bone- and fall-related risk factors still had a high fracture risk at short term. No difference was found between the groups on mortality rate. Possible explanations could be the low event rate in our study or the treatment with bisphosphonates, which might reduce mortality. The mechanism still remains unclear and could be its effect on subsequent fracture risk or on extraskeletal sites $^{9-11}$.

An evaluation of FLSs allowed identifying similarities and differences in the performance of evidence-based medicine and prevalence of clinical risk factors. Also, it can be helpful to detect strengths and weaknesses of guideline advices and their implementation.

In chapter $\mathbf{5}$ we aimed to identify similarities and differences in the performance and the prevalence of clinical risk factors in patients presented at a FLS in five large hospitals in the Netherlands. We hypothesized that the FLSs would all 
select patients based on guideline on osteoporosis and fracture prevention by the Dutch Institute for Healthcare Improvement ${ }^{7}$. In total 7,199 patients aged 50 years and over with a recent non-vertebral fracture were prospectively followed over a period of $39-58$ months. Of the 7,199 patients, $76.7 \%$ were women and the mean age was 66.7 years. There was a significant difference in the prevalence of reported clinical risk factors between the FLSs. Variability expressed as relative risks between the clinical risk factors ranged from 1.7 (previous vertebral fracture) to 37.0 (corticosteroids usage), depending on the risk factor. We concluded that a dedicated fracture nurse was the central responsible coordinator to identify fracture patients to evaluate risk factors for subsequent fractures and to organize secondary fracture prevention after counseling by the (orthopedic) surgeon, endocrinologist or rheumatologist. Also, we found that there was a striking difference in the prevalence of clinical risk factors and fall risks between the elderly screened for osteoporosis. This indicates that prevention strategies to avert subsequent fractures mainly have to focus on bone mineral density, clinical risk factors for osteoporosis and fall risks and potentially there are differences in the presence of risk factors between different fracture types.

In conclusion, in part II of this thesis we demonstrated that in patients with a recent non-vertebral fracture evaluated and treated at the FLS 51\% had at least one bone-related risk factor and $60 \%$ had at least one fall-related risk factor. Patients with the combination of both had a $99 \%$ higher risk of sustaining a subsequent fracture within 2-years after their initial fracture. Also a time-dependency was seen in patients with the combination of risk factors compared to patients with only a bone-related risk factor in timing of subsequent fracture incidence. In an evaluation of five FLSs throughout the Netherlands we found that a dedicated fracture nurse was the central responsible coordinator of this outpatient clinic. The assumption that all hospitals would strictly select the patients based on the guideline on osteoporosis and fracture prevention of the Dutch Institute for Healthcare Improvement, might not be correct, since differences were found in the performance of patient selection, clinical risk factors and prevalence of clinical risk factors, indicating the need for more concrete and standardized guidelines to organize evaluation of patients at the time of fracture in daily practice. 


\section{PART III FRACTURE LIAISON SERVICE: RISK REDUCTION?}

The third aim of this thesis was to investigate whether the implementation of a FLS could lower the risks on subsequent fracture incidence and mortality.

In chapter 6, we conducted a prospective cohort study of patients of 50+ years of age with a recent non-vertebral fracture treated at the FLS in the Maastricht University Medical Center. To assess whether a FLS with a dedicated fracture nurse could have a beneficial effect on subsequent fracture incidence and mortality we compared this patient cohort with a retrospective cohort of fracture patients treated in the same hospital (a so-called pre-post analysis). These patients received usual care and were treated before the implementation of the FLS. We found that systematic implementation of previously validated guidelines for osteoporosis and fall prevention resulted in a significantly lower incidence of subsequent non-vertebral fractures by $35 \%$ in two years, and a $33 \%$ lower incidence in mortality ${ }^{6,7}$. The lower incidence of subsequent fractures is most probably a multifactorial effect, including counseling, increased patient awareness, calcium and vitamin D supplements, drug treatment of osteoporosis and fall prevention measures. The reduction in mortality could only partly be explained by the lower subsequent fracture incidence, as seen by others ${ }^{11}$. This suggests that post-fracture care does not only have an effect on subsequent fracture risk, but also on other adverse outcomes like mortality. Changes over time in other components of post-fracture care (anesthesia, wound healing care), or improved post-fracture care by physicians who applied the guidelines could be related to the observed results.

Therefore, in chapter 7, we investigated the subsequent fracture incidence and mortality in a pre-specified group of fracture patients. We included all patients with a recent non-vertebral fracture between 2004-2006 in a hospital with and in a hospital without a FLS. In the no-FLS hospital, only standard fracture care procedures were followed to address proper fracture healing. In the FLS hospital, Dual-energy X-ray Absorptiometry scan (DXA-scan) and laboratory testing were performed. In total, 1412 patients attended the FLS and 1910 underwent standard fracture care. Patients treated at the FLS hospital had a significantly lower, timerelated incidence of a subsequent non-vertebral fracture after correction for age, 
sex and baseline fracture location. No significant difference in fracture rate was found within the first year, but from the second year on fracture incidence was $28 \%$ lower at 15 months and 56\% lower at 2 years after the initial non-vertebral fracture. Subgroup analyses according to baseline fracture indicated that the time-dependent effect was mainly driven by the effect in patients with a baseline hip fracture, since subsequent non-vertebral fracture incidence was 57-91\% lower after a hip fracture in the FLS group, without differences after baseline major or minor non-vertebral fracture. The mortality rate was also lower in the FLS hospital $(-35 \%)$ compared to the no-FLS hospital after correction for age, sex and baseline fracture location. These results indicate that a FLS should be considered in patients with a recent fracture, especially after a recent hip or major fracture.

In summary, we illustrated in part III that a FLS could have a beneficial effect on subsequent fracture incidence and mortality. We studied only patients with a recent non-vertebral fracture during a 2-year follow-up period and found a lower subsequent fracture incidence among patients evaluated and if needed treated at the FLS compared with both the historical control group and the no-FLS hospital group. Longer follow up studies will be needed to explore the long-term effect of the FLS.

\section{GENERAL CONCLUSION}

Due to the ageing population and the burden of fractures on morbidity the health care costs increase exponentially. Secondary prevention of fractures is still a low priority for health care physicians, specialist and the general population. However, during the last decades progress has been made to identify the fracture patients and subsequent fracture incidence ${ }^{1,12,13}$. The implementation of a FLS contributed to increased awareness towards the fracture patient by medical specialists, such as (orthopedic) surgeon. A FLS is the bridge between the fracture and the management of secondary fracture prevention. Possibly it could enhance patient's medication adherence overtime by structured follow-up. Data on the effectiveness of a FLS are scarce. However, the research presented in this thesis as well as other data suggest that a FLS is effective in identifying most non-vertebral fracture patients at risk of subsequent fractures ${ }^{14}$. A recent study 
into physical and cognitive functioning of people older than 90 years of age revealed that nowadays more people are living to older ages with better overall functioning ${ }^{15}$. Moreover, during the next two decades approximately 450 million people will reach retirement age, so the time has come to make FLS available for all older people suffering fractures throughout the world ${ }^{16}$.

The International Osteoporosis Foundation (IOF) has launched an international Capture the Fracture Campaign in 2012 to promote secondary fracture prevention by facilitating the implementation of $\mathrm{FLSs}^{17}{ }^{18}$. This website informs, as well as guides health care professionals to implement their own FLS and, furthermore, provides a platform for the global sharing of existing programs, resources about FLS and local implementation strategies ${ }^{17}$. A recent publication by the American Society for Bone and Mineral Research (ASBMR) entitled "Making the first fracture the last" showed the striking efforts health care professionals are trying to make to reduce subsequent fracture incidence in fragility fracture patients ${ }^{19}$. Similar initiatives are ongoing in collaboration of the European League against rheumatism (EULAR) with the European Federation of National Associations of Orthopaedics and Traumatology (EFORT) ${ }^{20}$.

In 2005, the total direct cost of osteoporotic fractures in Europe was $€ 32$ billon per year, and is expected to rise to $€ 37$ billion by the year $2025^{21}$. The cost-effectiveness of FLS for secondary prevention of fractures is another issue concerning the initiation of FLSs throughout the world. In the Netherlands, visits of patients at the outpatient clinic, as well as bone mineral density measurement are covered by health care insurance. Cost-effectiveness analyses based on fracture risk reduction assumptions indicate that FLSs could be cost-effective in fragility fracture patients for prevention of future fractures, but further prospective studies will be needed ${ }^{22,23}$.

The prevention of subsequent fractures is multifactorial. Possible factors contributing to a reduction of the risk could be the attention of the fracture nurse towards the patient, treatment with anti-osteoporosis medication, vitamin D and calcium supplements and fall prevention. The mechanisms by which mortality is reduced are still unclear and seem to be multifactorial and probably related to 
extra skeletal effects of bisphosphonates or calcium and vitamin D or other still unclear mechanisms ${ }^{10}$.

At the FLS the fracture nurse is the key figure in the assessment of fracture patients. They inquire into bone- and fall- related risk factors, previous medical history and arrange bone mineral density and laboratory tests. The leading goal is attempting to diminish possible reversible risk factors and to evaluate and treat the adverse risk factors, if applicable and to thereby reduce subsequent fractures and mortality.

In conclusion, the results of this thesis suggest that the implementation of a FLS is clinically important, possibly leading to a lower subsequent fracture risk and mortality. 


\section{REFERENCES}

1. Klotzbuecher CM, Ross PD, Landsman PB, et al. Patients with prior fractures have an increased risk of future fractures: a summary of the literature and statistical synthesis. J Bone Miner Res 2000; 15(4):721-39.

2. van Geel TA, van Helden S, Geusens PP, et al. Clinical subsequent fractures cluster in time after first fractures. Ann Rheum Dis 2008.

3. Chevalley $\mathrm{T}$, Hoffmeyer $\mathrm{P}$, Bonjour JP, et al. An osteoporosis clinical pathway for the medical management of patients with low-trauma fracture. Osteoporosis international : a journal established as result of cooperation between the European Foundation for Osteoporosis and the National Osteoporosis Foundation of the USA 2002; 13(6):450-5.

4. Hegeman JH, Willemsen G, van Nieuwpoort J, et al. [Effective tracing of osteoporosis at a fracture and osteoporosis clinic in Groningen; an analysis of the first 100 patients]. Nederlands tijdschrift voor geneeskunde 2004; 148(44):2180-5.

5. McLellan AR, Gallacher SJ, Fraser M, et al. The fracture liaison service: success of a program for the evaluation and management of patients with osteoporotic fracture. Osteoporos Int 2003; 14(12):1028-34.

6. CBO. Preventie van valincidenten bij ouderen 2004. Available at: http://www.cbo.nl/ thema/richtlijnen/overzicht-richtlijnen/geriatrie/.

7. $\mathrm{CBO}$ KvdG. Osteoporose, tweede herziene richtlijn. Van Zuiden Communications 2002.

8. CBO. Osteoporosis and fracture prevention 2011. Available at: http://www.cbo.nl/ thema/Richtlijnen/Overzicht-richtlijnen/Geriatrie/. Accessed 2011-11-07.

9. Bliuc D, Nguyen ND, Milch VE, et al. Mortality risk associated with low-trauma osteoporotic fracture and subsequent fracture in men and women. JAMA : the journal of the American Medical Association 2009; 301(5):513-21.

10. Center JR, Bliuc D, Nguyen ND, et al. Osteoporosis medication and reduced mortality risk in elderly women and men. The Journal of clinical endocrinology and metabolism 2011; 96(4):1006-14.

11. Colon-Emeric CS, Mesenbrink P, Lyles KW, et al. Potential mediators of the mortality reduction with zoledronic acid after hip fracture. Journal of bone and mineral research : the official journal of the American Society for Bone and Mineral Research 2010; 25(1):91-7.

12. Johnell O, Kanis JA, Oden A, et al. Fracture risk following an osteoporotic fracture. Osteoporos Int 2004; 15(3):175-9.

13. Center JR, Bliuc D, Nguyen TV, et al. Risk of subsequent fracture after low-trauma fracture in men and women. JAMA : the journal of the American Medical Association 2007; 297(4):387-94. 
14. Vaile JH, Sullivan L, Connor D, et al. A Year of Fractures: a snapshot analysis of the logistics, problems and outcomes of a hospital-based fracture liaison service. Osteoporosis international : a journal established as result of cooperation between the European Foundation for Osteoporosis and the National Osteoporosis Foundation of the USA 2013.

15. Christensen $\mathrm{K}$, Thinggaard M, Oksuzyan A, et al. Physical and cognitive functioning of people older than 90 years: a comparison of two Danish cohorts born 10 years apart. Lancet 2013.

16. Global Coalition on Ageing. Available at: http://www.globalcoalitiononageing.com. Accessed 07-11-2013.

17. IOF. Capture the Fracture. Available at: http://www.capturethefracture.org/. Accessed 07-11-2013.

18. Akesson K, Marsh D, Mitchell PJ, et al. Capture the Fracture: a Best Practice Framework and global campaign to break the fragility fracture cycle. Osteoporosis international : a journal established as result of cooperation between the European Foundation for Osteoporosis and the National Osteoporosis Foundation of the USA 2013; 24(8):2135-52.

19. Eisman JA, Bogoch ER, Dell R, et al. Making the first fracture the last fracture: ASBMR task force report on secondary fracture prevention. Journal of bone and mineral research : the official journal of the American Society for Bone and Mineral Research 2012; 27(10):2039-46.

20. Traumatology) EEFoNAoOa. EFORT. Available at: https://http://www.efort.org. Accessed 08-11-2013.

21. Kanis JA, Johnell O. Requirements for DXA for the management of osteoporosis in Europe. Osteoporosis international : a journal established as result of cooperation between the European Foundation for Osteoporosis and the National Osteoporosis Foundation of the USA 2005; 16(3):229-38.

22. McLellan AR, Wolowacz SE, Zimovetz EA, et al. Fracture liaison services for the evaluation and management of patients with osteoporotic fracture: a cost-effectiveness evaluation based on data collected over 8 years of service provision. Osteoporosis international : a journal established as result of cooperation between the European Foundation for Osteoporosis and the National Osteoporosis Foundation of the USA 2011; 22(7):2083-98.

23. Cooper MS, Palmer AJ, Seibel MJ. Cost-effectiveness of the Concord Minimal Trauma Fracture Liaison service, a prospective, controlled fracture prevention study. Osteoporosis international : a journal established as result of cooperation between the European Foundation for Osteoporosis and the National Osteoporosis Foundation of the USA 2012; 23(1):97-107. 



\section{Chapter 9}

Samenvatting en conclusies 

Op het gebied van fractuurbehandeling is er de laatste jaren een substantiële progressie geweest in het identificeren en herkennen van hoog risico patiënten voor een nieuwe fractuur. Hierbij is er ook een toenemende mate van bewijs dat een toegewijde en gespecialiseerde osteoporoseverpleegkundige, gesuperviseerd door (orthopedisch) chirurgen, rheumatologen en/of endocrinologen, zorgt voor het integreren van osteoporose- en valrichtlijnen in de "Fracture Liaison Service" (=Osteoporose Poli) (FLS).

In dit proefschrift hebben we onderzoek gedaan bij patiënten met een recente niet-wervelfractuur naar de timing en de risicofactoren voor een nieuwe, opeenvolgende niet-wervel fractuur en overlijden. Ook hebben we het nieuwe fractuurrisico en overlijdensrisico vergeleken in patiënten die behandeld zijn voor en na de implementatie van de Osteoporose Poli.

\section{DEEL 1 NIEUWE OPEENVOLGENDE FRACTUUR INCIDENTIE IN PATIËNTEN MET EEN RECENTE NIET-WERVELFRACTUUR}

Het eerste doel van dit proefschrift was om de nieuwe, opeenvolgende fractuur incidentie te evalueren in patiënten met een recente niet-wervel fractuur. Hiervoor hebben we in hoofdstuk 2 retrospectief een cohort van fractuurpatiënten van 50 jaar en ouder onderzocht. Allen hadden een recente niet-wervelfractuur. Het absolute risico voor een nieuwe, opeenvolgende niet-wervel fractuur binnen 5 jaar was $17.6 \%$. Hogere leeftijd was een significante risicofactor voor het optreden van een nieuwe, opeenvolgende niet-wervelfractuur (Figuur 1). Het absoluut risico op overlijden was $32.3 \%$. Significante risicofactoren voor overlijden waren hogere leeftijd, mannelijk geslacht en een initiële majeure fractuur (heup, bekken, multipele ribfracturen, proximale tibia/humerus en distale femurfractuur). Ook het hebben van een nieuwe, opeenvolgende niet-wervelfractuur was een significante risicofactor op overlijden binnen 5 jaar follow-up. 

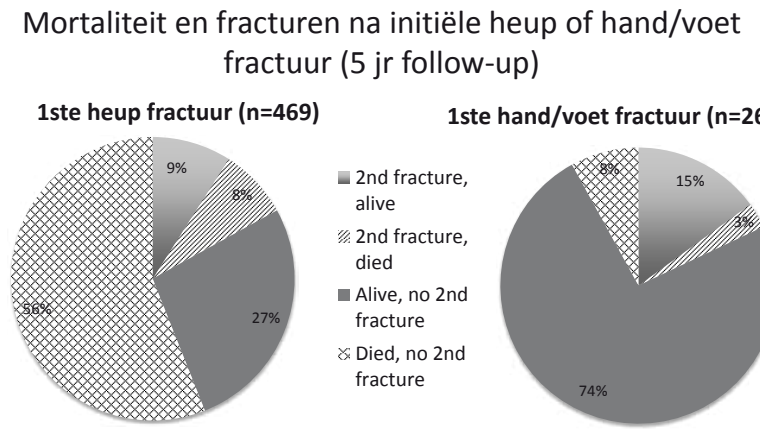

1ste hand/voet fractuur ( $n=263)$

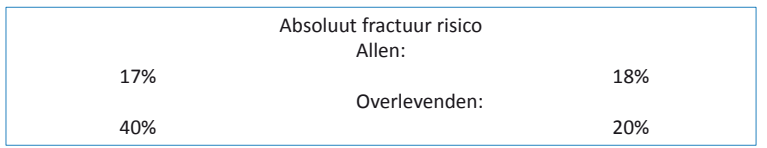

\section{Figuur 1.}

Nleuwe opeenvolgende fractuurincidentie en mortaliteit ingedeeld naar baseline fractuurlokatie

Verder vonden we ook een tijdsgerelateerd effect: het risico op een nieuwe, opeenvolgende fractuur, alsmede overlijden, was het hoogst direct na de niet-wervelfractuur. Na multivariabele analyses zagen we dat patiënten met een mineure fractuur een gelijkwaardig risico op een nieuwe, opeenvolgende niet-wervelfractuur hadden vergeleken met patiënten met een initiële majeure fractuur. Echter het risico op overlijden was wel hoger in de groep patiënten met een initiële majeure fractuur vergeleken met patiënten met een initiële mineure fractuur. Vanuit klinisch oogpunt gezien wijzen deze resultaten erop dat fractuurpreventie overwogen zou moeten worden na alle niet-wervelfracturen, en meteen gestart zou moeten na de initiële niet-wervelfractuur. Echter, er is nog steeds uitgebreid onderzoek nodig om te evalueren welke reversibele factoren gecorrigeerd kunnen worden om nieuwe, opeenvolgende niet-wervelfracturen en overlijden te voorkomen.

In hoofdstuk 3, werd een overzicht verricht naar studies die zich toespitsen op de tijd en timing van nieuwe, opeenvolgende fracturen. Het Relatieve Risico (RR) van fracturen is verdubbeld na een fractuur, echter deze meta-analyse kon geen uitspraak doen over de timing van deze fracturen omdat deze studies nog niet 
beschikbaar waren ten tijde van de geïncludeerde onderzoeken'1. Onderzoeken die wel het tijdseffect tussen het onstaan van fracturen bestudeerden vonden een clustering van fracturen over de tijd, bijvoorbeeld het risico op een opeenvolgende nieuwe fractuur is het hoogst het eerste jaar na de initiële fractuur en neemt af in de tijd na een fractuur. Dit is te zien bij herhaalde radiologische en klinische wervelfracturen, herhaalde heupfracturen en herhaalde laagenergetische fracturen. Ook na een klinische wervelfractuur of heupfractuur werd dit tijdseffect gevonden.

De resultaten van het onderzoek bij postmenopauzale vrouwen in ZuidNederland toonde dat het risico voor een initiële fractuur 1\% per jaar bedraagt en het opeenvolgende, nieuwe fractuur risico het hoogst was binnen het eerste jaar na de initiële fractuur (absoluut risico (AR): $6 \%$ ) en dit daalde gestaag gedurende de jaren (AR over 20 jaar: 40\%). Als men alleen keek naar de patiënten met een nieuwe, opeenvolgende fractuur zag men dat $23 \%$ van al deze fracturen optraden binnen het eerste jaar na de fractuur, binnen 5 jaar was dit 54\%. Echter, na 15 jaar was het risico op een nieuwe, opeenvolgende fractuur niet langer hoger dan het initiële fractuurrisico (Figuur 2)2.
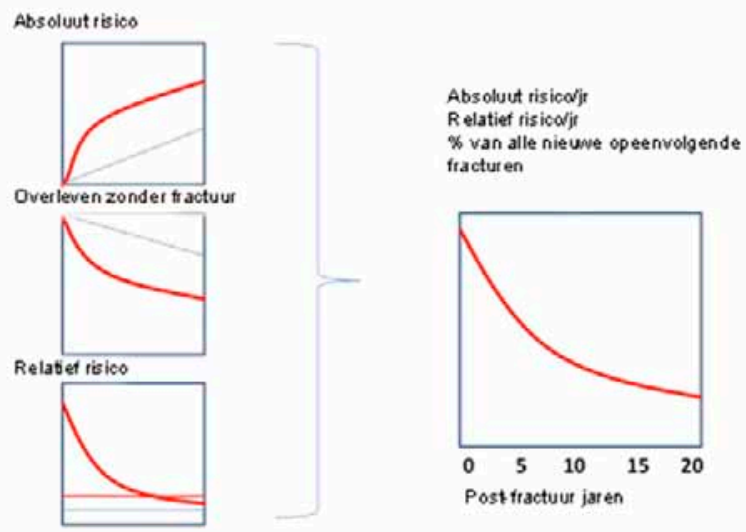

Figuur 2.

Clustering van fracturen in de tijd, met name in de eerste jaren 
Deze clustering van fracturen over de tijd toont aan dat men aandacht moet hebben voor de fractuurpatiënt meteen na de fractuur om een nieuwe, opeenvolgende fractuur te voorkomen. Wanneer men overweegt antiosteoporose medicijnen te starten, zou dit gebaseerd moeten zijn op basis van bewezen effect op korte termijn.

Samenvattend tonen de resultaten van deel I van dit proefschrift dat binnen 5 jaar follow-up bijna 1 op 5 patiënten met een recente niet-wervelfractuur een nieuwe, opeenvolgende fractuur oplopen. In overeenstemming met de recente literatuur traden de meeste nieuwe, opeenvolgende fracturen op binnen het 1ste jaar na de initiële fractuur. Mortaliteit was ook het hoogst binnen 1 jaar na de initiële fractuur. Om het risico op een nieuwe fractuur te verminderen is hierdoor onmiddellijke actie na de initiële fractuur vereist.

\section{DEEL 2 RISICO EVALUATIE OP DE FRACTURE LIAISON SERVICE}

Het tweede doel van deze thesis was het evalueren van het implementeren van richtlijnen met betrekking tot osteoporose en vallen op de Fracture Liaison Service door een gespecialiseerde fractuurverpleegkundige. Systematische aanpak van fractuurpatiënten op een FLS leidt tot verhoging van de identificatie van risicopatiënten ${ }^{3-5}$.

In hoofdstuk 4 hebben we de risicofactoren geanalyseerd in patiënten met een recente niet-wervelfractuur gedurende 2 jaar follow-up. De hypothese was dat patiënten met een initiële niet-wervelfractuur met bot- en valgerelateerde risicofactoren een hoger risico hadden op een nieuwe, opeenvolgende fractuur en overlijden ondanks dat ze val- en fractuurpreventie kregen overeenkomstig de Nederlandse osteoporose en valpreventie richtlijnen ${ }^{6-8}$. Van alle geïncludeerde patiënten, had 51\% tenminste één botgerelateerde risicofactor en $60 \%$ had tenminste één valgerelateerde risicofactor. Univariabele Cox regressie analyse toonde een $99 \%$ hoger risico op een nieuwe opeenvolgende fractuur bij patiënten met de combinatie van bot- en valgerelateerde risicofactoren in vergelijking met alle andere patiënten. In multivariabele analyse (met leeftijd, geslacht en initiële fractuurlokatie geincludeerd) was deze tendens ook zichtbaar, echter het 
was niet statistisch significant. We vonden ook een tijdseffect in patiënten met de combinatie van risicofactoren vergeleken met patiënten met alleen een botgerelateerde risicofactor. Meteen na de initiële fractuur tot 8 maanden hierna hebben patiënten met de combinatie van bot- en valgerelateerde risicofactoren een hoger risico op een nieuwe, opeenvolgende fractuur. Echter een nieuw onderzoek met meer events is nodig om deze data te bevestigen. In univariabele analyse hadden patiënten met de combinatie van bot- en valgerelateerde risicofactoren een significant hoger risico op een nieuwe, opeenvolgende fractuur in vergelijking met patiënten met alleen valgerelateerde risicofactoren (Hazard Ratio (HR) 2.41; 95\% Confidentie Interval (Cl) 1.06-6.46). Echter dit was niet significant in de multivariabele analyse. Deze data laten zien dat, ondanks dat alle patiënten waren geëvalueerd op de FLS, patiënten met een combinatie van bot- en valgerelateerde risicofactoren nog steeds een hoog fractuurrisico hebben op korte termijn. Er werd geen verschil gevonden tussen de patiënten met betrekking tot mortaliteit tijdens de 2 jaar follow-up. Mogelijke verklaringen hiervoor zijn dat het totale aantal overlijdens lag was (weinig events) of de behandeling met bisfosfonaten zijn. Bisfosfonaten zouden mogelijk mortaliteit reduceren, echter het exacte mechanism hierachter is nog onduidelijk. Mogelijk komt het door het effect op nieuwe, opeenvolgende fracturen of het effect op het lichaam buiten het skelet ${ }^{9-11}$.

Een evaluatie van meerdere FLS identificeerde verschillen en overeenkomsten in de uitvoering van op evidentie gebaseerde geneeskunde ("evidence-based") en prevalentie van klinische risicofactoren. Dit kan ook helpen bij het opsporen van sterktes en zwakheden van richtlijnen en de implementatie hiervan.

In hoofdstuk $\mathbf{5}$ was het doel om overeenkomsten en verschillen in de uitvoering van 5 FLSs in Nederland te analyseren en daarbij de prevalentie van klinische risicofactoren te identificeren in deze groep. Onze hypothese was dat de FLSs patiënten selecteerden op basis van de geldende richtlijn osteoporose en vallen van het Kwaliteitsinstituut voor de Zorg (CBO $)^{7}$. In totaal werden er 7199 patiënten van 50 jaar en ouder met een recente niet-wervelfractuur prospectief gevolgd tijdens een periode van 39-58 maanden. Van deze 7199

patiënten waren $76.7 \%$ vrouwen en de gemiddelde leeftijd was 66.7 jaar. Er was een significant verschil tussen de gerapporteerde prevalentie van de klinische risicofactoren tussen de verschillende FLSs. De variabiliteit tussen de gerapporteerde prevalenties van klinische risicofactoren werd uitgedrukt in 
relatief risico (RR) en varieerde tussen 1.7 (eerdere wervelfractuur) tot 37.0 (glucocorticoïd gebruik). We concludeerden uit deze data dat een gespecialiseerde osteoporoseverpleegkundige een central rol speelde in het identificeren van fractuurpatiënten voor het evalueren van risicofactoren voor nieuwe, opeenvolgende fracturen en het organiseren van secundaire fractuurpreventie onder supervisie van een traumachirurg, orthopeed, endocrinoloog of rheumatoloog. We vonden ook dat er opvallend veel verschil is in de prevalentie van klinische risicofactoren en valrisico factoren in de gescreende fractuurpopulatie. Dit impliceert dat preventie strategieën om nieuwe, opeenvolgende fracturen te voorkomen vooral toegespitst moeten zijn op botdichtheid, klinische risicofactoren voor osteoporose en valrisicofactoren. Mogelijk zijn er ook verschillen in het voorkomen van risicofactoren tussen verschillende type fracturen.

Als conclusie van deel II van deze thesis zagen we dat bij patiënten met een recente niet-wervelfractuur, die geëvalueerd en behandeld zijn op de FLS, 51\% tenminste een botgerelateerde risicofactor had en $60 \%$ tenminste een valgerelateerde risicofactor. Patiënten met de combinatie van beiden hadden een 99\% hoger risico op een nieuwe, opeenvolgende fractuur binnen twee jaar na hun initiële fractuur. Er werd ook een tijdsafhankelijk effect waargenomen bij patiënten met de combinatie van risicofactoren vergeleken met patiënten met alleen een botgerelateerde risicofactor met betrekking tot een nieuwe, opeenvolgende fractuur. Bij de evaluatie van de 5 FLSs in Nederland vonden we dat een gespecialiseerde osteoporoseverpleegkundige een centrale rol speelt in de polikliniek. De veronderstelling dat alle ziekenhuizen patiënten strict selecteren op basis van de richtlijn osteoporose en fractuurpreventie van het Kwaliteitsinstituut voor de Zorg $(\mathrm{CBO})$ is waarschijnlijk onjuist, aangezien we verschillen vonden in patientselectie, klinische risicofactoren en prevalentie van klinische risicofactoren. Dit impliceert dat er meer concrete en gestandaardiseerde richtlijnen moeten komen om fractuurpatiënten in de dagelijkse praktijk te evalueren. 


\section{DEEL 3 FRACTURE LIAISON SERVICE: RISICO REDUCTIE?}

Het derde doel van deze thesis was te onderzoeken of het implementeren van een FLS het risico op een nieuwe, opeenvolgende fractuur en overlijden zou kunnen verminderen.

In hoofdstuk $\mathbf{6}$ hebben we op een prospectieve wijze patiënten van 50 jaar en ouder met een recente niet wervelfractuur die behandeld waren op de FLS in het Maastricht Universitair Medisch Centrum (MUMC) geïncludeerd. We hebben dit cohort vergeleken met een retrospectief cohort van fractuurpatiënten die behandeld waren in hetzelfde ziekenhuis voordat er een FLS was (pre-post analyse). In deze studie kwam naar voren dat implementatie van de osteoporose en valpreventie richtlijnen geassocieerd was met een significant lagere incidentie van nieuwe, opeenvolgende niet-wervelfracturen met 35\% binnen twee jaar en voor overlijden was dit $33 \%$ lager ${ }^{6,7}$. De lagere incidentie van nieuwe, opeenvolgende fracturen is waarschijnlijk multifactorieel van origine, inclusief begeleiding, meer aandacht vanuit de patiënt met betrekking tot het ziektebeeld, calcium en vitamine $D$ supplementen, antiosteoporose medicatie en valpreventie maatregelen. De afname in mortaliteit kan maar voor een gedeelte worden verklaard door het lagere nieuwe, opeenvolgende fractuurincidentie, zoals bij anderen ook naar voren is gekomen"1. Dit suggereert dat postfractuur behandeling niet alleen een effect heeft op nieuwe, opeenvolgende fracturen maar ook op andere nadelige uitkomsten zoals mortaliteit. Verschillen in andere componenten van postfractuur behandeling (anesthesie, wondbehandeling) of verbeterde fractuurbehandeling door artsen die de richtlijnen toepassen, kunnen gerelateerd zijn aan de geobserveerde resultaten.

Daarom hebben we in hoofdstuk $\mathbf{7}$ de nieuwe, opeenvolgende fractuurincidentie en mortaliteit geanalyseerd in een vooraf gespecificeerde groep van fractuurpatiënten. We hebben alle patiënten met een recente niet-wervelfractuur tussen 2004-2006 geïncludeerd die behandeld waren in een ziekenhuis met en een ziekenhuis zonder FLS. In het niet-FLS ziekenhuis werd alleen de normale fractuurbehandeling toegepast met als doel fractuurheling. In het ziekenhuis met een FLS ondergingen patiënten een Dual-energy X-ray Absorptiometry scan (DXA-scan) en een bloedonderzoek. In totaal warden er 1412 patiënten gezien in 
het ziekenhuis met een FLS en 1910 in het ziekenhuis zonder FLS. Patiënten die warden behandeld in het ziekenhuis met een FLS hadden een significante lagere, tijdsafhankelijke incidentie van nieuwe, opeenvolgende niet-wervelfracturen na correctie voor leeftijd, geslacht en baseline fractuurlokatie. Er werd geen significant verschil gevonden in het eerste jaar na de initiële fractuur, maar vanaf het tweede jaar was de fractuurincidentie 28\% lager na 15 maanden follow-up en $56 \%$ na twee jaar follow-up. Subgroep analyses ingedeeld naar baseline fractuurlokatie toonde een tijdsafhankelijk effect en dit was met name bij patiënten met een initiële heupfractuur. De nieuwe, opeenvolgende niet-wervelfractuur incidentie in deze patiënten was $57-91 \%$ lager in de groep van het ziekenhuis met een FLS vergeleken met de groep zonder FLS. Er waren geen verschillen gevonden in subgroup analyse bij patiënten met een initiële major of minor niet wervelfractuur. Mortaliteit was ook lager in de patiënten behandeld in het ziekenhuis met een FLS (-35\%) na correctie voor leeftijd, geslacht en baseline fractuurlokatie. Deze resultaten tonen aan dat bij patiënten met een recente niet wervelfractuur behandeling in een ziekenhuis met een FLS overwogen dient te worden, met name na een recente heup of majeure fractuur.

Samenvattend, in het III $^{\mathbf{e}}$ deel van dit proefschrift toonden we aan dat een FLS geassocieerd is met een voordelig effect op de incidentie van een nieuwe, opeenvolgende fractuur en mortaliteit gedurende twee jaar follow-up. Verder vonden we bij patiënten geëvalueerd en behandeld in een ziekenhuis met een FLS een lagere incidentie van een nieuwe, opeenvolgende fractuur ten op zichte van zowel de historische controle groep als de groep patiënten behandeld in het ziekenhuis zonder FLS. Langere follow-up duur is nodig om deze resultaten verder te verifiëren.

\section{ALGEMENE CONCLUSIE}

Gezien de vergrijzing met daarbijhorende stijging van het aantal fracturen in deze populatie zullen de ziektekosten de komende jaren exponentieel stijgen. Secundaire fractuurpreventie is een groeiende, maar nog steeds onvoldoende hoge prioriteit voor de arts, ziekenhuisspecialist of de algemene bevolking. Echter, tijdens de laatste decennia is er vooruitgang geboekt ten aanzien van 
het identificeren van fractuurpatiënten en de nieuwe, opeenvolgende fractuurincidentie ${ }^{1,12,13}$. De implementatie van een FLS heeft bijgedragen aan een toenemende aandacht voor de fractuurpatiënten bij medisch specialisten, zoals een traumachirurg of orthopeed. Een FLS is de brug tussen de fractuur en secundaire fractuurpreventie. Mogelijk zou een FLS de therapietrouw van fractuurpatiënten kunnen verbeteren door middel van gestructureerde follow-up. Data over de effectiviteit van een FLS zijn schaars. Echter, zowel deze thesis alsmede andere data suggereren dat een FLS effectief kan zijn in het identificeren van patiënten met een recente niet wervelfractuur met een verhoogd risico op een nieuwe, opeenvolgende niet wervelfractuur ${ }^{14}$. Een recente studie met betrekking tot lichamelijk en cognitief functioneren in patiënten van 90 jaar en ouder, toonde dat deze ouderen tegenwoordig langer leven met een betere algehele condi$\mathrm{tie}^{15}$. Bovendien, de komende twee decennia zullen er 450 miljoen mensen de pensioengerechtigde leeftijd bereiken, dus de tijd is aangebroken om een FLS beschikbaar te maken voor alle ouderen met fracturen in de wereld ${ }^{16}$.

De International Osteoporosis Foundation (IOF) heeft in 2012 een "Capture the Fracture Campaign" op de markt gebracht om secundaire fractuurpreventie te stimuleren door de implementatie van een FLS te faciliteren ${ }^{17,18}$. Deze website informeert en leidt zorgprofessionals om een eigen FLS te starten. Daarbij geeft het ook de mogelijkheid tot delen van bestaande fractuurprogramma's en implementatie van FLS strategieën ${ }^{17}$. Een recente publicatie van de American Society for Bone and Mineral Research (ASBMR) getiteld "Making the first fracture the last" toonde de initiatieven van de zorgprofessionals om de nieuwe, opeenvolgende fractuurincidentie te reduceren in kwetsbare ouderen ${ }^{19}$. Gelijkwaardige initiatieven komen vanuit de samenwerking tussen de European League against rheumatism (EULAR) en de European Federation of National Associations of Orthopaedics and Traumatology (EFORT) ${ }^{20}$.

In 2005 waren de totale directe kosten van osteoporotische fracturen in Europa 32 miljard Euro per jaar. Men verwacht dat deze kosten zullen stijgen tot 37 miljard Euro in $2025^{21}$. De kosteneffectiviteit van een FLS voor secundaire preventie van fracturen is een ander punt van aandacht als men een FLS wil implementeren in het ziekenhuis. In Nederland worden zowel de kosten met betrekking tot het bezoek van de FLS alsmede de DXA scan vergoed door de zorgverzekering. 
Kosteneffectiviteitsstudies gebaseerd op fractuurreductie laten zien dat FLSs kosteneffectief zouden kunnen zijn in kwetsbare ouderen voor de preventie van nieuwe fracturen, echter meer onderzoek is noodzakelijk ${ }^{22,23}$.

De preventie van nieuwe, opeenvolgende fracturen is multifactorieel. Mogelijke factoren die zouden kunnen bijdrage aan het verlagen van het risico zijn de aandacht van de osteoporoseverpleegkundige, antiosteoporose medicatie, calcium en vitamine D suppletie, valpreventie en follow-up. Het mechanisme waardoor mortaliteit gereduceerd is is nog onbekend en lijkt ook multifactorieel en mogelijk gerelateerd aan niet botgerelateerde effecten van bisfosfonaten of calcium en vitamine $\mathrm{D}$ of door andere nog onbekende mechanismen ${ }^{10}$.

De osteoporoseverpleegkundige heeft een centrale rol in de beoordeling van fractuurpatiënten op de FLS. Die informeert naar bot- en valgerelateerde risicofactoren, medische voorgeschiedenis en draagt zorg voor bloedonderzoek en DXA scan afspraak. Het hoofddoel is om de mogelijke reversibele risicofactoren te corrigeren en evaluatie en behandeling van de risicofactoren in de individuele patiënt om zodoende nieuwe, opeenvolgende fracturen en mortaliteit te verlagen. Dit opent de weg naar "treat-to-target' en geïndividualiseerde fractuurpreventie.

Concluderend, suggereren de resultaten van deze thesis dat de implementatie van een FLS klinisch van belang is omdat het geassocieerd is met een lager nieuw, opeenvolgend fractuurrisico en mortaliteit. 


\section{LITERATUUR}

1. Klotzbuecher CM, Ross PD, Landsman PB, et al. Patients with prior fractures have an increased risk of future fractures: a summary of the literature and statistical synthesis. J Bone Miner Res 2000; 15(4):721-39.

2. van Geel TA, van Helden S, Geusens PP, et al. Clinical subsequent fractures cluster in time after first fractures. Ann Rheum Dis 2008.

3. Chevalley T, Hoffmeyer P, Bonjour JP, et al. An osteoporosis clinical pathway for the medical management of patients with low-trauma fracture. Osteoporosis international : a journal established as result of cooperation between the European Foundation for Osteoporosis and the National Osteoporosis Foundation of the USA 2002; 13(6):450-5.

4. Hegeman JH, Willemsen G, van Nieuwpoort J, et al. [Effective tracing of osteoporosis at a fracture and osteoporosis clinic in Groningen; an analysis of the first 100 patients]. Nederlands tijdschrift voor geneeskunde 2004; 148(44):2180-5.

5. McLellan AR, Gallacher SJ, Fraser M, et al. The fracture liaison service: success of a program for the evaluation and management of patients with osteoporotic fracture. Osteoporos Int 2003; 14(12):1028-34.

6. CBO. Preventie van valincidenten bij ouderen 2004. Available at: http://www.cbo.nl/ thema/richtlijnen/overzicht-richtlijnen/geriatrie/.

7. CBO KvdG. Osteoporose, tweede herziene richtlijn. Van Zuiden Communications 2002.

8. CBO. Osteoporosis and fracture prevention 2011. Available at: http://www.cbo.nl/ thema/Richtlijnen/Overzicht-richtlijnen/Geriatrie/. Accessed 2011-11-07.

9. Bliuc D, Nguyen ND, Milch VE, et al. Mortality risk associated with low-trauma osteoporotic fracture and subsequent fracture in men and women. JAMA : the journal of the American Medical Association 2009; 301(5):513-21.

10. Center JR, Bliuc D, Nguyen ND, et al. Osteoporosis medication and reduced mortality risk in elderly women and men. The Journal of clinical endocrinology and metabolism 2011; 96(4):1006-14.

11. Colon-Emeric CS, Mesenbrink P, Lyles KW, et al. Potential mediators of the mortality reduction with zoledronic acid after hip fracture. Journal of bone and mineral research : the official journal of the American Society for Bone and Mineral Research 2010; 25(1):91-7.

12. Johnell $\mathrm{O}$, Kanis JA, Oden $\mathrm{A}$, et al. Fracture risk following an osteoporotic fracture. Osteoporos Int 2004; 15(3):175-9.

13. Center JR, Bliuc D, Nguyen TV, et al. Risk of subsequent fracture after low-trauma fracture in men and women. JAMA : the journal of the American Medical Association 2007; 297(4):387-94. 
14. Vaile JH, Sullivan L, Connor D, et al. A Year of Fractures: a snapshot analysis of the logistics, problems and outcomes of a hospital-based fracture liaison service. Osteoporosis international : a journal established as result of cooperation between the European Foundation for Osteoporosis and the National Osteoporosis Foundation of the USA 2013.

15. Christensen K, Thinggaard M, Oksuzyan A, et al. Physical and cognitive functioning of people older than 90 years: a comparison of two Danish cohorts born 10 years apart. Lancet 2013.

16. Global Coalition on Ageing. Available at: http://www.globalcoalitiononageing.com. Accessed 07-11-2013.

17. IOF. Capture the Fracture. Available at: http://www.capturethefracture.org/. Accessed 07-11-2013.

18. Akesson K, Marsh D, Mitchell PJ, et al. Capture the Fracture: a Best Practice Framework and global campaign to break the fragility fracture cycle. Osteoporosis international : a journal established as result of cooperation between the European Foundation for Osteoporosis and the National Osteoporosis Foundation of the USA 2013; 24(8):2135-52.

19. Eisman JA, Bogoch ER, Dell R, et al. Making the first fracture the last fracture: ASBMR task force report on secondary fracture prevention. Journal of bone and mineral research : the official journal of the American Society for Bone and Mineral Research 2012; 27(10):2039-46.

20. Traumatology) EEFoNAoOa. EFORT. Available at: https://http://www.efort.org. Accessed 08-11-2013.

21. Kanis JA, Johnell O. Requirements for DXA for the management of osteoporosis in Europe. Osteoporosis international : a journal established as result of cooperation between the European Foundation for Osteoporosis and the National Osteoporosis Foundation of the USA 2005; 16(3):229-38.

22. McLellan AR, Wolowacz SE, Zimovetz EA, et al. Fracture liaison services for the evaluation and management of patients with osteoporotic fracture: a cost-effectiveness evaluation based on data collected over 8 years of service provision. Osteoporosis international : a journal established as result of cooperation between the European Foundation for Osteoporosis and the National Osteoporosis Foundation of the USA 2011; 22(7):2083-98.

23. Cooper MS, Palmer AJ, Seibel MJ. Cost-effectiveness of the Concord Minimal Trauma Fracture Liaison service, a prospective, controlled fracture prevention study. Osteoporosis international : a journal established as result of cooperation between the European Foundation for Osteoporosis and the National Osteoporosis Foundation of the USA 2012; 23(1):97-107. 
Dankwoord 

Dit proefschrift was nooit afgekomen zonder de hulp en inzet van velen, waarvoor hartelijk dank! Een aantal mensen wil ik graag in het bijzonder bedanken:

Prof. dr. PRG Brink, beste Peter, de vraag die je me stelde bij het sollicitatiegesprek in augustus 2007 herinner ik me nog goed: wat ga je doen als het maken van je thesis niet verloopt zoals je verwacht had dat het zou verlopen? Het antwoord hierop ligt nu voor je! Hartelijk dank voor alle wijze raad en adviezen met betrekking tot het proefschrift en natuurlijk ook met mijn verdere (klinische) carriere!

Prof. dr. PP Geusens, beste Piet, dankuwel voor alle inspirerende besprekingen en al uw inzet: het resultaat mag er zijn! Heb veel van u geleerd, waarvoor veel dank. Ook al botsten onze karakters soms, het was een "journey l'll never forget"!

Dr. SH van Helden, beste Svenhjalmar, zonder jou was het nooit gelukt! Dank dat je een rots in de branding was. Ik bewonder je inzet, je toewijding en je inventieve manier van onderzoek doen! Het is een eer dat je mijn co-promotor bent!

Dr. TACM van Geel, beste Tineke, de eerste keer dat we elkaar ontmoet hebben was Sven net op congres en was ik net een weekje AIO. We hadden een afspraak, alleen vroegen we ons beiden af wat de precieze reden van het overleg was... Gelukkig is dat de volgende keren meer dan goed gekomen! Dankjewel voor al je hulp en kostbare adviezen!

Veel dank ben ik ook verschuldigd aan de beoordelingscommissie voor hun vakkundige oordeel: prof. dr. LW van Rhijn, prof. dr. M Verhofstad, prof. dr. WF Lems en dr. AAM Franken.

Secretaresses van de afdeling heelkunde, in het bijzonder Yvonne Daemen, dank voor al jullie hulp en gezellige momenten! Daaaaag!

Hartelijk dank aan alle collega AIO's van de afdeling heelkunde MUMC voor alle gezelligheid en de vrijdagmiddagborrels: Tim, Joep, Joep, Bas, Iris, Geertje, Tim, Jacco, Johanne, Mo, Simon, Kostan, Dennis, Caroline, Kim, Aron, Guy, 
Kaatje, Sander, Bas, Charlotte, Marc, Froukje, Annemarie, Hans, Eva, Maarten, Irma, Tiara, Givan, Freek, Dennis, Prof Buurman.

Chirurgen van het Reinier de Graaf Gasthuis te Delft en Erasmus MC te Rotterdam, hartelijk dank voor de leerzame tijd en natuurlijk voor alle interesse en steun tijdens het afronden van het proefschrift. Hoop nog veel van jullie te kunnen leren! Ook de collega arts- assistenten van het Reinier en Erasmus MC, dankjulliewel voor alle gezelligheid!

Ook mijn oud kamergenootjes vegeet ik natuurlijk niet! Nina, aka Ricci, dankjewel voor alle gezellige momenten, veel succes met je boekje en opleiding tot orthopeed! Liliane, het was kort maar krachtig! Veel succes met je verdere loopbaan. Ruben, de enige man op de kamer en dat heb je geweten ook! Dank voor alle hulp en waardevolle adviezen, met name al die keren met mijn statististische 'probleempjes'. Jij ook veel succes met je opleiding en promotie! Maartje, aka Bonnie, von den Hosen, het waren een aantal 'bikkeljaren' daar in het zuiden, maar we hebben ons er maar mooi doorheen geslagen. Beiden gepromoveerd en werkzaam in het westen waar onze gezamenlijk opgedane zuiderlijke invloeden nog goed merkbaar zijn: bier en bitterballen!

Mechteld, samen op een kamer zitten of in de auto door Australie: het blijft een gezellig 'avontuur'! Dankjewel voor je hulp bij mijn proefschrift en voor alle etentjes en borrels door de jaren heen! Hoop dat er nog velen zullen volgen!

Ook alle gezellige (borrel)avondjes met Mijke, Yvette, Hilde, Marloes, Marieke, Maartje, Eline en Marleen hebben de promotietijd in zeer positieve zin opgefleurd. Meh jong Coen, aka Coenie, wat hebben we gelachen na (te)veel biertjes in Mestreech. Géraldine, dank voor alle etentjes en muzikale intermezzo's (Preuve, André), ik kijk er altijd naar uit! Havva, ook al zien we elkaar wat minder vaak, als we elkaar zien dan is het net als toen bij wiskunde A! En niet te vergeten Shirin, oud overbuurmeisje van het eerste uur, altijd gezellig om biertje te doen op "t Vriethof met de Vastelaovend"! 
Lieve Hilda, dankjewel voor al je steun en bemoedigende woorden tijdens de laatste loodjes van het proefschrift. Deze woorden en natuurlijk alle gezellige uitjes en borrels hebben ertoe bijgedragen dat deze dag een feit is! Proost op de toekomst!

Lieve Caroline, vind het super dat je mijn paranimf wil zijn. Het begon met die ene Access vraag (toen ik eindelijk het juiste emailadres gevonden had) en het gaat verder vandaag: beiden gepromoveerd! Je hebt vaak om mijn 'inventieve' ICT manieren moeten lachen, de "trial and error" methode of andere 'blunders' die ik beter hier niet kan noemen. Wat hebben we een mooie tijd gehad in Maastricht: (veel) koffie drinken ("meh jong"), lunchen, enz... Sjol op de toekomst!!

Lleve Janneke, "vriendinnetje van mijn zus", maar opeens ook een vriendinnetje van mij dankzij Evi, die nu helaas wat minder fier is op ons (iig op mij...). Alle stapavondjes, carnaval, terrasjes, ik mis het heel erg nu ik in het westen van het land zit, dus misschien moet je overwegen te verhuizen...! Maar hopelijk nu meer tijd voor deze leuke dingen, heb er zin in! Ben heel blij dat je mijn paranimf wil zijn, je debuut, komt goed!

Last but not least: mijn familie. Alle verhalen hebben jullie moeten aanhoren, leuke en minder leuke. Dank dat jullie er altijd voor me zijn. Johan, Regine en Rens, dank voor alle steun en afleiding in Mestreech! Lieve Dymphy, mijn grote zus, dankjewel dat je er altijd voor me bent, me probeert alle statistische achtergronden uit te leggen ook al ben je me na de eerste zin al kwijt, de gezellige etentjes en sleep-overs! Het heeft iets langer geduurd, maar uiteindelijk is het boekje toch af! Lieve Kasper, wat vond ik het fijn dat jij in hetzelfde gebouw zat, waar ik soms even kon langslopen om mijn frustratie of vreugde te uiten... Lieve Lars en Elin, wat een genot is het om bij jullie op bezoek te komen. Jullie enthousiasme laat me alle zorgen vergeten! Dankjewel Elin, voor de mooie kaft, ik hou ook van roze! Lieve pap en mam, dank dat jullie er altijd voor me zijn en altijd voor me klaar staan en hebben gestaan. Het proefschrift is eindelijk klaar, de rustigere periode kan beginnen! 

Curriculum Vitae 

Kirsten Huntjens was born in Maastricht, the Netherlands, on April $6^{\text {th }} 1981$. After graduating from secondary school (Sint Maartenscollege, Maastricht, 1999), she started her medical training at Leiden University. As a medical student, she spent her research period ( 6 months) at the Children's Department of Karolinska Institutet in Stockholm, Sweden. After obtaining her master's degree (2004), she started her internships. She graduated from medical school in 2006 and subsequent to graduating; she worked as a surgical resident at Reinier de Graaf Gasthuis, Delft (Prof. dr. L Stassen).

In October 2007, she started her PhD project at the Department of Surgery of Maastricht University Medical Center, which resulted in this present thesis (prof. dr. PRG Brink, prof. dr. PP Geusens, dr. SH van Helden, dr. TACM van Geel). She was awarded grants at several congresses: Kuentscher Society (2009), European Society of Trauma and Emergency Surgery (ESTES; 2010), Fragility Fracture Care Congress (2013) and Biomet Award Dutch Trauma Society (2013). The scientific work described in this thesis was presented at multiple national and international conferences.

In January 2011, she started her surgical training at the Department of Surgery of Reinier de Graaf Gasthuis (dr. M. van der Elst; prof. dr. J Ijzermans; dr. B Wijnhoven). 


